Aus der Abteilung Vegetativen Physiologie und Pathophysiologie (Prof. Dr. med. G. Burckhardt) im Zentrum Physiologie und Pathophysiologie der Medizinischen Fakultät der Universität Göttingen

\title{
Die Expression von Sulfattransportern als Funktion einer fortschreitenden Nierenfibrose am Modell der Alport-Maus
}

\author{
INAUGURAL - DISSERTATION \\ zur Erlangung des Doktorgrades \\ der Medizinischen Fakultät der \\ Georg-August-Universität zu Göttingen
}

vorgelegt von

Marcia Mirgel

aus Nürnberg

Göttingen 2011 
Dekan: Prof. Dr. med. C. Frömmel

I. Berichterstatterin: Prof. Dr. phil. nat. B. C. Burckhardt

II. Berichterstatterlin: Priv.-Doz. Dr. med. O. Gross

III. Berichterstatter/in: Prof. Dr. rer. Nat. Virsik-Köpp

Tag der mündlichen Prüfung: 10.10.2011 


\section{Inhaltsverzeichnis}

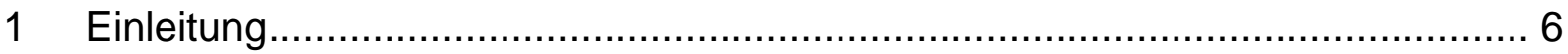

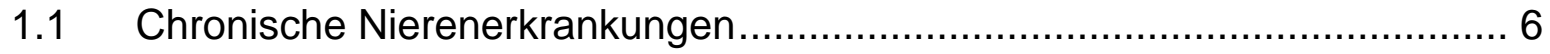

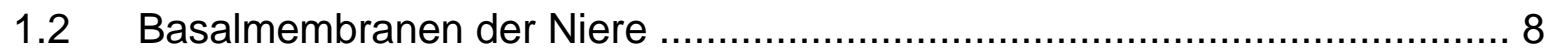

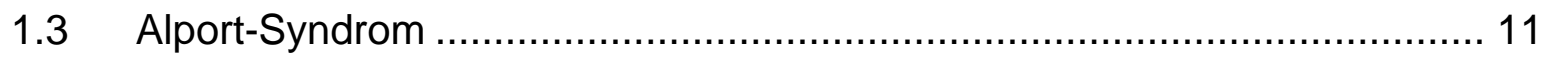

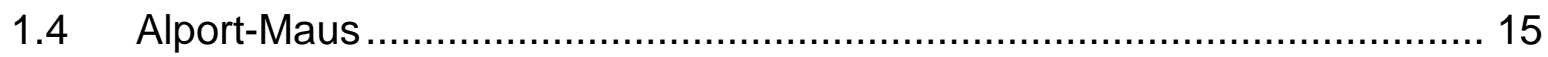

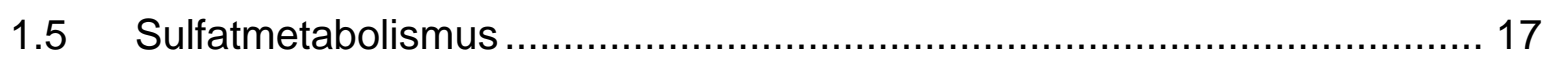

1.6 Die solute-çarrier (SLC)-Transporterfamilie......................................... 18

1.6.1 Funktion und Eigenschaften der Transporter vom SLC-Gentyp.......... 18

1.6.2 Der natriumabhängige Sulfattransporter 1 (NaS1) ............................ 21

1.6.2.1 Eigenschaften des NaS1-Gens und seiner Genprodukte ............... 21

1.6.2.2 Lokalisation des NaS1 .................................................................. 24

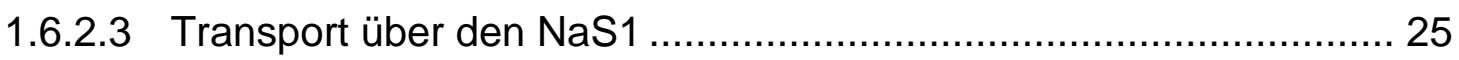

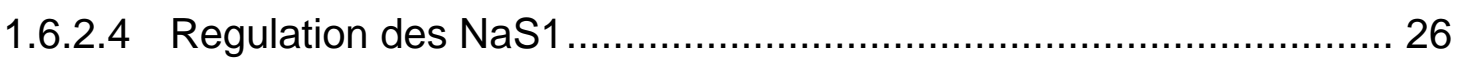

1.6.2.5 NaS1-knock-out-Maus ( $\mathrm{NaS1}^{-1-M a u s) ~ . . . . . . . . . . . . . . . . . . . . . . . . . . . . . . . . . . . . . . . . . . ~} 26$

1.6.3 Der Sulfat-Anionen-Transporter1 (sat1) ....................................... 27

1.6.3.1 Eigenschaften des sat1-Gens und seiner Genprodukte ................ 27

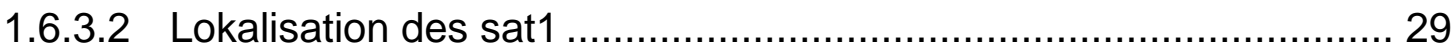

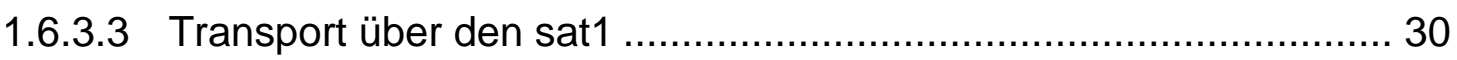

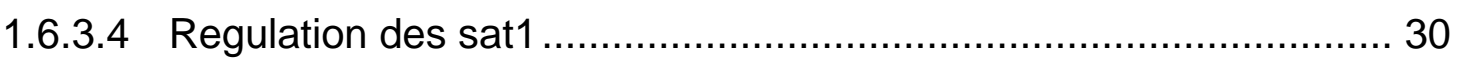

1.6.3.5 sat1-knock-out-Maus (sat $1^{-/}$-Maus) …....................................... 31

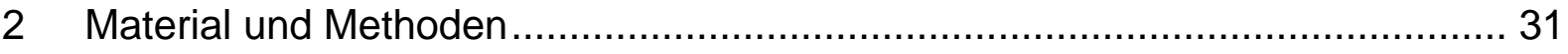

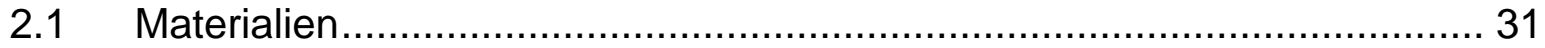

2.1.1 Tiere

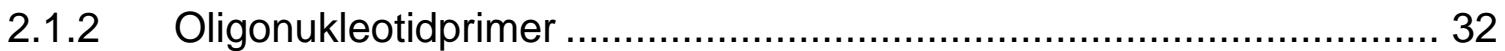

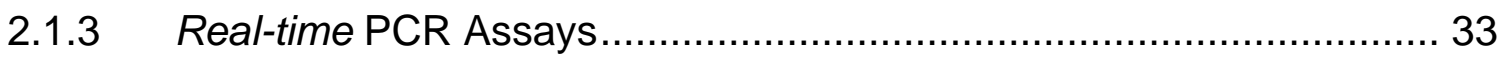

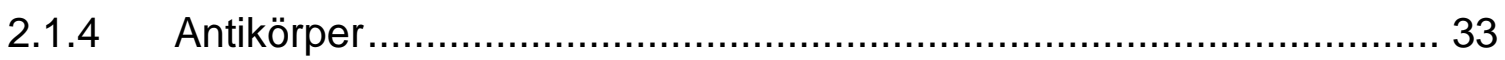

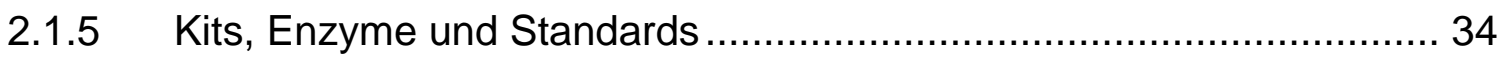

2.1.6 Chemikalien und Medikamente ........................................................ 34

2.1.7 Medien, Lösungen und Puffer ....................................................... 34

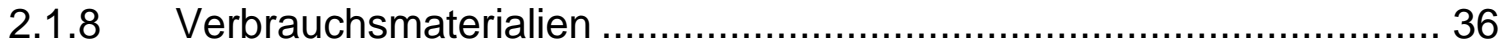

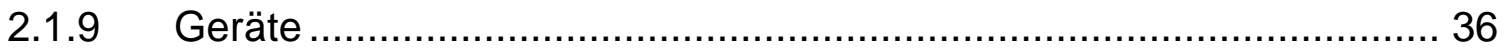

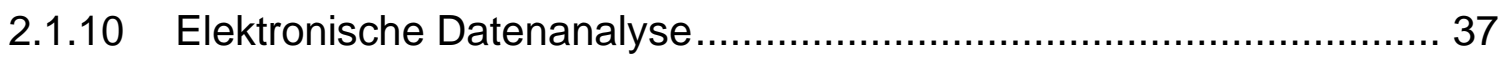




\section{Inhaltsverzeichnis}

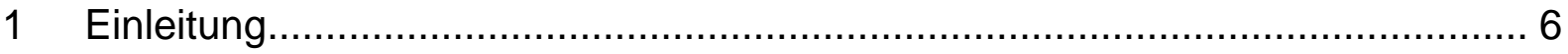

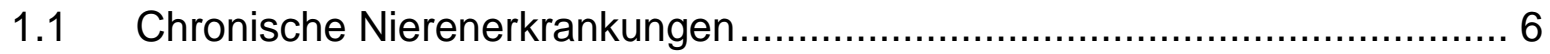

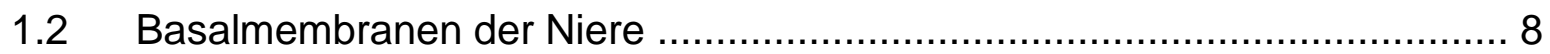

1.3 Alport-Syndrom …................................................................... 11

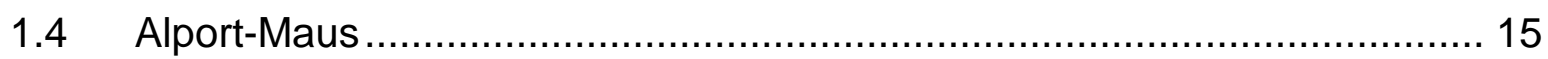

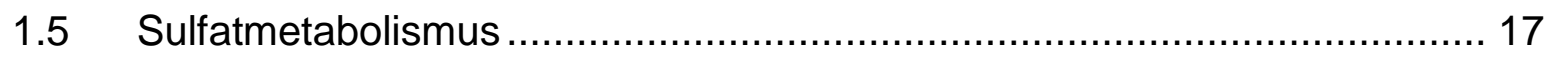

1.6 Die solute-çarrier (SLC)-Transporterfamilie........................................ 18

1.6.1 Funktion und Eigenschaften der Transporter vom SLC-Gentyp.......... 18

1.6.2 Der natriumabhängige Sulfattransporter 1 (NaS1) ........................... 21

1.6.2.1 Eigenschaften des NaS1-Gens und seiner Genprodukte ............... 21

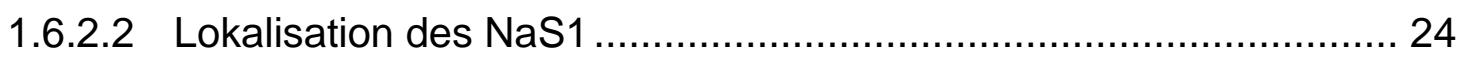

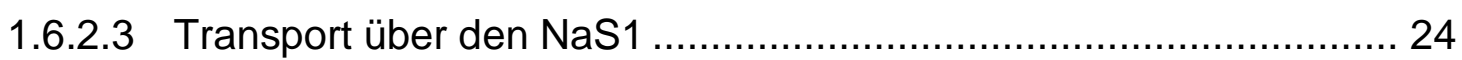

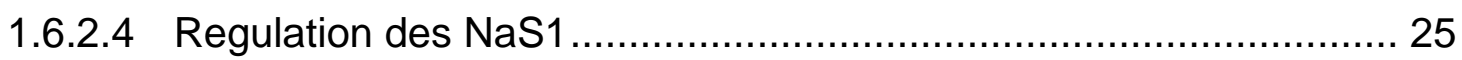

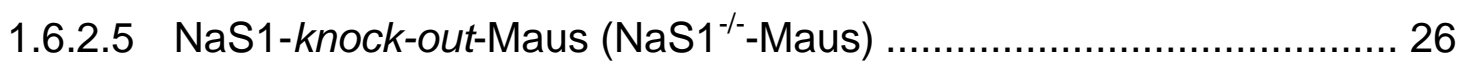

1.6.3 Der Sulfat-Anionen-Transporter1 (sat1) ......................................... 26

1.6.3.1 Eigenschaften des sat1-Gens und seiner Genprodukte ................ 26

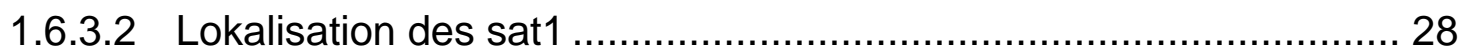

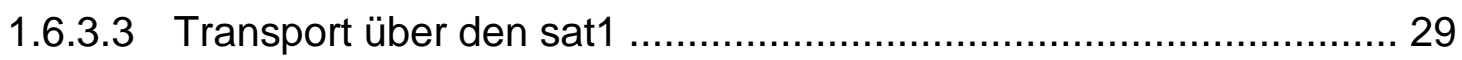

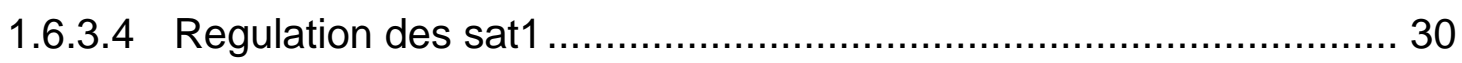

1.6.3.5 sat1-knock-out-Maus (sat1 ${ }^{-1}$-Maus) ............................................ 30

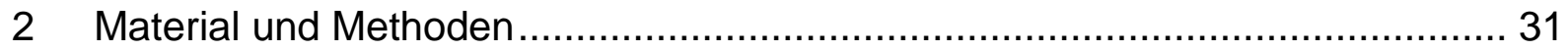

$2.1 \quad$ Materialien

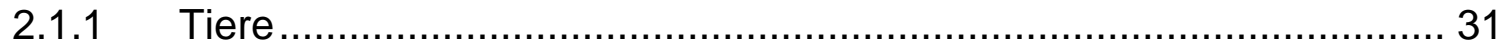

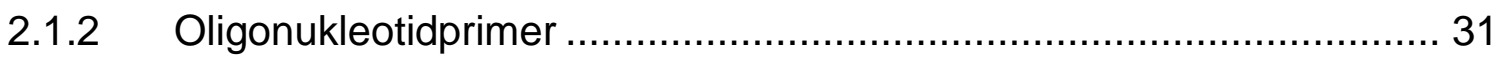

2.1.3 Real-time PCR Assays............................................................. 32

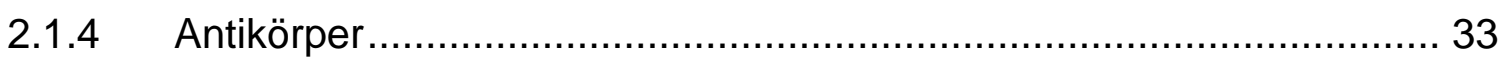

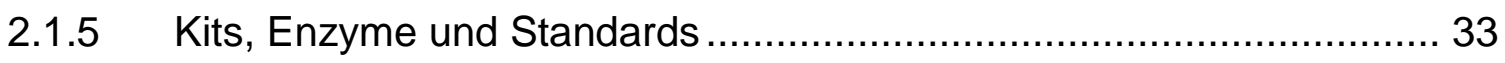

2.1.6 Chemikalien und Medikamente .................................................... 33

2.1.7 Medien, Lösungen und Puffer …………....................................... 34

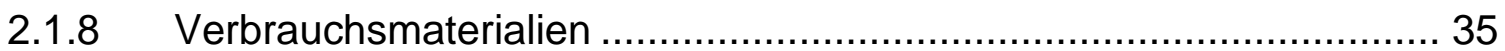

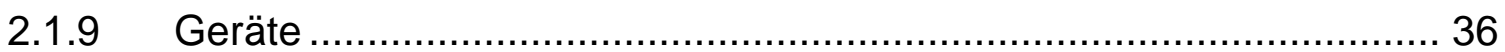

2.1.10 Elektronische Datenanalyse ...................................................... 37 


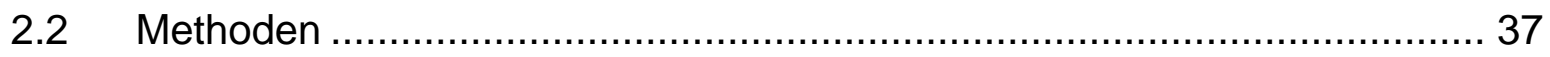

2.2.1 Einführung .............................................................................. 37

2.2.1.1 Gewebeentnahme und -aufbereitung …................................... 37

2.2.1.2 Gewebeentnahme und -aufbereitung bei Mäusen ......................... 37

2.2.1.3 Gewebeentnahme und -aufbereitung bei Ratten ........................... 38

2.2.2 Molekularbiologische Methoden................................................... 39

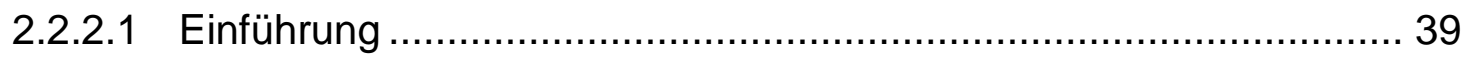

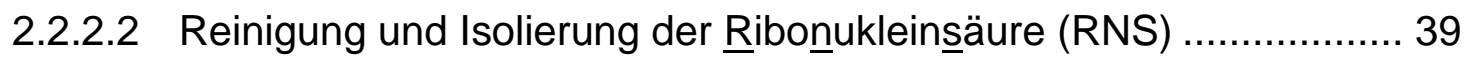

2.2.2.3 Bestimmung der RNS-Konzentration und -Qualität ........................ 41

2.2.2.4 Isolierung der messenger RNS (mRNS) .................................... 41

2.2.2.5 Umwandlung der mRNS in complementary DNS (cDNS) (reverse

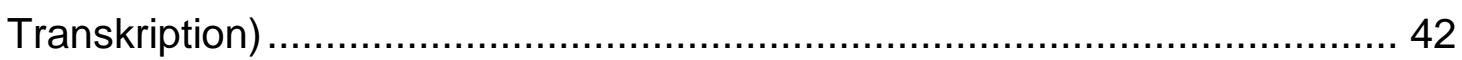

2.2.2.6 Polymerase-Kettenreaktion (PCR) …........................................ 43

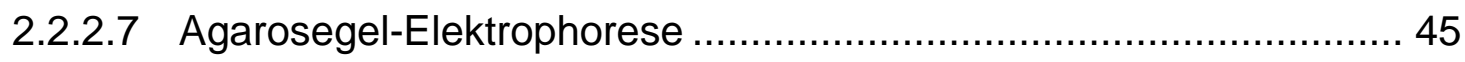

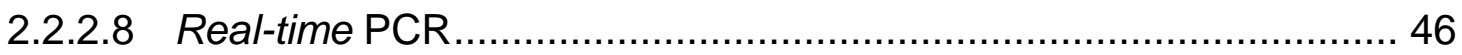

2.2.3 Immunhistochmische Methoden .................................................. 49

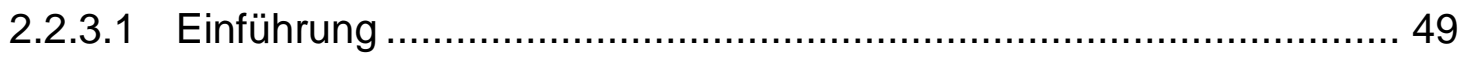

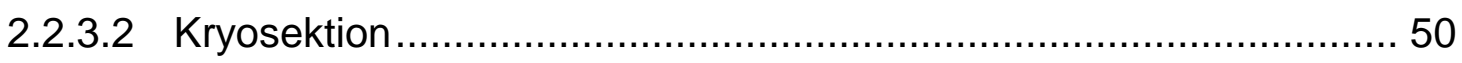

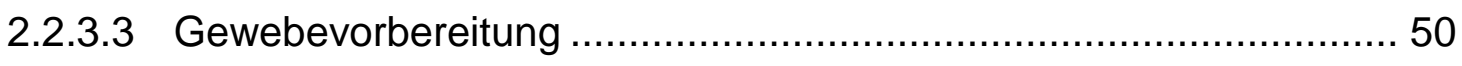

2.2.3.3.1 Methoden zur Gewebevorbereitung ...................................... 50

2.2.3.3.2 Methode mit unbehandelten Proben ..................................... 50

2.2.3.3.3 SDS-Methode (Sodium-Dodecyl-Sulfate-Methode)................... 50

2.2.3.3.4 Citratpuffer-Methode ........................................................ 50

2.2.3.3.5 Deparaffinisierungs-Citrat-Methode ...................................... 51

2.2.3.4 Immunhistochemische Färbung ................................................ 51

2.2.4 Proteinbiochemische Methoden .................................................... 52

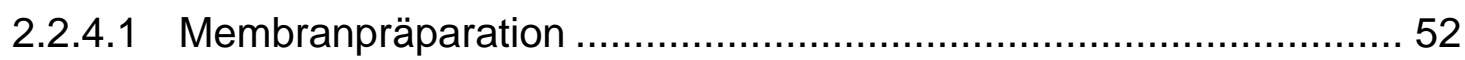

2.2.4.2 SDS-Polyacrylamid-Gelelektropherese ..................................... 52

2.2.4.3 Proteintransfer auf die PVDF (Polyinnylidenfluorid) -Membran........ 53

2.2.4.4 Proteindetektion auf Western Blots ............................................ 54

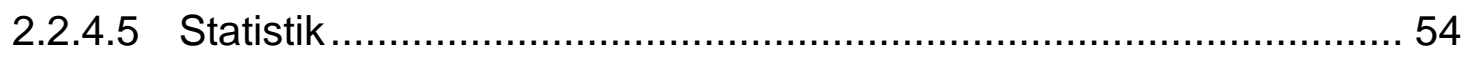

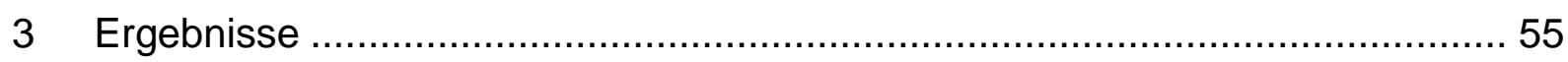

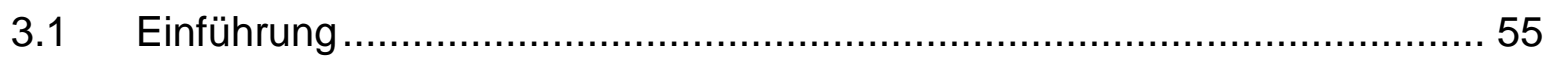


3.2 Untersuchung der Sulfattransporter NaS1 und sat1 auf Transkriptionsebene 56

3.2.1 Nachweis von mNaS1- und msat1-RNS in Leber und Nieren von NMRIMäusen 56

3.2.2 Geschlechtsabhängige RNS-Expression von NaS1 und sat1 in den Nieren und sat1 in der Leber von NMRI-Mäusen .......................................... 56 3.2.3 Nachweis von mNaS1 und msat1 in den Nieren von $\mathrm{COL}_{4} \mathrm{A3}^{+/+}$- und

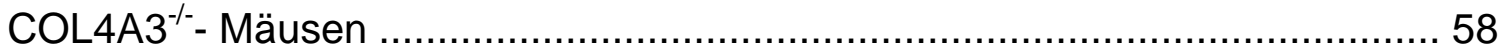

3.2.4 NaS1- und sat1-RNS-Expression in den Nieren von $\mathrm{COL}_{4} \mathrm{A3}^{+/+}{ }_{-}$ Männchen in Abhängigkeit vom Alter 59

3.2.5 NaS1- und sat1-RNS-Expression in den Nieren von COL4A3 ${ }^{-1-}$ Männchen in Abhängigkeit vom Alter 61

3.2.6 NaS1- und sat1-RNS-Expression in den Nieren von $\mathrm{COL} 4 \mathrm{~A}^{+/+}$- und $\mathrm{COL} 4 \mathrm{~A}^{-{ }^{-}}$-Weibchen in Abhängigkeit vom Alter. 62

3.2.7 Geschlechtsabhängige RNS-Expression von NaS1 und sat1 in den Nieren von $\mathrm{COL} 4 \mathrm{~A} 3^{+/+}$- und $\mathrm{COL} 4 \mathrm{~A} 3^{-/-}$-Mäusen. 63

3.2.8 Expression von NaS1- und sat1-RNS in den Nieren von männlichen

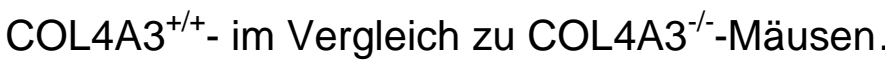
65

3.2.9 Expression von NaS1- und sat1-RNS in den Nieren von weiblichen $\mathrm{COL}_{4} \mathrm{~A}^{+/+}{ }^{\text {- im Vergleich zu COL4A3 }}{ }^{-/}$-Mäusen. 65

3.2.10 Expression von NaS1- und sat1-RNS in den Nieren von NMRI- und SvJ/129-Mäusen

3.3 Untersuchung des sat1 auf Proteinebene 67

3.3.1 Testung des polyklonalen anti-sat1-Antikörpers an Nieren und Leber von Mäusen und Ratten 67

3.3.2 Testung des polyklonalen anti-sat1-Antikörpers an Rattengewebe..... 70

3.3.3 Testung des monoklonalen anti-sat1-Antikörpers an Nieren und Leber von Mäusen. 71

3.3.3.1 Spezifische immunhistochemische Färbungen von sat1 in Nierenund Lebergewebe von Mäusen 71

3.3.3.2 Geschlechtsabhängige Proteinexpression von sat1 in den Nieren von NMRI-Mäusen 72 
3.3.3.3 Geschlechtsabhängige Proteinexpression von sat1 in der Leber von

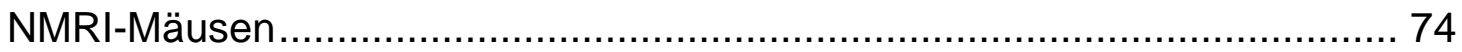

3.3.3.4 Proteinexpression von sat1 in den Nieren von $\mathrm{COL} 4 \mathrm{~A}^{+/+}$- und ...... 76

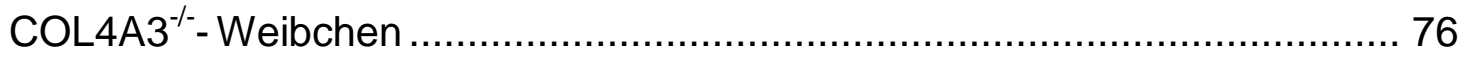

3.3.3.5 Proteinexpression von sat1 in den Nieren von $\mathrm{COL} 4 \mathrm{~A} 3^{--}$-Weibchen und -Männchen 77

3.3.3.6 Vergleich der Proteinexpression von sat1 in den Nieren von weiblichen Mäusen des NMRI- und des SvJ/129-Stammes 78

4 Diskussion 79

4.1 Diskussion der Methoden 79

4.1.1 Real-time PCR und Immunhistochemie als geeignete Methoden für den Nachweis und die Quantifizierung von NaS1 und sat1 .................................. 79

4.1.2 Darstellung der molekularbiologischen Methoden.............................. 79

4.1.3 Darstellung der proteinbiochemischen Methoden ............................. 82

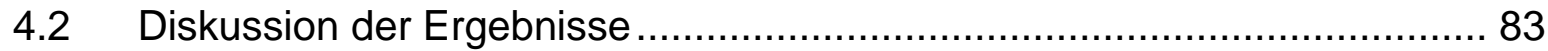

4.2.1 Physiologische Wirkungen von Sulfat ………............................... 83

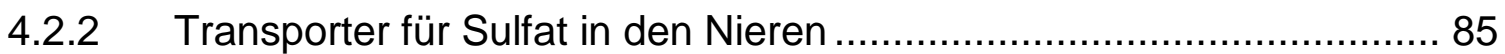

4.2.3 Sulfattransporter-Expression bei NMRI- und SvJ/129-Maus ............... 85

4.2.4 Pathophysiologie des Transports von Sulfat ...................................... 86

4.2.5 Nierenversagen bei der Alport-Maus............................................ 87

4.2.5.1 Expression der Sulfattransporter bei $\mathrm{COL}_{4 A} 3^{+/+}{ }_{-}$und $\mathrm{COL} 4 \mathrm{~A} 3^{-{ }^{-}}$Mäusen

4.2.5.2 Zeitlicher Verlauf der Expression von NaS1 und sat1 bei $\mathrm{COL} 4 \mathrm{~A}^{+/+}$-

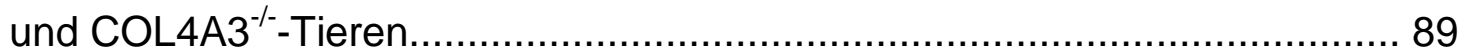

5 Zusammenfassung und Ausblick.............................................................. 91

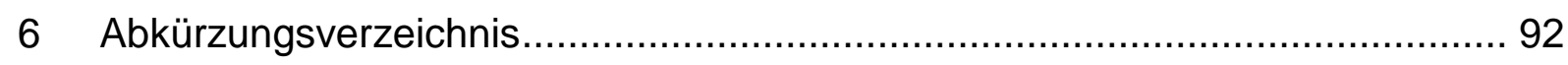

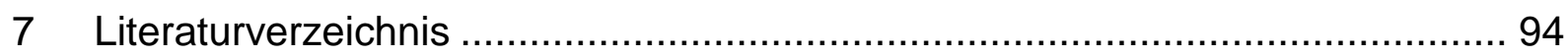




\section{Einleitung}

\subsection{Chronische Nierenerkrankungen}

Chronische Nierenerkrankungen sind ein häufiges Leiden in unserer Gesellschaft. Circa $5 \%$ der norwegischen Bevölkerung, stellvertretend für die europäische Bevölkerung, haben eine glomeruläre Filtrationsrate (GFR) von $<60 \mathrm{ml} / \mathrm{min} / 1,73 \mathrm{~m}^{2}$ und somit per Definition eine chronische Nierenerkrankung (Hallan et al., 2006). Die Erkrankung geht mit erhöhtem Risiko für kardiovaskuläre Ereignisse und Hospitalisierung einher, außerdem steigt die Mortalität stark an, wenn die GFR unter $45 \mathrm{ml} / \mathrm{min} / 1,73 \mathrm{~m}^{2}$ sinkt (Go et al., 2004, Johnson et al., 2007). Mit dem zunehmenden Vorkommen von Diabetes mellitus und Bluthochdruck in der Gesellschaft als Hauptursache für chronische Nierenerkrankungen ist auch die Anzahl der Fälle von terminalem Nierenversagen angestiegen. Die Schädigung der Nieren, wie zum Beispiel durch erhöhten Druck in den Nierengefäßen bei Hypertension oder Ablagerungen in den Gefäßen bei Diabetes mellitus, zieht fibrotische Veränderungen nach sich. Diese reaktive Bildung von fibrotischem Gewebe zeichnet sich durch eine Zunahme von extrazellulärer Matrix aus, ähnlich wie bei der Narbenbildung. Bei der Narbenbildung nach Verletzungen vermehrt sich Bindegewebe, um den entstandenen Defekt zu schließen. Ein ähnlicher Mechanismus vollzieht sich bei Nierenschädigung. Ist die Nierenschädigung zu stark, chronisch oder die reaktive Fibrosebildung überschießend, kann die Bindegewebevermehrung zum Verlust der Nierenfunktion führen (Wynn, 2007).

Der Prozess der progressiven Nierenfibrose ist irreversibel und führt ohne Behandlung unweigerlich zum terminalen Nierenversagen, einem Zustand, der zu lebenslanger Dialyse oder Transplantation verpflichtet (Hewitson, 2009). Histologisch sind im Endstadium der Erkrankung die Sklerose von Glomeruli und Gefäßen, sowie eine tubulointerstitielle Fibrose auszumachen (Bohle et al., 1987). Weiterhin atrophieren oder dilatieren die Nierentubuli und es ist eine Infiltration des Gewebes mit Leukozyten und akkumulierenden Fibroblasten zu finden (Zeisberg et al., 2001). Fibroblasten gelten bei der Fibroseentstehung als Schlüsselmediatoren. Sie produzieren viele extrazellulärmatrixbildene Komponenten, wie zum Beispiel Fibronektin und die Kollagene Typ I, Typ III, Typ V und Typ VII (Eddy, 1996, Strutz und Zeisberg, 2006). Durch Gewebeschäden aktivierte Fibroblasten werden als Myofibroblasten bezeichnet. Diese gehören zu den Hauptfaktoren bei der Entstehung 
von tubulointerstitieller Fibrose. Myofibroblasten synthetisieren zusammen mit anderen mesenchymalen Zellen der Nieren die Komponenten der extrazellulären Matrix und bewirken eine Kontraktion und Reorganisation derselben. Neben der Zunahme der extrazellulären Matrix kommt es zusätzlich zur, für Narbengewebe typischen, „Fibrokontraktion“ und damit zum Kollaps des renalen Parenchyms und zu einer Dichtezunahme des Gewebes (Hewitson, 2009). Die Fibrose ist eine komplexe Zusammensetzung von sulfatierten Proteoglykanen und anderen Komponenten, wie Fibronektin, Elastin, Laminin und Kollagenenen (siehe auch Tabelle 1) (Dubey et al., 1997, Hewitson et al., 1995).

Tabelle 1: Proteine, die im Rahmen der interstitiellen Nierenfibrose in der Matrix akkumulieren (modifiziert nach Eddy, 1996, S. 2496)

\begin{tabular}{|c|c|}
\hline Interstitielle Matrixproteine & $\begin{array}{l}\text { Kollagen Typ I, Typ III, Typ V, Typ VII } \\
\text { Fibronektin } \\
\text { Tenaskin }\end{array}$ \\
\hline Proteine der Basalmembran & $\begin{array}{l}\text { Kollagen Typ IV } \\
\text { Laminin }\end{array}$ \\
\hline Extrazelluläre Proteoglykane & $\begin{array}{l}\text { Hochmolekulare Chondroitin-Sulfat-Proteoglykane } \\
\text { Niedermolekulare Proteoglykane } \\
\text { Proteoglykane der Basalmembran (Heparin-Sulfat- } \\
\text { Proteoglykan, Perlekan) }\end{array}$ \\
\hline $\begin{array}{l}\text { Polysaccharide und } \\
\text { Glycoproteine }\end{array}$ & $\begin{array}{l}\text { Hyaluronan } \\
\text { Thrombospondin } \\
\text { SPARC (secreted protein, acidic and rich in cysteine) }\end{array}$ \\
\hline
\end{tabular}

Einige der Proteine sind keine regulären Matrixproteine. Die netzbildenden Komponenten Laminin und Kollagen IV beispielsweise sind im Normalfall Bestandteile von Basalmembranen (Eddy, 1996). Die Differenzierung, Proliferation und Kollagensynthese von Myofibroblasten wird von vielen verschiedenen Faktoren beeinflusst. Tubuluszellen, Leukozyten und Fibroblasten selbst schütten bei 
Stimulation eine Reihe von zirkulierenden Mediatoren aus, die wiederrum die Myofibroblasten aktivieren (Hewitson, 2009).

\subsection{Basalmembranen der Niere}

Basalmembranen sind im ganzen Körper zu finden. Sie umgeben Epithelien, Endothelien, periphere Nerven, Muskelzellen und Fettzellen. Mit ihrer netzartigen Struktur dienen sie dem Erhalt von Gewebestrukturen, bilden selektiv permeable Membranen zwischen verschiedenen Gewebekomponenten, ermöglichen die Kommunikation zwischen verschiedenen Geweben und beeinflussen das Wachstum und die Differenzierung von umliegenden Zellen. Basalmembranen spielen in den Nieren eine unerlässliche Rolle, was dadurch bewiesen ist, dass Basalmembranerkrankungen mit einer reduzierten Nierenfunktion einhergehen (Miner, 1999, Yurchenco und O'Rear, 1994). Die glomeruläre Basalmembran der Nieren liegt zwischen den Endothelzellen der Blutgefäße und den Podozyten, die die zur Filtration nötige Schlitzmembran bilden (siehe Abbildung 1).

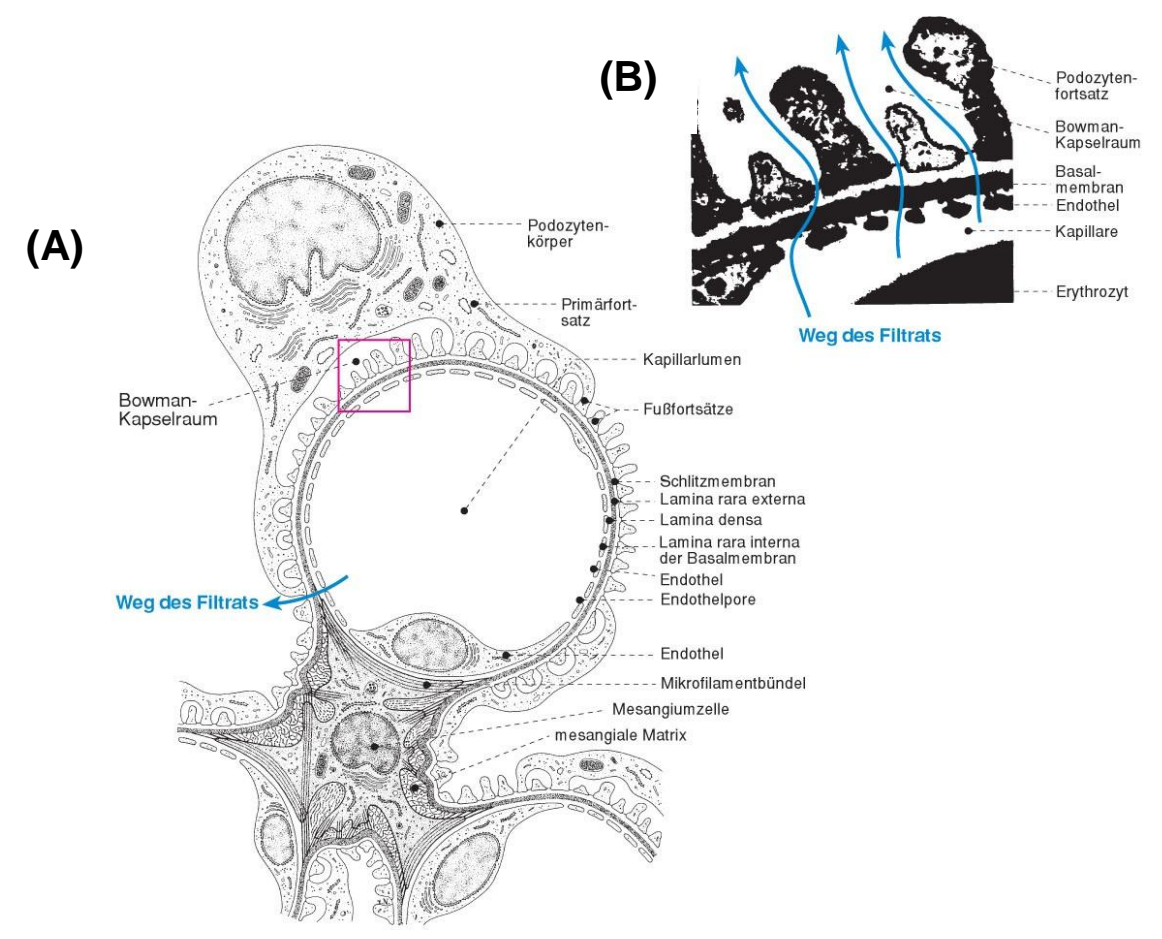

Abbildung 1: Anatomie des Glomerulus der Nieren $(A)$ und des glomerulären Filters (B) (aus: Deetjen et al., 2005, S. 526) 
Die glomeruläre Basalmembran ist eine spezialisierte Basalmembran, die zusammen mit Podozyten und fenestriertem Gefäßendothel der glomerulären Filtration und damit der Bildung des Urins dient. Die tubuläre Basalmembran hingegen ist nötig für die Bewältigung der Aufgaben der Tubuluszellen, zu welchen Resorption von Bestandteilen des Ultrafiltrats und Sekretion proteingebundener Stoffe gehören. Die Hauptkomponenten von Basalmembranen sind Kollagen Typ IV, Laminin, Fibronektin und Heparansulfat-Proteoglykane. Alle vier Bestandteile liegen in gewebespezifischen Isoformen vor (Timpl, 1989). Kollagen Typ IV besteht aus drei $\alpha-$ Ketten, die umeinander gedrillt eine Tripelhelix bilden. Die einzelnen a-Ketten bestehen aus Wiederholungen von Gly-X-Y und tragen an ihrem 3'-Ende eine nicht kollagene globuläre NC1-Domäne, sowie an ihrem 5'-Ende eine kurze 7S Domäne (Gubler, 2008). Im Gegensatz zu den a-Ketten der faserbildenen Kollagene (Typ I, II, III und V) beinhalten die Ketten von Kollagen Typ IV Unterbrechungen der Gly-X-YWiederholungen, wodurch eine höhere Flexibilität gewährleistet wird. Kollagen Typ IV kann aus sechs verschiedenen $\alpha$-Ketten, a1(IV)-a6(IV), gebildet werden. Die Ketten lagern sich zu verschiedenen Tripelhelices zusammen (a1a1a2(IV)-, a3a4a5(IV)- und a5a5a6(IV)-Helix (siehe Abbildung 2).

Kollagen Typ IV Ketten

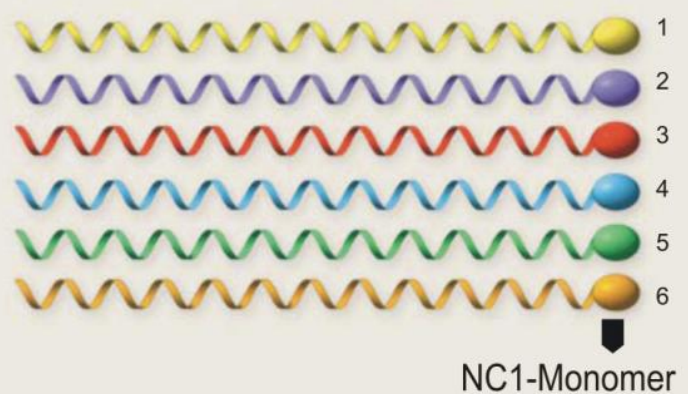

Protomere

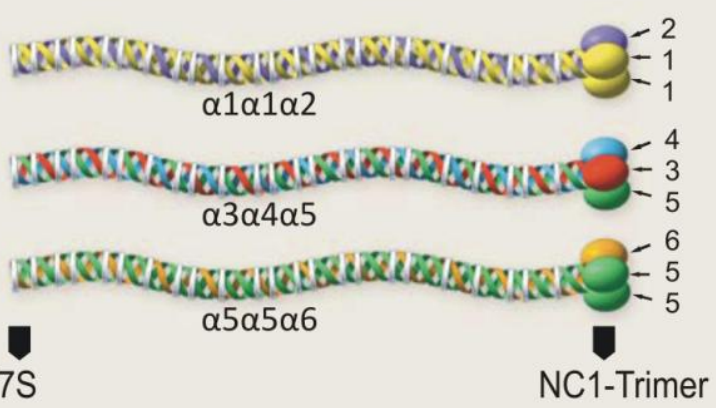

\section{Abbildung 2: Organisation von Tripelhelices der Kollagenfamilie Typ IV (modifiziert nach Hudson et al., 2003, S. 2544) \\ Sechs genetisch unterschiedliche $\alpha$-Ketten fügen sich zu Tripelhelix-Protomeren zusammen. Jedes Protomer besitzt eins 7S-Domäne am N-terminalen Ende, eine lange tripelhelikale Kollagendomäne und ein nichtkollagenes (NC1) Trimer am C-terminalen Ende. Unterbrechungen (weiße Ringe) der Gly-X-Y-Struktur sorgen für Flexibilität des Protomers.}

Diese Tripelhelices wiederum bilden über Disulfidbrücken drei verschiedene

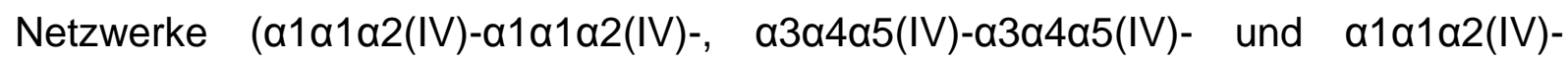
a5a5a6(IV)-Netzwerk), die alle als Kollagen Typ IV bezeichnet werden (Hudson et 
al., 2003, Khoshnoodi et al., 2008). Die Gene (COL4A1-6) der a1(IV)-a6(IV)-Ketten sind paarweise auf drei Chromosomen verteilt. COL4A1 und COL4A2 auf Chromosom 13q34, COL4A3 und COL4A4 auf Chromosom 2q35-37 und COL4A5 und COL4A6 auf dem X-Chromosom (Gubler, 2008, Khoshnoodi et al., 2008) (siehe Abbildung 3).
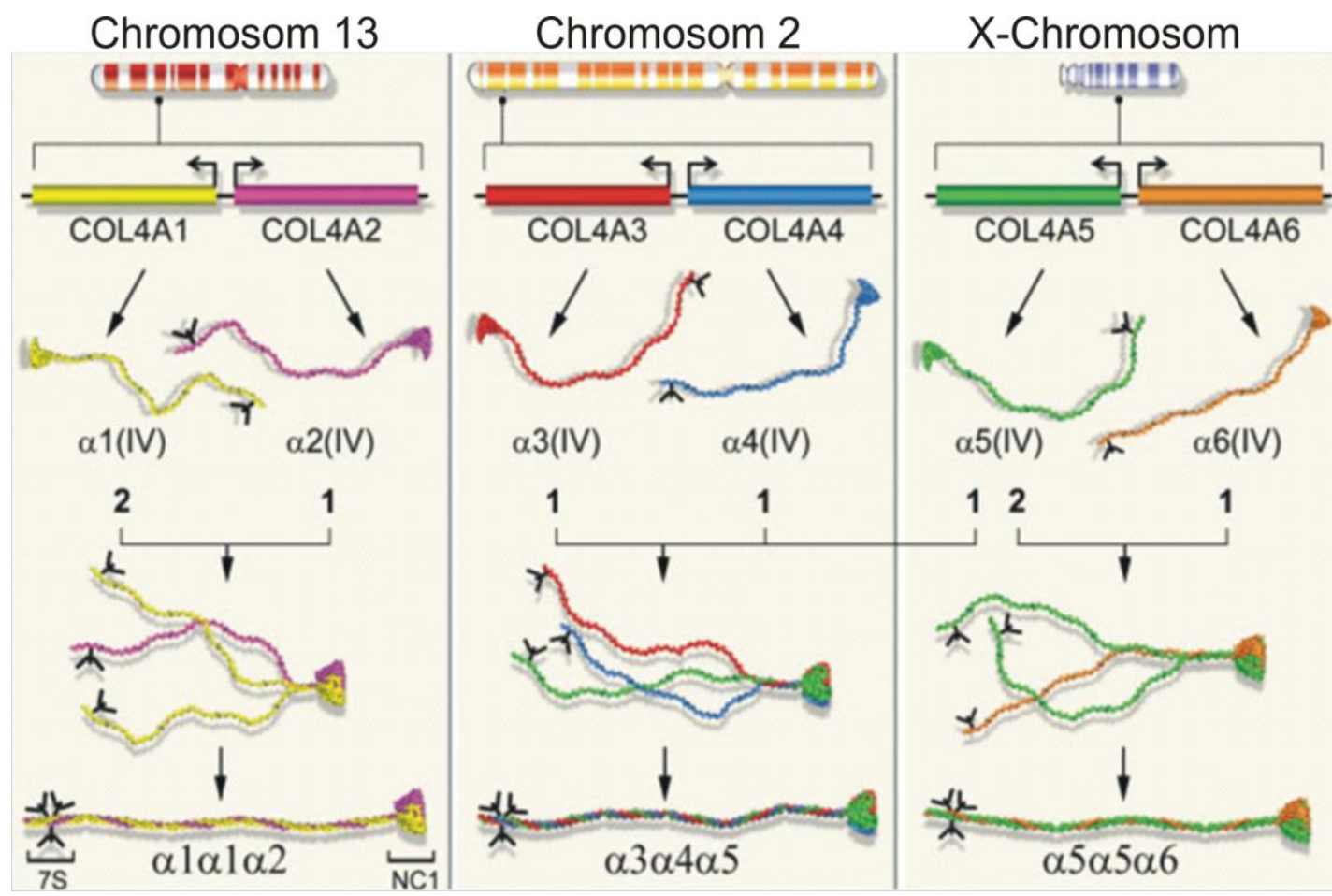

\begin{abstract}
Abbildung 3: Schematische Darstellung der Lokalisation, Organisation und Zusammensetzung der sechs verschiedenen Isoformen des Kollagen-Typ IVGens (modifiziert nach Khoshnoodi et al., 2008, S. 358)

Die Gene von COL4A1/COL4A2 auf Chromosom 13, von COL4A3/COL4A4 auf Chromosom 2 und von COL4A5/COL4A6 auf dem X-Chromosom. Die entsprechenden, nach Transkription und Translation enstehenden $\alpha$-Ketten lagern sich zu verschiedenen Tripelhelices zusammen.
\end{abstract}

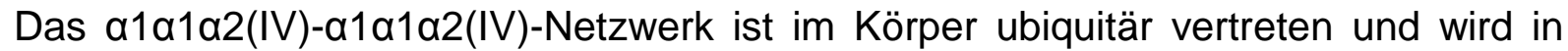
allen Basalmembranen der unreifen Nephrone exprimiert. Während der Entwicklung kommt es zu einer Umwandlung des Kollagen Typ IV in den Nieren und die a1a1a2(IV)-Trimere werden zum größten Teil durch a3a4a5(IV)-Trimere ersetzt (Kalluri et al., 1997). Das a3a4a5(IV)-a3a4a5(IV)-Netzwerk ist die Hauptkomponente der 300-350 nm dicken glomerulären Basalmembran und der tubulären Basalmembran. Außerdem findet sich dieses Netzwerk in der alveolären Basalmembran und in spezialisierten Basalmembranen von Linse und Cochlea (Cheong et al., 1994, Cosgrove et al., 1996, Hudson et al., 2003). Das a1a1a2(IV)- 
a5a5a6(IV)-Netzwerk ist Teil der Bowman-Kapsel (nicht aber des Glomerulus) und der Basalmembranen von Sammelrohren, epidermalen Zellen und glatten Muskelzellen (Borza et al., 2001, Hudson et al., 2003, Peissel et al., 1995).

Laminine sind heterotrimere Glykoproteine aus einer $\alpha$-, einer $\beta$ - und einer $\gamma$-Kette, angeordnet in einer kreuzförmigen Struktur (Hudson et al., 2003). Laminine interagieren mit verschiedenen Zellen, Rezeptoren, Integrinen und über Fibronektin mit dem Kollagen Typ IV. Die in der glomerulären Basalmembran vorhandene Isoform ist Laminin $\alpha 5 \beta 2 \gamma 1$, in anderen Kompartimenten der Nieren sind andere Laminine zu finden. Fibronektin dient in allen Basalmembranen der Brückenbildung zwischen Laminin- und Kollagen-Typ-IV-Netzwerken, bindet an verschiedene Komponenten der extrazellulären Matrix und über Integrin an Zellen. HeparansulfatProteoglykane setzen sich aus einem Kernprotein mit daran bindenden hydrophilen Heparansulfat-Glykosaminoglykanen zusammen. Agrin, das hauptsächlich in der glomerulären Basalmembran vertretene Heparansulfat-Proteoglykan, ist bei der glomerulären Filtration für die elektronegative Selektion von Stoffen verantwortlich, während Perlecan nur auf der endothelialen Seite der glomerulären Basalmembran sowie in der mesangialen Matrix vertreten ist (Miner, 1999).

\subsection{Alport-Syndrom}

Das Alport-Syndrom ist eine erbliche Erkrankung von Basalmembranen und ist mit sensorischer Taubheit, spezifischen Linsenveränderungen am Auge und progressiver Nephropathie bis hin zum terminalen Nierenversagen assoziiert. Das Alport-Syndrom tritt mit einer Häufigkeit von $0,02 \%$ in der Bevölkerung auf (Haas, 2009). Durch zahlreiche Mutationen der Gene COL4A1-6, die für die Kollagen Typ IV bildenden $\alpha$-Ketten kodieren, entstehen Defekte des a3a4a5-Netzwerkes zahlreicher Basalmembranen. Beim Alport-Syndrom sind unter anderem die Basalmembranen der Glomeruli und Tubuli in den Nieren, sowie Basalmembranen des vorderen Linsenanteils im Auge und der Cochlea im Ohr geschädigt, sodass die betroffenen Organe ihre Funktion nicht mehr vollständig wahrnehmen können. Ist eine der drei $\alpha(I V)-K e t t e n$ durch Mutation verändert, fehlen auch die anderen, mit ihr im Netzwerk assoziierten Ketten. Stattdessen persistiert das instabilere Netzwerk aus a1(IV)- und a2 (IV)-Ketten, wie es normalerweise in den fetalen Nieren zu finden ist (siehe hierzu Abbildung 4) (Hudson et al., 2003, Jais et al., 2003, Knebelmann et al., 1996, Miner, 1999, Nakanishi et al., 1994, Peissel et al., 1995). 


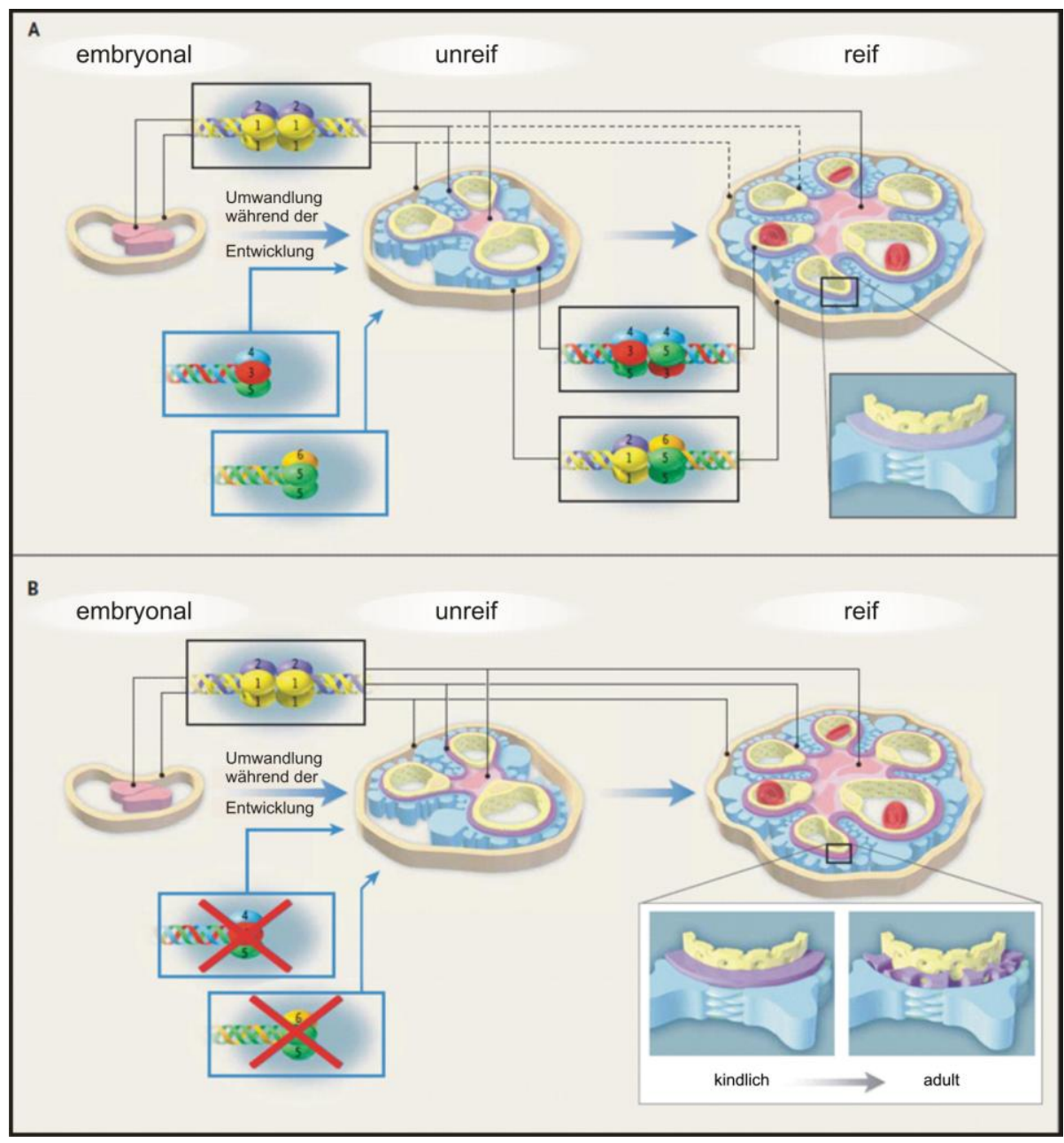

\section{Abbildung 4: Expression und Umwandlung von Kollagen Typ IV in der Entwicklung des Glomerulus (modifiziert nach Hudson et al., 2003, S. 2546)}

Während der frühen embryonalen Entwicklung ist das a1a1a2 (IV)-Netzwerk in allen Abschnitten vertreten (Fenster A links), d.h. das Netzwerk ist Bestandteil der Basalmembranen von Bowmankapsel, mesangialer Matrix und des Glomerulus. Das a3a4a5 (IV)-Netzwerk und das a5a5a6 (IV)-Netzwerk entstehen erst in der weiteren Entwicklung der Nieren und ersetzen dann zum großen Teil die a1a1a2 (IV)-Netzwerke der Bowmankapsel und des Glomerulus (gestrichelte Linien). Bei der X-chromosomal erblichen Form des Alport-Syndroms (Fenster B) kann die Umwandlung nicht stattfinden, da die a5 (IV)-Kette mutiert ist. Auf Grund dieser Mutation persistiert das a1a1a2 (IV)Netzwerk. Das a3a4a5 (IV)- und das a5a5a6 (IV)-Netzwerk fehlen in den Nieren bei von der Xchromosomalen Alportkrankheit Betroffenen.

Ungefähr 0,3-2,3 \% der Patienten mit terminalem Nierenversagen sind vom AlportSyndrom betroffen. Ein Frühzeichen der Erkrankung ist die Hämaturie. Früher oder später tritt sie bei allen Erkrankten auf (Gubler, 2008). Während globaler Infekte, zum Beispiel des oberen Respirationstraktes, treten bei $60 \%$ der Betroffenen unter 15 Jahren und bei allen älteren Betroffenen Episoden von Makrohämaturie auf. Abhängig vom Geschlecht, dem Alter und der Mutation entwickelt sich die anfänglichen Hämaturie zu einer fortschreitenden Nierenerkrankung (Gross et al., 
2002, Zhang et al., 2008,). Durch die geschädigte Filtrationsbarriere kommt es zur Proteinurie, die die glomeruläre Basalmambran weiter schädigt, bis sie schließlich sklerosiert. Der Glomerulosklerose folgt die fibrotische Veränderung des Parenchyms und die Nieren verlieren nach und nach ihre Funktion (Hudson et al., 2003). Mit dem Beginn der chronisch renalen Insuffizienz entwickelt sich ein Bluthochdruck. Der bilaterale sensoneurinale Hörverlust kann sich schon im ersten Lebensjahrzehnt entwickeln und ist dann meist progressiv (Gubler, 2008). Am Auge findet sich eine progressive, kegelförmige Verformung der Linse, sowie asymptomatische gelbe Flecken auf der Retina, deren Erscheinen sich im Verlauf der Krankheit häuft. Die Augenveränderungen sind spezifisch für das Alport-Syndrom und eignen sich damit zur Diagnosestellung. Sie treten jedoch nur bei circa einem Drittel der Patienten auf (Zhang et al., 2008). Mikroskopisch ist zu beobachten, dass sich die glomeruläre Basalmembran erkrankter Nieren auf 800-1200 nm verdickt. Weiterhin ist diese Basalmembran durch segmentales Splitting, Ausstülpungen und unregelmäßige Konturen gekennzeichnet. All dies sind Zeichen der Instabilität des Kollagen-Typ-IVNetzwerkes. Abhängig vom Krankheitsstadium finden sich unspezifische Kennzeichen der Nierenschädigung, wie Vermehrung und Sklerose der Glomeruli, Kapillarwandverdickung und -sklerose, tubulointerstitielle Fibrose mit Anreicherung von extrazellulärer Matrix und Ansammlung von Entzündungszellen (Gubler, 2008).

Mutationen im COL4A5-Gen auf dem X-Chromosom, das für die a5-Kette des Netztwerkes kodiert, sind mit $85 \%$ die häufigste Ursache für das Alport-Syndrom. Die autosomal rezessive Form des Alport-Syndroms (10-15 \%) resultiert aus Mutationen des COL4A3- oder COL4A4-Gens, die für die a3- und a4-Kette kodieren. Die autosomal dominant vererbliche Mutation von COL4A3 und COL4A4 ist mit $<5 \%$ die seltenste Ursache des Alport-Syndroms (Gubler, 2008).

Die häufgste Form des Alport-Syndroms führt, da sie X-chromosomal vererbt wird, meist nur bei Männern zum terminalen Nierenversagen, sensorischem Hörverlust (60-80 \%) und Linsenveränderungen (25-40\%) (Hudson et al., 2003). Eine Vererbung von Vater zu Sohn ist nicht möglich. Es können zwei Verlaufsformen des X-chromosomalen Alport-Syndroms beobachtet werden. Der "juvenile“ Typ hat in jeder Familie einen stereotypen Ablauf, wobei Männer meist schon mit circa 20 Jahren ein terminales Nierenversagen erleiden. Beim „adulten“ Typ ist der Verlauf 
der Krankheit sehr viel variabler und das terminale Nierenversagen tritt erst im durchschnittlichen Alter von 40 Jahren auf.

Bei heterozygoten Frauen findet man eine intermittierende Hämaturie, die oft erst im Erwachsenenalter auftritt, oder aber die Frauen bleiben asymptomatische Trägerinnen der Krankheit. Das Risiko, vor dem Alter von 40 Jahren ein terminales Nierenversagen zu erleiden, beträgt für Mädchen $12 \%$, für Jungen 90 \%. Bei Frauen über 60 Jahren steigt das Risiko für das Fortschreiten der Krankheit stark an (Jais et al., 2003). Der Verlauf und die Schwere der Erkrankung hängen mit der Art der Mutation zusammen. Bei der autosomal-rezessiv erblichen Form des AlportSyndroms sind Klinik und Morphologie identisch zu der X-chromosomal vererbten Form. Allerdings erkranken bei der autosomal-rezessiven Form im Gegnensatz zur X-chromosomalen Form auch Frauen, die Symptome sind meist stärker und es kommt früher zum terminalen Nierenversagen (Gubler, 2008). Ungefähr $1 \%$ der Bevölkerung sind heterozygote Träger der autosomal rezessiven Mutation. Bei diesen Patienten nimmt die Dicke der Basalmembran ab und es resultiert eine Durchlässigkeit des Filtrationsapparates. Die auf diesem Boden entstehende persistierende oder rekurrente benigne Hämaturie ist in $30 \%$ der Fälle mit erhöhtem Blutdruck assoziiert. Gelegentlich finden sich auch andere oben beschriebene Symptome des Alport-Syndroms (Beirowski et al., 2006, Gross, 2008). Ein verschwindend geringer Teil der am Alport-Syndrom erkrankten Patienten trägt eine autosomal dominante Mutation des COL4A3- oder COL4A4-Gens. Bisher ist die autosomal dominante Form erst in sechs nicht miteinander verwandten Familien diagnostiziert worden. Diese Form des Alport-Syndroms zeichnet sich dadurch aus, dass sie im Gegensatz zur X-chromosomalen Form auch von Vätern an Söhne vererbt werden kann. Zudem fält die Symptomatik im Vergleich milder aus. Das terminale Nierenversagen und der Hörverlust treten oft erst im Alter über 50 Jahren auf, während Augenbeteiligungen bisher nicht bekannt sind (Pescucci et al., 2004, van der Loop et al., 2000).

Wie stark die Alport-Erkrankung ausbricht, ist demnach von der Art der Mutation, der Anzahl der mutierten Gene, dem Erbgang, dem Geschlecht der betroffenen Person und von äußeren Einflüssen abhängig. Die klinische Pathophysiologie der verschiedenen Varianten des Alport-Syndroms ist in Tabelle 2 zu finden. 
Tabelle 2: Klinische Pathophysiologie des Alport-Syndroms (modifiziert nach Hudsonet al., 2003, S. 2548)

\begin{tabular}{|c|c|c|c|}
\hline Alport-Syndrom & Mutation & Proteinveränderung & Klinik \\
\hline $\begin{array}{l}\text { X-chromosomal } \\
-\quad \text { adult } \\
\\
\text { - juvenil }\end{array}$ & $\begin{array}{l}\text { Missense-Mutationen } \\
\text { oder Splicevarianten im } \\
\text { COL4A5 Gen } \\
\text { Deletion, nonsense- oder } \\
\text { missense-Mutationen im } \\
\text { COL4A5 Gen }\end{array}$ & $\begin{array}{l}\text { Verminderung oder } \\
\text { Verdrehung des } \\
\text { a3a4a5(IV)- und } \\
\text { a5a5a6(IV)-Netzwerkes } \\
\text { Fehlen des } \alpha 3 \alpha 4 \alpha 5(I V)- \\
\text { und } a 5 a 5 a 6(I V)- \\
\text { Netzwerkes }\end{array}$ & $\begin{array}{l}\text { Später Verlust der } \\
\text { Nierenfunktion (> } 30 \\
\text { Jahren) und leichte } \\
\text { Taubheit bei Männern; } \\
\text { leichte Erkrankung bei } \\
\text { Frauen } \\
\text { Früher Verlust der } \\
\text { Nierenfunktion (<30 } \\
\text { Jahren) bei Männern, oft } \\
\text { mit Taubheit und } \\
\text { Linsenschäden }\end{array}$ \\
\hline Autosomal-rezessiv & $\begin{array}{l}\text { Homozygote oder } \\
\text { compound-heterozygote } \\
\text { nonsense Mutationen, } \\
\text { Leserasterverschie- } \\
\text { bungen, kleine Deletionen } \\
\text { oder Splicevarianten im } \\
\text { COL4A3- oder COL4A4- } \\
\text { Gen }\end{array}$ & $\begin{array}{l}\text { Verlust des } \alpha 3 a 4 a 5(I V)- \\
\text { Netzwerkes }\end{array}$ & $\begin{array}{l}\text { Früher Verlust der } \\
\text { Nierenfunktion }(<30 \\
\text { Jahren) bei beiden } \\
\text { Geschlechtern }\end{array}$ \\
\hline Autosomal-dominant & $\begin{array}{l}\text { Missense-Mutation im } \\
\text { COL4A4-Gen; Splice- } \\
\text { varianten oder kleine in- } \\
\text { frame Deletionen, der für } \\
\text { Kollagen kodierenden } \\
\text { Region, oder verkürzte } \\
\text { Signalpeptid-Sequenzen } \\
\text { im COL4A3-Gen }\end{array}$ & $\begin{array}{l}\text { Aberrationen des } \\
\text { a3a4a5(IV)-Netzwerkes }\end{array}$ & $\begin{array}{l}\text { Nierenerkrankung } \\
\text { unterschiedlicher } \\
\text { Malignität }\end{array}$ \\
\hline $\begin{array}{l}\text { Benigne familiäre } \\
\text { Hämaturie }\end{array}$ & $\begin{array}{l}\text { Missense-Mutation des } \\
\text { COL4A3-Gens oder } \\
\text { Splicevarianten, } \\
\text { Leserasterverschie- } \\
\text { bungen oder missense- } \\
\text { Mutationen des COL4A4- } \\
\text { Gens, vererbbar wie } \\
\text { autosomal dominante } \\
\text { Erkrankungen }\end{array}$ & $\begin{array}{l}\text { Überproduktion des } \\
\text { a3a4a5(IV)-Netzwerkes }\end{array}$ & $\begin{array}{l}\text { Leichte Hämaturie mit } \\
\text { „dünnen“ } \\
\text { Basalmembranen, selten } \\
\text { Hypertonie oder nicht- } \\
\text { progressive Proteinurie; } \\
\text { keine Auffälligkeiten in der } \\
\text { Biopsie }\end{array}$ \\
\hline
\end{tabular}

\subsection{Alport-Maus}

Das knock-out-Maus-Modell des Alport-Syndroms auf dem genetischen Hintergrund von 129/SvJ-Mäusen trägt eine mutierte Form des COL4A3-Gens (Gross et al., 2003). Der Phänotyp der Tiere, der Ausbruch der Erkrankung und der Zeitpunkt des terminalen Nierenversagens sind stark von äußeren Einflüssen abhängig. Um eine 
Population von Tieren zu generieren, bei der der Phänotyp möglichst wenig variiert, sollte die genetische Variabilität durch Rückkreuzung in der Tierzucht minimiert werden, sodass alle Tiere die gleiche Mutation tragen. Außerdem muss die Haltung der Tiere standardisiert sein (Andrews et al., 2002).

Bei Mäusen, die homozygot negativ für das Gen der a3(IV)-Kette des Kollagens Typ IV $\left(\mathrm{COL} 4 \mathrm{~A} 3^{--}\right)$sind, ist immunhistochemisch statt des üblichen Netzes aus a3a4a5(IV)-Ketten eines aus a1a1a2(IV)-Ketten zu finden. Die Tiere haben eine durchschnittliche Lebensdauer von $71 \pm 5,7 d$ (Gross et al., 2003). Mit etwa sechs Wochen entwickeln die Tiere eine Proteinurie, die sich in den zwei darauf folgenden Wochen zu einem typischen nephrotischen Syndrom mit Ödemen und Hypercholesterinämie entwickelt. Mit acht Wochen scheiden die Tiere $>5 \mathrm{~g}$ Protein/l Urin aus. Circa ein bis zwei Wochen später stehen die Tiere kurz vor dem Nierenversagen. Sie haben eine Proteinurie von $>10 \mathrm{~g} / \mathrm{l}$, essen und trinken weniger und sterben kurz darauf. Elektronenmikroskopisch zeigen sich die typischen Bilder einer verdickten und gesplitteten glomerulären Basalmembran, sowie renal intrazelluläre Ansammlungen von fibrillärem Kollagen. Die Architektur der Podozytenfußfortsätze geht unwiederbringlich verloren. Lichtmikroskopisch ist eine periglomeruläre und tubulointerstitielle Fibrose zu beobachten, die Glomeruli sind hyperzellulär und die Basalmembranen der Bowmankapseln sind deutlich verdickt. In den Tubuluszellen findet sich eine große Anzahl von Vesikeln, die wahrscheinlich resorbierte Proteine aus dem Urin enthalten. Glomerulosklerose und Fibrose der Nieren verstärken sich weiterhin, bis die Nieren ihre Funktion nicht mehr wahrnehmen können und es zum terminalen Nierenversagen kommt. Auch im immunhistochemischen Bild ist die fibröse Nierenveränderung deutlich zu erkennen, da der Nachweis von Fibronektin in der extrazellulären Matrix bei kranken Mäusen stark positiv ist. Der Verlust der Funktion einzelner Nephrone ist durch deren entweder konstringiertes oder dilatiertes Lumen zu erkennen. Auch für Laminin 1 kann über immunhistochemische Färbung ein Expressionsanstieg verzeichnet werden. Das Protein zeigt sich intra- und periglomerulär, sowie zwischen den Tubuli (Gross et al., 2003). In COL4A3 ${ }^{-/}$-Mäusen vom Stamm SvJ/129 aus der Gruppe von Andrews (Andrews et al., 2002) findet sich in der glomerulären Basalmembran der an der Alport-Erkrankung leidenen Tiere statt dem normalerweise exprimierten Laminin 11 ( $\alpha 5 \beta 2 \gamma 1)$ die üblicherweise in der mesangialen Matrix vertretene a2-Kette. 


\subsection{Sulfatmetabolismus}

Sulfat ist das vierthäufigste Anion im menschlichen Blutplasma und spielt in einer Reihe von biochemischen Prozessen eine wesentliche Rolle (Fernandes et al., 1997, Markovich und Murer, 2004). Die Plasmasulfatkonzentration des Menschen beträgt 300-400 $\mu \mathrm{M}$ (die von Nagern $\sim 1 \mathrm{mM}$ (Lee, A. et al., 2000). Die Menge von anorganischem Sulfat im Blut folgt einem zirkadianen Rhythmus mit einer höheren Konzentration am Tag als in der Nacht. Sie ist abhängig von der Nahrungsaufnahme, dem Verbrauch bei metabolischen Prozessen und der Ausscheidung über den Urin (Krijgsheld et al., 1980). Außerdem kann die Sulfatkonzentration im Blut von dem Geschlecht, dem Menstruationszyklus, der Schwangerschaft und den Schilddrüsenhormonen beeinflusst werden (Fernandes et al., 1997).

Sulfat dient zum Großteil der Sulfatierung einer Reihe von exogenen und endogenen Komponenten. Für den Vorgang wird das Cosubstrat PhosphoadenosinPhosphosulfat (PAPS), bestehend aus anorganischem Sulfat und ATP, benötigt (Cole und Evrovski, 2000, Krijgsheld et al., 1980, Mulder und Keulemans, 1978). Die Sulfatierung dient der Aktivierung und der besseren Ausscheidung von Stoffen, sowie der Biosynthese von strukturellen Komponenten, wie sulfatierten Proteoglykanen zum Aufbau von Geweben und Membranen (Beck und Silve, 2001).

Der Sulfatmetabolismus der Niere beinhaltet zwei wesentliche Schritte: Zum einen die freie glomeruläre Filtration von Sulfat und zum anderen dessen Reabsorption im Tubulus. Wie viel Sulfat in den Urin gelangt, ist einerseits von der GFR abhängig (Cole und Scriver, 1980, Krijgsheld et al., 1980), andererseits von der Sulfatkonzentration im Blut. Die Rückresorption von Sulfat über die Zellen des proximalen Tubulus geschieht an der apikalen Bürstensaummembran über ein natriumabhängiges Sulfattransportsystem $\left(\mathrm{Na}^{+}-\mathrm{SO}_{4}{ }^{2-}\right.$ Cotransport $)$ und an der basolateralen Zellseite über einen Anionenaustauscher (Übersicht in Lee und Markovich, 2004). Dabei ist der Transport über die Bürstensaummembran der limitierende Faktor für die Reabsorption von Sulfat (Besseghir und Roch-Ramel, 1987, Frick und Durasin, 1986,). Auf die das Transportsystem bildenden Transporter wird im Kapitel 1.6.2 (NaS1) und 1.6.3 (sat1) eingegangen. NaS1 ist für die natriumabhängige Aufnahme von Sulfat in die Tubuluszelle verantwortlich, sat1 transportiert Sulfat im Austausch gegen Anionen aus der Zelle heraus (siehe Abbildung 5). 


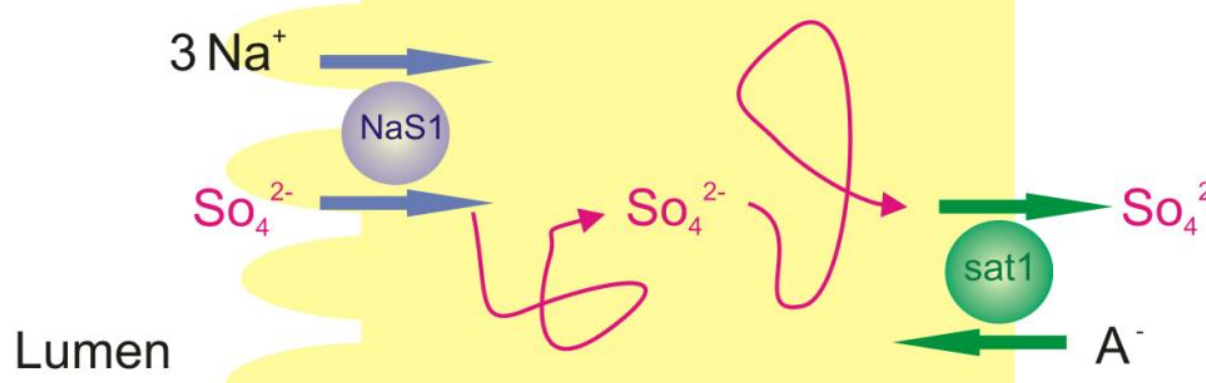

Interstitium/

Blut

$$
\mathrm{A}^{-}=\text {Anionen }\left(\mathrm{OH}^{-}, \mathrm{HCO}_{3}{ }^{-}, \mathrm{Oxalat}^{2-}\right)
$$

\section{Abbildung 5: Sulfattransport der Nierenepithelzelle im proximalen Tubulus}

Sulfat $\left(\mathrm{SO}_{4}{ }^{2}{ }^{-}\right)$wird durch den natriumabhängigen Sulfattransporter NaS1 zusammen mit drei NatriumIonen $\left(\mathrm{Na}^{+}\right)$über die apikale Bürstensaummembran ins Zellinnere transportiert um dann vom SulfatAnionen-Transporter sat1 im Austausch gegen ein Anion $\left(A^{-}\right)$ins Interstitium zu gelangen.

Unter normalen Umständen werden bereits 80 \% des filtrierten Sulfats im proximalen Tubulus rückresorbiert. Steigt die Plasmasulfatkonzentration, wie beispielsweise beim Nierenversagen, an, ist schnell die maximale Transportkapazität erreicht und das nicht rückresorbierte Sulfat wird über den Urin ausgeschieden (Lee, A. et al., 2000).

\subsection{Die solute-çarrier (SLC)-Transporterfamilie}

\subsubsection{Funktion und Eigenschaften der Transporter vom SLC-Gentyp}

Transporter sitzen in der Membran von Zellen und Organellen und regeln die Aufnahme und Abgabe von verschiedenen Stoffen, wie zum Beispiel Zuckern, Aminosäuren, Nukleotiden, Ionen und Medikamenten. Es gibt sowohl passive als auch aktive Transporter (siehe Abbildung 6). 


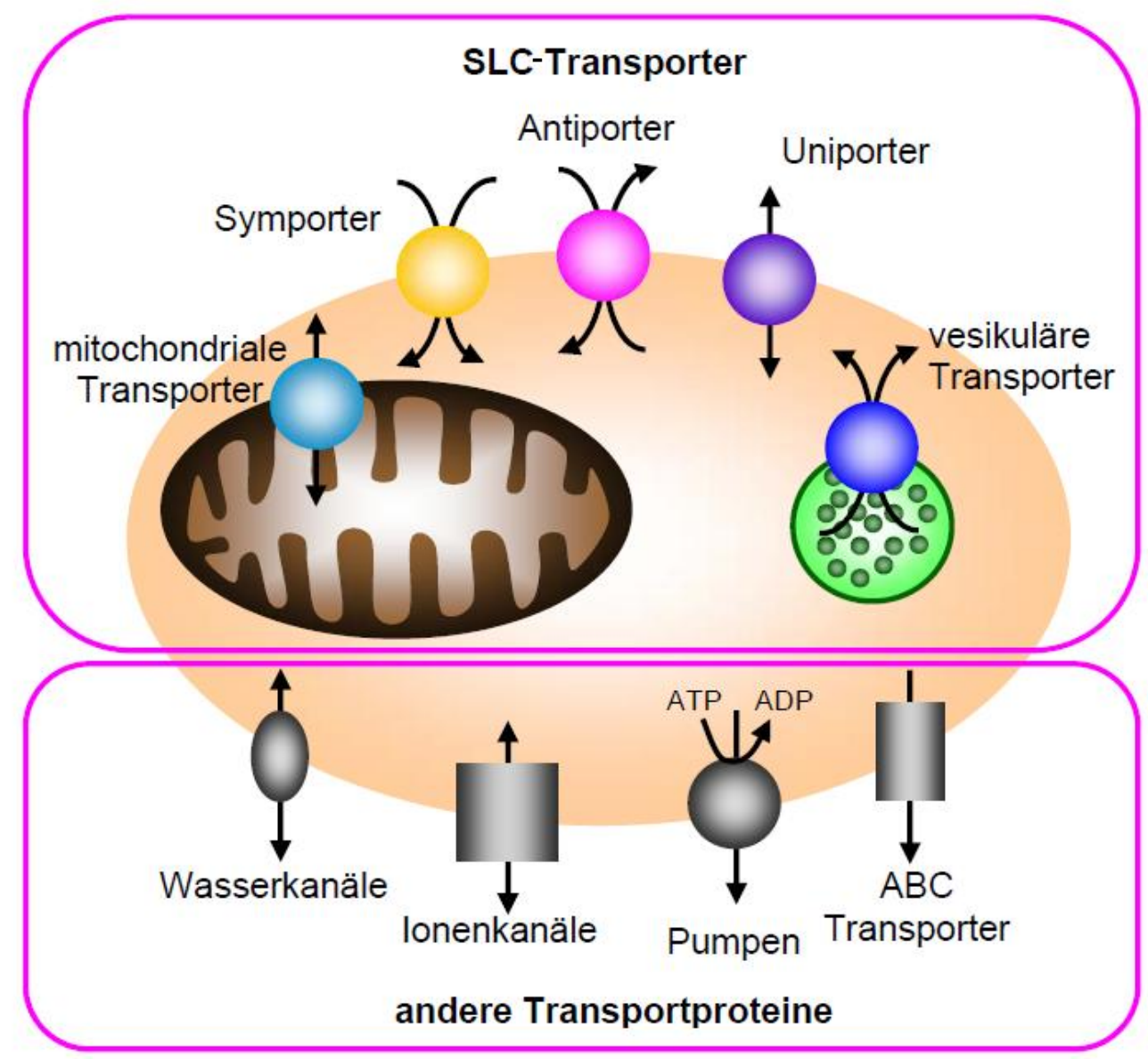

Abbildung 6: SLC- und nicht-SLC-Transportern in der Zellmembran oder in intrazellulären Organellen (modifiziert von Schnedler, N. nach Hediger et al., 2004, S. 465).

Während die passiven Transporter Nährstoffe, wie zum Beispiel Glukose und Aminosäuren, entlang ihres chemischen oder elektrochemischen Gradienten über die Membranen schleusen, generieren aktive Transporter mittels energiegekoppelter Prozesse Gradienten über die Zellmembran. Aktive Transporter verbinden den Transport eines Moleküls oder lons gegen seinen elektrochemischen Gradienten mit dem Transport eines anderen entlang seines Gradienten (Hediger et al., 2004). ATPabhängige Transporter oder Pumpen koppeln energetisch ungünstige Reaktionen mit energetisch günstigen Reaktionen (He et al., 2009). Die aktiven Transporter können in primäre und sekundäre eingeteilt werden. Die primär aktiven Transporter hydrolisieren ATP direkt, so zum Beispiel die ABC-Transporter, die in ihrer ATPbinding casette energiereiches ATP binden und spalten, um die frei werdende Energie für den Transport von Stoffen über die Zellmembran zu nutzen. Auch Ionenpumpen benötigen Energie aus ATP, um Ionen wie $\mathrm{Na}^{+}, \mathrm{K}^{+}, \mathrm{H}^{+}, \mathrm{Ca}^{2+}$ und $\mathrm{Cu}^{2+}$ 
entgegen einem Gradienten in Zellen oder Organellen zu transportieren. Den durch die lonenpumpen generierten elektrochemischen Gradienten nutzen sekundär aktive Transporter, um mit dem Stoff, der entlang des Gradienten transportiert wird, einen anderen Stoff dem Gradienten entgegengesetzt zu transportieren (Hediger et al., 2004). Eines der bekanntesten primär aktiven Membrantransportproteine ist die $\mathrm{Na}^{+}-$ $\mathrm{K}^{+}$-ATPase. Sie findet sich in der Plasmamembran fast aller Zellen und wird durch intrazelluläres $\mathrm{Na}^{+}$und extrazelluläres $\mathrm{K}^{+}$aktiviert. Pro Pumpzyklus wird ein Molekül ATP gespalten und die entstehende Energie dazu genutzt, $3 \mathrm{Na}^{+}$aus der Zelle heraus und $2 \mathrm{~K}^{+}$in die Zelle hinein zu transportieren. Somit gehört die $\mathrm{Na}^{+}-\mathrm{K}^{+}-$ ATPase zu den elektrogenen Transportmechanismen, die dadurch gekennzeichnet sind, dass der durch sie vermittelte Transport eine Nettoverschiebung von elektrischer Ladung über die Zellmembran bewirkt (Jorgensen et al., 2003). Werden Stoffe in dieselbe Richtung transportiert, ist der Transporter ein Symporter, werden sie in entgegengesetzte Richtungen transportiert, ein Antiporter. Weiterhin gilt die Einteilung in elektrogene und elektroneutrale Transporter, je nachdem, ob elektrische Ladungen verschoben werden oder nicht. Der Substratfluss von Kanälen wird durch ihre Offenwahrscheinlichkeit bestimmt, während bei Transportern die Stoffe nach einer bestimmten Stöchiometrie über die Membran gelangen (He et al., 2009).

Zur solute-çarrier (SLC)-Gen-Superfamilie gehören passive Transporter, IonenSymporter und -Austauscher (Antiporter), die in allen Membranen, ausgenommen die Kernmembran, sitzen (siehe Abbildung 6). Die Superfamilie setzt sich zusammen aus 55 Genfamilien mit mindestens 362 mutmaßlich funktionellen, proteinkodierenden Genen (He et al., 2009). Voraussetzung für die Zugehörigkeit zur SLC-GenSuperfamilie ist, dass ein Transporter mindestens zu 20-25\% mit der Aminosäuresequenz der anderen Transporter übereinstimmt (Hediger et al., 2004). Typisch für die Proteine sind mehrere Transmembrandomänen. SLC-Transporter dienen dem Transport von endogenen Stoffen, wie Aminosäuren und Oligopeptiden, Glukose und anderen Zuckern, anorganischen Anionen und Kationen, Gallensalzen, Carboxylaten und anderen organischen Anionen und Kationen, Acetyl-Coenzym A, essentiellen Metallen, biogenen Aminen, Neurotransmittern, Vitaminen, Fettsäuren und Lipiden, Nukleosiden, Ammonium, Cholin, Schilddrüsenhormonen und Harnsäure. Obwohl nicht dafür bestimmt, transportieren einige der Transporter auch exogene Stoffe, wie zum Beispiel Medikamente, nicht-essentielle Metalle und andere 
toxische Stoffe in Zellen oder Organellen hinein oder aus innen heraus. Mutationen der Gene aus der SLC-Superfamilie spielen bei vielen Erkrankungen vor allem von Kindern eine Rolle (He et al., 2009).

\subsubsection{Der natriumabhängige Sulfattransporter 1 (NaS1)}

\subsubsection{Eigenschaften des NaS1-Gens und seiner Genprodukte}

Der natriumabhängige Sulfattransporter-1 (NaS1) gehört zu der Genfamilie der SLC13 Transporter, deren fünf Mitglieder sich durch ihre Ähnlichkeit in der Sequenz auszeichnen. Außerdem bestehen alle Transporter der SLC13-Genfamilie aus 572 bis 672 Aminosäuren mit 8-13 Transmembrandomänen. Die Transporter, die von den SLC13 Genen kodiert werden, können in zwei Gruppen geteilt werden: Die Natrium-

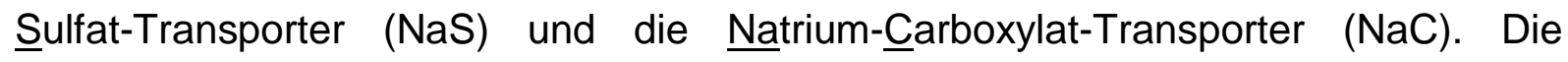
einzelnen Mitglieder der SLC13-Genfamilie sind mit ihren neuen und alten Namen und ihrem Genort in Tabelle 3 aufgelistet. NaS1 steht für den natriumabhängigen anorganischen Sulfattransporter-1 NaSi-1 (SLC13A1), NaS2 für den Sulfattransporter-1 SUT-1 (SLC13A4), NaC1 für den natriumabhängigen Dicarboxylattransporter-1 NaDC-1/SDCT1 (SLC13A2), NaC2 für den

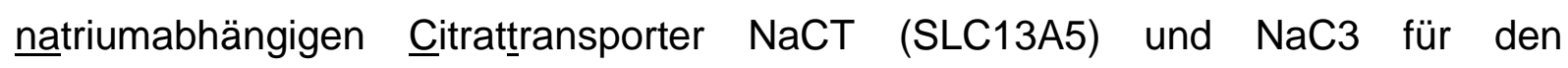
natriumabhängigen Diçarboxylattransporter NaDC-3/SDCT2 (Markovich und Murer, 2004). Auf die Mitglieder SLC13A2-A5 wird in dieser Arbeit nicht weiter eingegangen. Sie wurden nur erwähnt, um einen vollständigen Überblick über die SLC13-Familie zu geben. 
Tabelle 3: Mitglieder der humanen SLC13-Genfamilie (modifiziert nach Markovich und Murer, 2004, S. 595)

\begin{tabular}{|l|l|l|l|}
\hline $\begin{array}{l}\text { Humanes } \\
\text { Gen }\end{array}$ & $\begin{array}{l}\text { Neuer } \\
\text { Proteinname }\end{array}$ & $\begin{array}{l}\text { Alte } \\
\text { Proteinnamen }\end{array}$ & $\begin{array}{l}\text { Genort auf dem menschlichen } \\
\text { Genom }\end{array}$ \\
\hline SLC13A1 & NaS1 & $\begin{array}{l}\text { NaSi-1 } \\
\text { Na-Sulfat }\end{array}$ & $7 q 31-q 32$ \\
\hline SLC13A2 & NaC1 & $\begin{array}{l}\text { NaDC-1 } \\
\text { SDCT1 }\end{array}$ & $17 p 11.1-11.1$ \\
\hline SLC13A3 & NaC3 & NaDC-3 & 20q12-q13.1 \\
\hline SLC13A4 & NaS2 & SUCT2 1 & $7 q 33$ \\
\hline SLC13A5 & NaC2 & NaCT & $12 p 12-13$ \\
\hline
\end{tabular}

Das Gen SLC13A1 kodiert für den NaS1-Transporter, der Natrium und Sulfat in die Zelle gerichtet über die apikale Tubuluszellmembran transportiert. Für das Protein stimmen die Aminosäure-Sequenzen beim Menschen (hNaS1), bei der Maus (mNaS1) und bei der Ratte (rNaS1) zu jeweils 80-92 \% überein. Der Transporter hat bei Säugetieren ein Molekulargewicht von $\sim 66,1 \mathrm{kDa}$, wobei hNaS1 und mNaS1 aus 595 Aminosäuren bestehen, mNaS1 aus einer Aminosäure weniger, da Glutamat an Position 314 fehlt. Das NaS1-Protein besitzt sehr wahrscheinlich 13 Transmembrandomänen mit einem intrazellulären $\mathrm{NH}_{2}$-Terminus und einem extrazellulären $\mathrm{COOH}-$ Terminus (siehe Abbildung 7) (Markovich und Murer, 2004). 


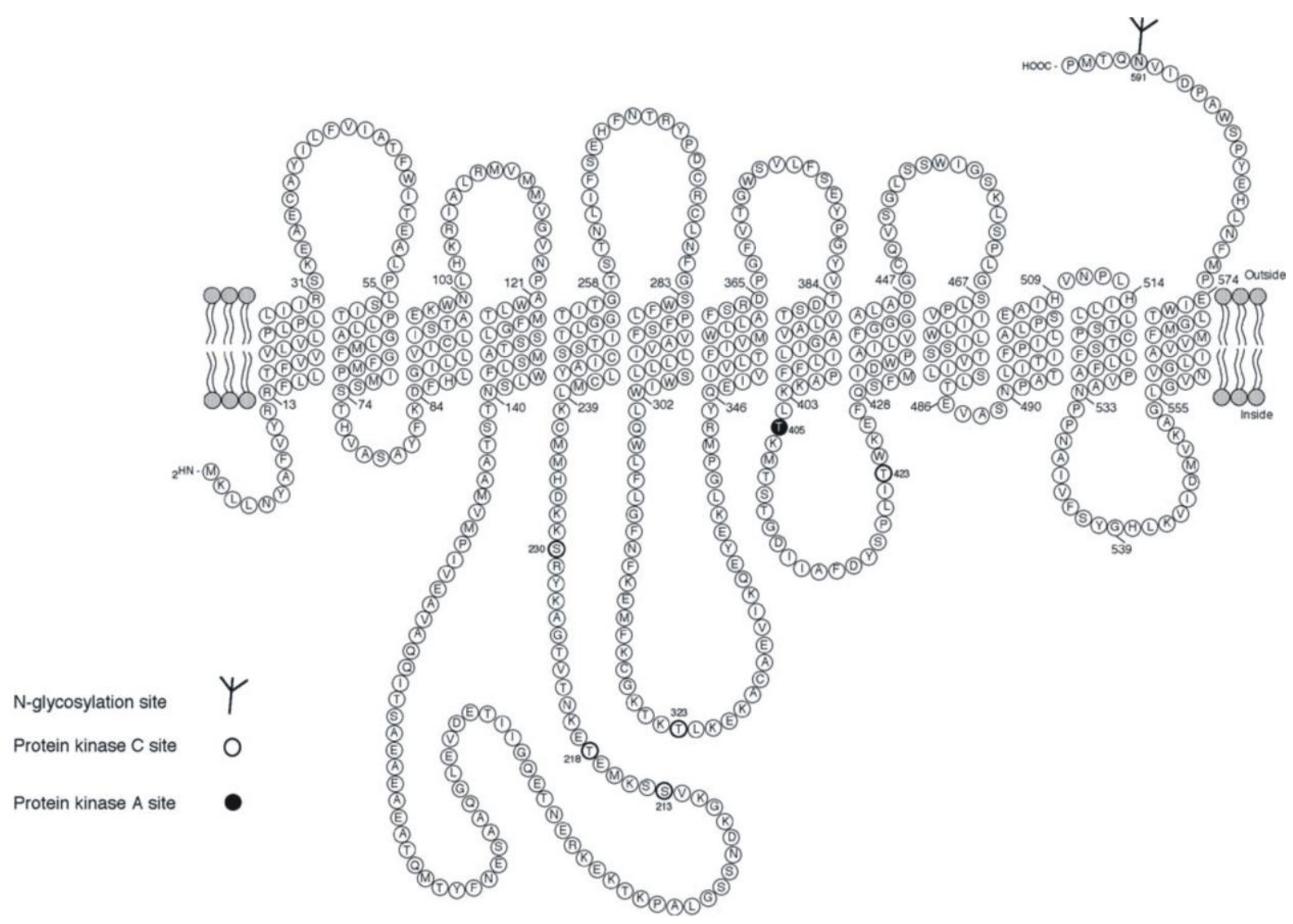

Abbildung 7: Sekundärstruktur des rNaS1-Proteins mit intrazellulärem NTerminus und extrazellulärem C-Terminus (Markovich and Murer, 2004, S. 598).

Der humane NaS1 besitzt wahrscheinlich eine $N$-gekoppelte Glykosylierungsstelle $\left(A s n^{591}\right)$ und drei weitere intrazelluläre Glykosylierungsstellen (Asn ${ }^{140}, \mathrm{Asn}^{147}$, $\left.A s n^{207}\right)$. Weiterhin gibt es fünf intrazelluläre Phosphorylierungsstellen $\left(\mathrm{Ser}^{213}, \mathrm{Thr}^{230}\right.$, $\mathrm{Thr}^{236}$ und $\mathrm{Thr}^{423}$ für Proteinkinase $\mathrm{C}$ und $\mathrm{Thr}^{240}$ für Proteinkinase $\mathrm{A}$ ) und fünf Kaseinkinase-II-Phosphorylierungsstellen $\left(\mathrm{Ser}^{74}, \mathrm{Thr}^{209}, \mathrm{Ser}^{214}, \mathrm{Thr}^{423}\right.$ und $\mathrm{Ser}^{483}$ ) (Lee, A. et al., 2000). Die cDNS des NaS1 der Maus besteht aus 3814 Basenpaaren (bp) (Beck und Markovich, 2000), die des Menschen aus 2314 bp (Lee, A. et al., 2000) und die der Ratte aus 2239 bp (Markovich et al., 1993). Für die RNS von hNaS1 wurden Werte von 2,8 und 3,8 kb detektiert (Lee, A. et al., 2000), für die von mNaS1 2,2 und 2,5 kb (Beck und Markovich, 2000) und für rNaS1 2,3 und 2,9 kb (Markovich et al., 1993).

Das NaS1-Gen des Menschen besitzt 15 Exons und 14 Introns, sein Molekulargewicht beträgt 83kb (Lee, A. et al., 2000). Das Molekulargewicht des entsprechenden Gens bei der Maus beträgt 75kb (Beck und Markovich, 2000) und das der Ratte $\sim 77,5 \mathrm{~kb}$ (Markovich et al., 2008). 


\subsubsection{Lokalisation des NaS1}

Beim Menschen findet sich RNS des NaS1 in den Nieren. Bei Ratten sind RNS und Protein in Nieren und Dünndarm zu finden (Markovich et al., 1993). Mäuse exprimieren RNS und Protein in den Nieren im proximalen Tubulus und im Darm im Jejunum/Duodenum, lleum und Colon, sowie etwas schwächer im Blinddarm, in den Hoden, den Nebennieren und im Fettgewebe (Lee, A. et al., 2000). In den Nieren befindet sich der Transporter in der apikal gelegenen Bürstensaummembran der proximalen Tubuluszellen, wie immunhistochmisch nachgewiesen werden konnte (siehe Abbildung 8) (Markovich et al., 1999).

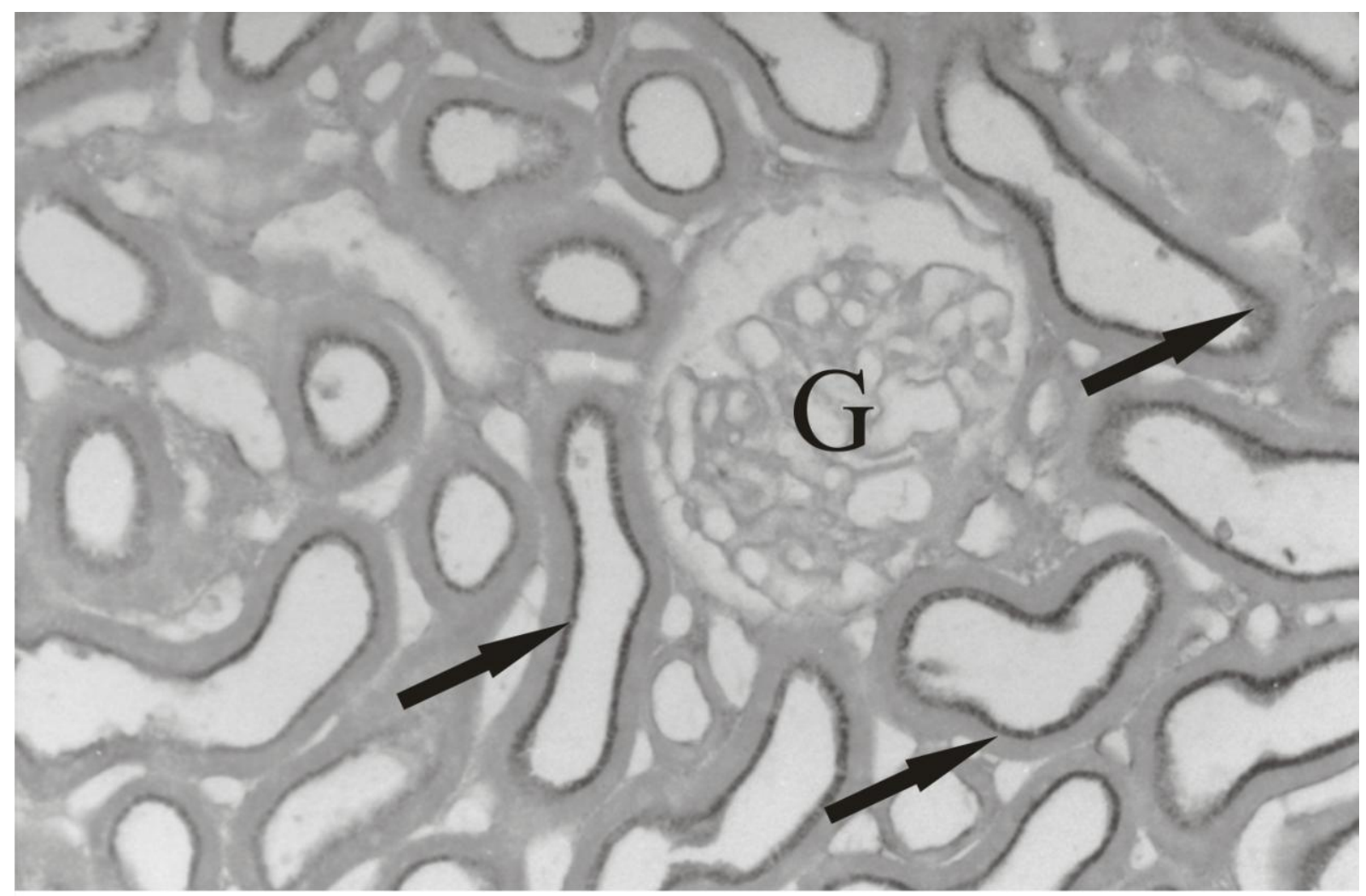

Abbildung 8: Immunhistochemische Färbung des NaS1 in der apikalen Membran proximaler Tuluszellen in Rattennieren (modifiziert nach Markovich et al., 1999, S. 248).

Die dunkle Färbung (Pfeile) bezieht sich auf das Vorhandensein von NaS1-Protein, das Glomerulus $(G)$ ist nicht angefärbt.

\subsubsection{Transport über den NaS1}

$\mathrm{NaS} 1$ transportiert $3 \mathrm{Na}^{+}$zusammen mit einem $\mathrm{SO}_{4}{ }^{2-}$ in die Zellen hinein und baut dabei eine Elektrogenität auf (Beck und Silve, 2001). Die Transporteigenschaften der 
NaS1-Transporter wurden an mit NaS1-mRNS injizierten Xenopus-Oozyten getestet. Der menschliche NaS1 transportiert Sulfat mit einer Michaelis-Menten-Konstante $\mathrm{K}_{\mathrm{m}}$ von $0,31 \pm 0,06 \mathrm{mM}$ und einer maximalen Transportgeschwindigkeit $V_{\max }$ von 180,5 \pm 9 pmol/Oozyte $\times$ h. Die Unterschiede der Transporteigenschaften des NaS1 von Mensch, Maus und Ratte sind in Tabelle 4 aufgelistet.

Tabelle 4: Transporteigenschaften des NaS1 von Mensch (hNaS1), der Maus (mNaS1) und der Ratte (rNaS1) gemessen im Oozyten Expressionssystem (modifizierte nach Beck and Silve, 2001, S. 839)

\begin{tabular}{|l|c|c|c|}
\cline { 2 - 4 } \multicolumn{1}{l|}{} & hNaS1 & mNaS1 & rNaS1 \\
\hline $\begin{array}{l}V_{\max } \text { für Sulfat, } \\
\text { pmol/h }\end{array}$ & $180 \pm 9$ & $49 \pm 4$ & $43 \pm 2$ \\
\hline$K_{m}$ für Sulfat, $m$ mol// & $0,31 \pm 0,06$ & $0,20 \pm 0,06$ & $0,62 \pm 0,08$ \\
\hline $\begin{array}{l}V_{\max } \text { für Natrium, } \\
\text { pmol/h }\end{array}$ & $25 \pm 2$ & $15 \pm 1$ & $17 \pm 1$ \\
\hline $\begin{array}{l}K_{m} \text { für Natrium, } \\
\text { mmol/I }\end{array}$ & $24 \pm 2$ & $21 \pm 2$ & $17 \pm 3$ \\
\hline $\begin{array}{l}\text { Hill-Koeffizient* für } \\
\text { Sulfat }\end{array}$ & 1 & 1 & 1 \\
\hline $\begin{array}{l}\text { Hill-Koeffizient* für } \\
\text { Natrium }\end{array}$ & $2,6 \pm 0,6$ & $2,8 \pm 0,6$ & $1,8 \pm 0,4$ \\
\hline
\end{tabular}

${ }^{*}$ Der Hill-Koeffizient zeigt an, wieviele lonen im Cotransport transportiert werden

\subsubsection{Regulation des NaS1}

Die Expression der rNaS1-RNS und des Proteins wird von vermehrter Sulfat- und Natriumaufnahme durch die Nahrung positiv beeinflusst (Sagawa et al., 1998b, Markovich et al., 1998). Die verminderte Serumkonzentration von Sulfat bei Vitamin D-Mangel (Fernandes et al., 1997), Hypothyreodismus (Sagawa et al., 1999), chronischem Kaliummangel, Gabe von Ibuprofen (Markovich et al., 1999, Sagawa et al., 1998a), metabolischer Azidose (Puttaparthi et al., 1999) und Glucocorticoideinnahme (Lee, H. et al., 2000) werden der verminderten Expression der RNS und des Proteins zugeschrieben. Die responsiven Elemente für Vitamin D 
und Schilddrüsenhormone (VDRE und $T_{3} R E$ ) liegen in der Promotorregion bei -535 bp und -436 bp (Dawson und Markovich, 2002). Bei der subtotalen Nephrektomie an Ratten, als ein Modell für chronische Nierenerkrankung, ist ein Abfall der Menge des NaS1-Proteins mit gleichzeitiger Dichtezunahme zu beobachten (Fernandes et al., 2001). Ein erhöhter RNS- und Proteingehalt ist im Tiermodel unter Wachstumshormoneinfluss (Sagawa et al., 1999) und postnatal (Markovich et al., 1993) zu verzeichnen.

Thiosulfat, Selenat, Molybdat und Wolframat hemmen die Aufnahme von Sulfat über den NaS1 von Mensch, Ratte und Maus, Citrat und Succinat haben nur Einfluss auf hNaS1. Phosphat, Oxalat, Cholin und Probenezid haben keinen signifikanten Effekt auf die Aufnahme von Sulfat und auch Stilbenderivate, die teilweise die Aktivität von Anionenaustauschern hemmen, inhibieren den NaS1-Transport nicht (Lee, A. et al., 2000, Markovich und Aronson, 2007).

\subsubsection{NaS1-knock-out-Maus (NaS1 ${ }^{-/}$-Maus)}

$\mathrm{NaS1-knock-out-Mäuse} \mathrm{zeigen} \mathrm{einen} \mathrm{verminderten} 3 \mathrm{Na}^{+} \mathrm{SO}_{4}{ }^{2-}$-Cotransport in Niere und Darm und leiden unter allgemeiner Wachstumsverzögerung (Dawson et al., 2003). Weibliche $\mathrm{NaS}^{-1-}$-Mäuse sind weniger fertil als ihre gesunden Geschwister. Außerdem erleiden kranke Tiere häufiger Schlaganfälle, besitzen eine beeinträchtigte Erinnerungs- und Riechfunktion (Dawson et al., 2005) und zeigen eine reduzierte objektbezogene Vorsicht und erhöhte motorische Aktivität (Dawson et al., 2004).

\subsubsection{Der Sulfat-Anionen-Transporter1 (sat1)}

\subsubsection{Eigenschaften des sat1-Gens und seiner Genprodukte}

Der Sulfat-Anionen-Iransporter1 (sat1) gehört zur Genfamilie der SLC26Transporter. Die SLC26-Familie umfasst beim Menschen die Gene für 11 Transporter, wobei SLC26A10 ein Pseudogen ist und so nicht für ein funktionelles Protein kodiert (Dorwart et al., 2008). Die Gene dieser Superfamilie kodieren für Proteine, die mit unterschiedlicher Spezifität Anionen transportieren. Die Anionentransporter dieser Gruppe werden in vielen verschiedenen Epithelien exprimiert und spielen eine wesentliche Rolle bei der Anionensekretion und absorption (Ohana et al., 2009). Die Mitglieder können in drei verschiedene Gruppen eingeteilt werden: (1) Die $\mathrm{SO}_{4}{ }^{2-}$-Transporter SLC26A1 und SLC26A2, (2) die $\mathrm{Cl}^{-}$ $/ \mathrm{HCO}_{3}{ }^{-}$-Austauscher SLC26A3, SLC26A4 und SLC26A6 und (3) die lonenkanäle 
SLC26A7 und SLC26A9 (Dorwart et al., 2008). Für SLC26A5 wird vermutet, das er einen Clorid/Formiat-Austausch vermittelt. Die Transportfunktionen von SLC26A8 und SLC26A11 sind bisher nicht geklärt (Ohana et al., 2009). Die SCL26 Transporter sind Proteine mit 700-1000 Aminosäuren, wobei zwischen den einzelnen Mitgliedern 21-43\% der Aminosäuresequenzen übereinstimmen. Vermutlich liegen die Transporter als Dimere vor (Detro-Dassen et al., 2008). Die zum $\mathrm{NH}_{2}$-Terminus gelegenen zweidrittel des Proteins sind zum großen Teil hydrophob und enthalten wahrscheinlich die anionenbindenden Segmente (Aravind und Koonin, 2000). $\mathrm{NH}_{2}-$ und $\mathrm{COOH}$-Terminus der Transporter SLC26A1, SLC26A3, SLC26A5 und SLC26A6 liegen zytosolisch. Die Anzahl der Transmembrandomänen wird bei 8-14 vermutet (Dorwart et al., 2008).

Das Gen SLC26A1 kodiert für den Sulfat-Anionen-Austauscher sat1, der Sulfat über die basolaterale Membran der proximale Tubuluszelle aus der Zelle ins Interstitium der Nieren transportiert. Die Proteinsequenzen des sat1 des Menschen (hsat1) und der Maus (msat1) stimmen zu $77 \%$ und $78 \%$ mit der von Ratten (rsat1) überein. Die Proteine msat1 und rsat1 tragen zu $94 \%$ die gleichen Aminosäuren (Markovich und Aronson, 2007, Regeer et al., 2003). Das hsat1-Protein setzt sich aus 701 Aminosäuren zusammen (Regeer et al., 2003), das rsat1-Protein aus 703 und das msat1-Protein aus 704 Aminosäuren (Lee et al., 2003). Die Transporter tragen eine errechnete Masse von ungefähr $75 \mathrm{kDa}$ und besitzen wahrscheinlich 12 Transmembrandomänen, wobei das $\mathrm{NH}_{2-}$ und das $\mathrm{COOH}$-Ende vermutlich zytosolisch liegen (Lee et al., 2003, Regeer et al., 2003). Immunoblots des Nierenkortex von Ratten mit anti-sat1-Antikörper (Ak) detektierten eine glykosylierte Bande bei $98 \mathrm{kDa}$, sowie eine unglykolysierte Bande bei $68 \mathrm{kDa}$ (Karniski et al., 1998). In nach folgenden Versuchen findet sich mit demselben Antikörper bei Ratten eine Bande bei 85 kDa (Brzica et al., 2009a). Die Ursache für das unterschiedliche Molekulargewicht der Banden ist nicht geklärt.

Unterschiede zu den vermuteten Eigenschaften der Proteinsequenzen im sat1Protein von Mensch und Maus sind in Tabelle 5 aufgelistet (Markovich und Aronson, 2007). 
Tabelle 5: Vermutliche Eigenschaften bestimmter Aminosäuresequenzen im sat1-Protein von Mensch und Maus (nach Regeer et al., 2003 und Lee et al., 2003)

\begin{tabular}{|l|l|l|}
\hline Eigenschaften des Proteins & \multicolumn{1}{|c|}{ hsat1 } & \multicolumn{1}{|c|}{ msat1 } \\
\hline Proteinkinase C consensus sites & $\begin{array}{l}\mathrm{Thr}^{117}, \mathrm{Ser}^{281}, \mathrm{Ser}^{370}, \\
\mathrm{Ser}^{449}, \mathrm{Thr}^{505}, \mathrm{Ser}^{597}, \\
\mathrm{Thr}^{686}\end{array}$ & $\begin{array}{l}\mathrm{Thr}^{30}, \mathrm{Thr}^{634}, \mathrm{Ser}^{657}, \\
\mathrm{Thr}^{661}\end{array}$ \\
\hline Caseinkinase II consensus sites & $\begin{array}{l}\mathrm{Ser}^{358}, \mathrm{Ser}^{467}, \mathrm{Thr}^{526}, \\
\mathrm{Thr}^{629}, \mathrm{Thr}^{670}, \mathrm{Ser}^{679}\end{array}$ & $\mathrm{Ser}^{318}, \mathrm{Ser}^{472}, \mathrm{Ser}^{685}$ \\
\hline $\begin{array}{l}\text { Extrazelluläre } \mathrm{N}- \\
\text { Glykosylierungsstelle }\end{array}$ & $\mathrm{Asn}^{158}, \mathrm{Asn}^{163}$ & $\mathrm{Asn}^{158}, \mathrm{Asn}^{163}, \mathrm{Asn}^{588}$ \\
\hline Tyrosinphosphorylierungsstelle & $\mathrm{Y}^{522}$ & - \\
\hline
\end{tabular}

Die cDNS des hsat1 besitzt eine Länge von 3678 bp (Lee et al., 2003), der msat1 von 3821bp (Regeer et al., 2003) und der rsat1 von 3726 bp (Bissig et al., 1994). Das RNS-Transkript von sat1 beträgt ungefähr 3,7 kb. Das Gen des sat1 hat eine Länge von $\sim 6 \mathrm{~kb}$ und enthält 4 Exons. Beim Menschen liegt es auf Chromosom 4p16.3 (Markovich und Aronson, 2007).

\subsubsection{Lokalisation des sat1}

Beim Menschen findet sich die RNS des hsat1 in hoher Konzentration in Nieren und Leber, sowie in schwächerer Konzentration in Gehirn, Kolon, Thymus, Milz, Dünndarm, Leukozyten, Pankreas, Hoden und Prostata (Regeer et al., 2003). Die Maus exprimiert msat1-RNS vor allem in Nieren und Leber, sowie in Herz, Blinddarm, Hirn und Schädelkalotte (Lee et al., 2003). Die RNS für rsat1 ist in großer Menge in Nieren und Leber vertreten, in schwächerer Ausprägung in Skelettmuskel und Gehirn (Bissig et al., 1994).

Mittels Immunhistochemie zeigt sich, dass sich der sat1 in den Nieren in den basolateralen Membranen der proximalen Tubuli befindet. Die stärkste Färbung zeigt sich im kortikalen Konvolut. Die Färbung der geraden Teile der proximalen Tubuli in den Markstrahlen nimmt zu den äußeren Markstreifen der Medulla hin ab. Die 
distalen Teile der proximalen Tubuli sind nur schwach angefärbt. Der sat1 befindet sich demnach im S1, S2 und S3 Segment der proximalen Tubuli. Die Glomeruli und die distalen Nephrone sind nicht angefärbt (Karniski et al., 1998). In weiteren Versuchen (Brzica et al., 2009a) findet sich der sat1 in der Leber immunhistochemisch in den sinusoidalen Membranen der Hepatozyten (Quondamatteo et al., 2006) (siehe Abbildung 9).
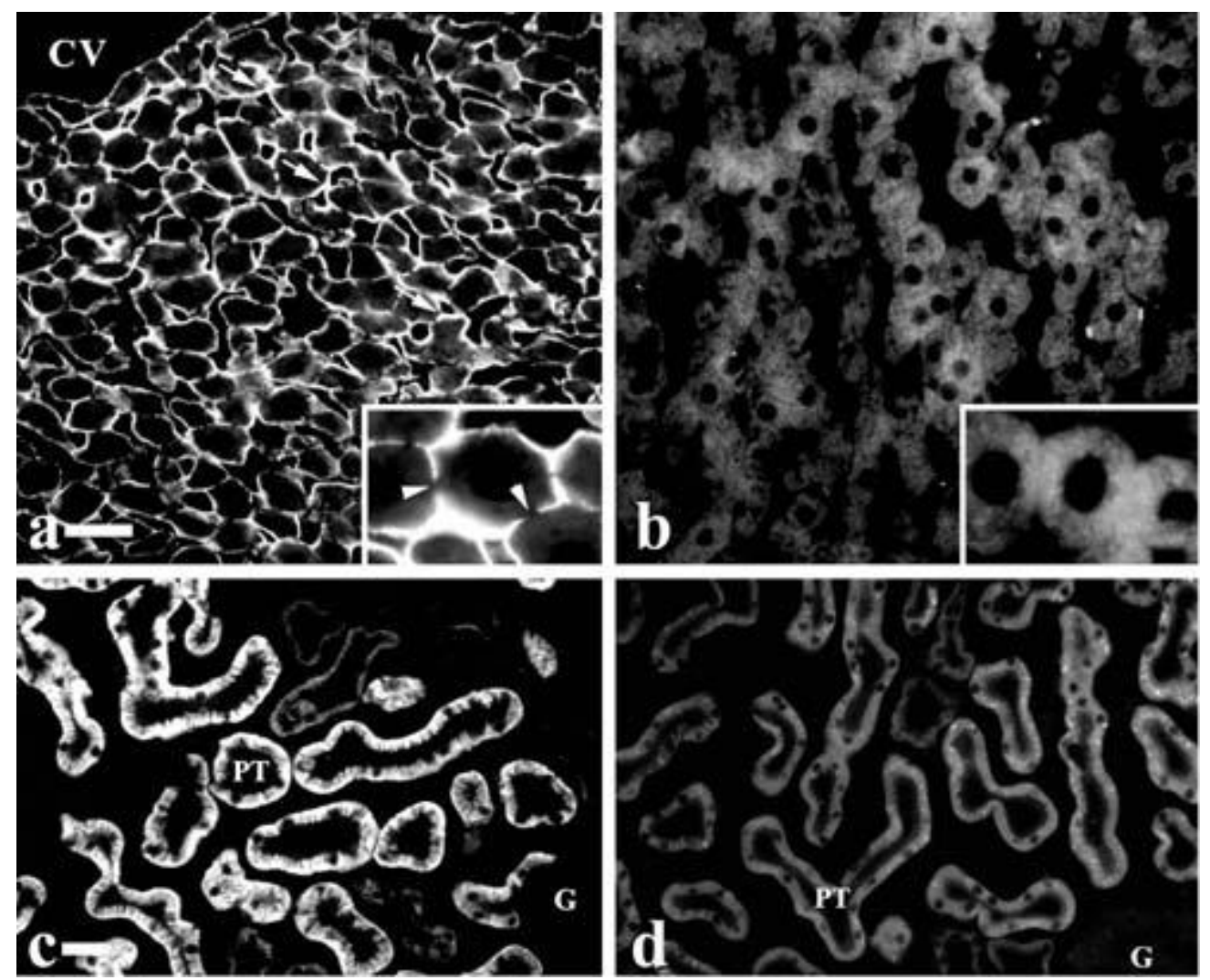

Abbildung 9: Immunhistochemische Charakterisierung des sat1-Proteins in Leber und Nieren von Ratten (nach Brzica et al., 2009b, S. 1386)

a) Leber: Die sinusoidale Zellmembran der Hepatozyten ist durch den anti-sat1-Antikörper stark angefärbt (Pfeile), während die kanikuläre Membran unangefärbt ist (Pfeilköpfe in der Vergrößerung). c) Nierenkortex: Die basolateralen Invaginationen der proxiamlen Tubuluszellen $(P T)$ sind stark angefärbt. $(b+d)$ Die alleinige Inkubation mit sekundärem Antikörper ergibt keine spezifischen Färbungen. CV, central vain (zentral Vene); G, Glomerulus.

\subsubsection{Transport über den sat1}

Sat1 transportiert speziesspezifisch Sulfat im Austausch gegen die Anionen Chlorid, Oxalat, Bikarbonat und Glyoxylat aus der Zelle heraus (Dorwart et al., 2008, Krick et al., 2009, Lee et al., 2003, Reeger et al., 2003, Schnedler et al., 2010).

Versuche an mit sat1-RNS injizierten Xenopus-Oozyten ergaben folgende Werte: Der Transporter hsat1 besitzt einen $K_{m}$-Wert für Sulfat von 0,19 $\pm 0,066 \mathrm{mM}$ und eine 
$V_{\max } 52,35 \pm 3,30 \mathrm{pmol} /$ Oozyte $\times \mathrm{h}$. (Regeer et al., 2003) Für msat ergeben sich für den Sulfattransport Werte von $K_{m}=0,31 \pm 0,05 \mathrm{mM}$ und $V_{\max } 143,90 \pm 5,32 \mathrm{pmol} /$ Oozyte $\times \mathrm{h}$ (Lee et al., 2003) und für rsat1 ein $K_{m}$-Wert von $\sim 0,14$ (Bissig et al., 1994).

\subsubsection{Regulation des sat1}

Die Transkription des msat1-Gens (SLC26A1) wird von Schilddrüsenhormonen, aber nicht von Vitamin $D$, stimuliert. Eine entsprechende Sequenz des $\underline{I}_{3}-$ responsiven Elements ( $T_{3} R E$ ) liegt bei -454 bp (Lee et al., 2003). Obwohl beim menschlichen Gen $\mathrm{T}_{3} \mathrm{RE}$ und VDRE (Vitamin D-responsives Element) vorhanden sind, stimulieren weder Schilddrüsenhormone noch Vitamin D die Aktivität des Gens. Mutationen in der Aktivator Protein-1 (AP-1) Stelle an Position -52 bp führen zur verminderten Transkription von sat1, sodass vermutet werden darf, dass diese Region für die Transkription verantwortlich ist (Regeer et al., 2003).

Der Sulfattransport an rsat1 transfizierten Xenopus-Oozyten wird stark von DIDS (4,4'-Diisothiocyanatostilben 2,2'-Disulfonat) und Oxalat, nicht aber von Succinat oder Cholat gehemmt. Die Sulfataufnahme durch hsat1 wird von Molybat, Wolframat, Selenat, DIDS, Thiosulfat und Phenolrot gehemmt. Citrat und Glukose haben keinen Effekt. Beim msat1-Transport wirken die, den hsat1-Transport inhibierenden Stoffe und zusätzlich Probenezid hemmend, auch hier haben Citrat und Glukose keinen Effekt (Bissig et al., 1994, Regeer et al., 2003).

\subsubsection{5 sat1-knock-out-Maus (sat $1^{-/-}$-Maus)}

Dawson et al. generierten 2010 ein sat1-knock-out-Mausmodell. Tiere, die homozygot negativ (sat $1^{-/}$) für das Gen SLC26A1 sind, bilden Calciumoxalatsteine, die sich in der Blase und in den Tubuli von Nierenmark und Nierenkortex ablagern. Daraus ist zu folgern, dass sat1 eine wesentliche Rolle bei der Ausscheidung von Oxalat besitzt. Ebenfalls passend sind die Erhöhung des Oxalatspiegels im Blut und die Erhöhung der Oxalat/Kreatinin-Ratio. Weiterhin gibt es Hinweise auf einen verminderten Sulfattransport, sowie auf eine erhöhte Sulfatexkretion. Auch sind der Transport von Oxalat und Sulfat im Darm vermindert. Ferner finden sich bei diesen Tieren Leukozyteninfiltrationen um die Nierenkortexgefäße, was ein Hinweis auf Obstruktion des Ureters und damit auf eine obstruktive Nephropathie ist. Die Leber nimmt ihre Entgiftungsfunktion nicht mehr ausreichend wahr, sodass es zur schadstoffinduzierten Leberschädigung kommt. 


\section{Material und Methoden}

\subsection{Materialien}

\subsubsection{Tiere}

Für diese Arbeit wurden Lebern und Nieren aus Mäusen vom NMRI- und SvJ/129Stamm aus Göttingen (zentrale Tierexperimentelle Einheit, UMG) verwendet (NMRIMäuse siehe Abbildung 10). Die Abkürzung NMRI bezeichnet die ursprüngliche Herkunft des Stammes aus dem Naval Medical Research Institute.

Es lag eine Anzeige „Zur Mitteilung von Tötungen von Wirbeltieren zu wissenschaftlichen Zwecken (§4 Abs.3 Tierschutzgesetz)“ vor. Außerdem wurden vom Institute for Medical Research and Occupational Health in Zagreb freundlicherweise Gewebe aus Ratten vom Stamm Wistar aus der dortigen Tierzucht zur Verfügung gestellt.

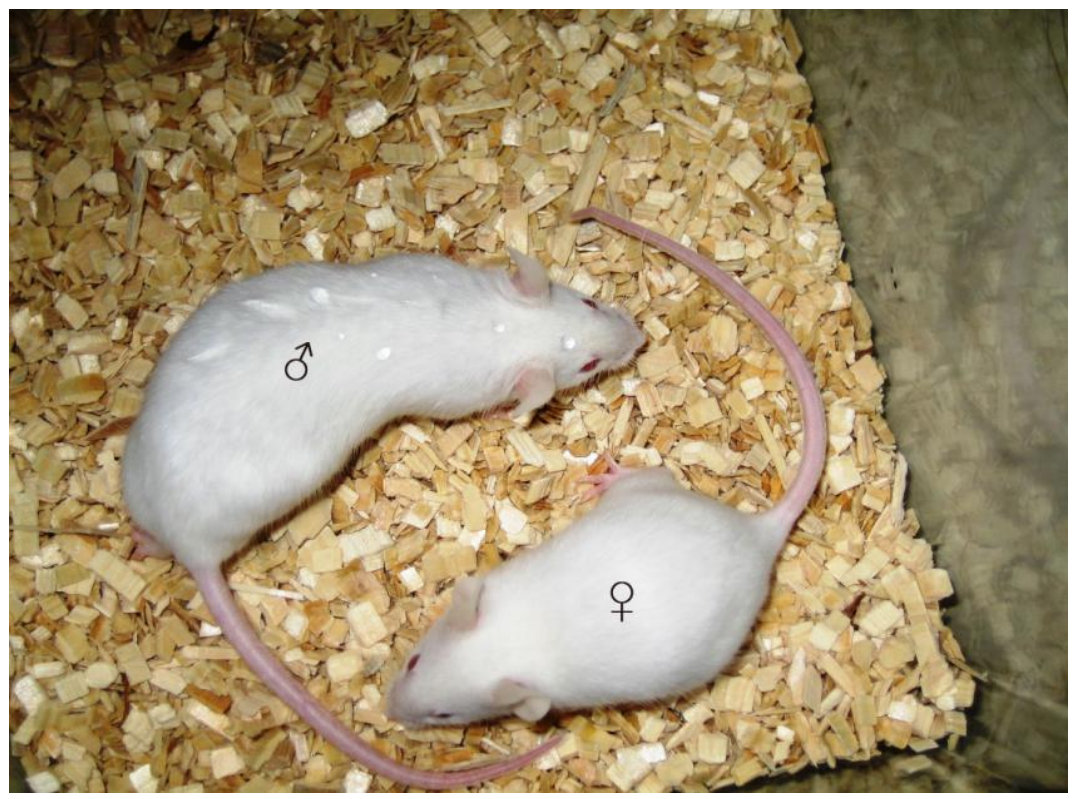

Abbildung 10: Männliche $\left({ }^{\top}\right)$ und weibliche ( + ) NMRI-Mäuse aus der Tierexperimentellen Einheit, UMG

\subsubsection{Oligonukleotidprimer}

Sequenzspezifische Primer für die reverse Transkription mit anschließender Polymerase-Kettenreaktion (RT-PCR) wurden von Eurofins MWG Operon (Ebersberg, Deutschland) bezogen und sind in Tabelle 6 aufgelistet. 
Tabelle 6: RT-PCR Primer

\begin{tabular}{|c|c|c|c|c|c|c|}
\hline $\begin{array}{l}\text { Protein } \\
\text { (Gen) }\end{array}$ & Primer & Sequenz $5^{\prime}-3^{\prime}$ & Produktlänge & $\begin{array}{l}\text { Annealing } \\
\text { Temperatur }\end{array}$ & Zyklen & Gel \\
\hline GAPDH & $\begin{array}{l}334 \text { for } \\
905 \mathrm{rev}\end{array}$ & $\begin{array}{c}\text { TCA CCA TCT TCC } \\
\text { AGG ACG } \\
\text { CTG CTT CAC CAC } \\
\text { CTT CTT GA }\end{array}$ & 572 bp & $58^{\circ} \mathrm{C}$ & 25 & $1,5 \%$ \\
\hline NaS1 & $\begin{array}{l}252 \text { for } \\
1220 \mathrm{rev}\end{array}$ & $\begin{array}{l}\text { CTT TCA CCT TCT } \\
\text { GCA AAT TGG A } \\
\text { GTC ATT TTT GTC } \\
\text { AGT TTC TTG GC }\end{array}$ & $969 \mathrm{bp}$ & $52^{\circ} \mathrm{C}$ & 25 & $1,5 \%$ \\
\hline sat1 & $\begin{array}{l}494 \mathrm{for} \\
698 \mathrm{rev}\end{array}$ & $\begin{array}{l}\text { CAT CTT CAG CCT } \\
\text { GCT TTG CCT C } \\
\text { CTG GTA AAG CCC } \\
\text { GGT CAT CAG }\end{array}$ & $205 \mathrm{bp}$ & $57^{\circ} \mathrm{C}$ & 25 & $2 \%$ \\
\hline
\end{tabular}

Gen-spezifische Primer, ihre Position und Sequenz in 5'-3'-Richtung, die Länge des PCR-Produkts, „Annealing“ Temperatur, Anzahl der Zyklen bei der PCR und die Agarose-Konzentration im Gel, die NaS1-Sequenz wurde der Arbeit von Beck und Markovich (Beck und Markovich, 2000) entnommen, GAPDH: Glycerinaldehyd-3-phosphat-dehydrogenase, NaS1: Natriumabhängiger-Sulfattranspoter1, sat1: Sulfat-Anionen-Transporter1.

\subsubsection{Real-time PCR Assays}

Assays für die real-time PCR wurden bei Applied Biosystems (Foster City, CA,USA) erworben und sind in Tabelle 7 zusammengefasst.

Tabelle 7: Real-time PCR Assays

\begin{tabular}{ccc}
\hline Protein (Gen) & Assay & Spleißvariante \\
\hline mGAPDH & Mm99999915_g1 & NM_008084.2 \\
\hline mNaS1 (SLC13A1) & Mm00490339_m1 & NM_010481.2 \\
\hline msat1 (SLC26A1) & Mm01198850_m1 & NM_174870.3 \\
\hline
\end{tabular}




\subsubsection{Antikörper}

Es wurden folgende in Tabelle 8 aufgeführte Antikörper für die immunhistochemischen Versuche verwendet.

Tabelle 8: Primär- und Sekundärantikörper

\begin{tabular}{|l|c|l|}
\hline Primärantikörper SLC26A1 & Konzentration & Anbieter/Katalognummer \\
\hline Polyklonales anti-Maus IgG & $1: 50$ & $\begin{array}{l}\text { Santa Cruz Biotechnology / } \\
\text { sc-132090, Santa Cruz, } \\
\text { CA, USA }\end{array}$ \\
\hline Monoklonales anti-Ratten IgG & $1: 50$ & (Karniski et al., 1998) \\
\hline Sekundärantikörper & $1: 100$ & $\begin{array}{l}\text { Jackson ImmunoResearch, } \\
\text { West grove, PA, USA }\end{array}$ \\
\hline Esel anti-Maus & \multicolumn{2}{|l}{} \\
\hline Esel anti-Ziege & $1: 400$ & $\begin{array}{l}\text { Jackson ImmunoResearch, } \\
\text { West Grove, PA, USA }\end{array}$ \\
\hline
\end{tabular}

\subsubsection{Kits, Enzyme und Standards}

\section{Name}

SV Total RNA Isolation System

Moloney Maus Leukämievirus (M-MLV) Reverse Transkriptase, RNAse $\mathrm{H}$ minus

Taq-Polymerase

\section{Anbierter / Katalognummer}

Promega / \#TM048

(Madison, WI, USA)

AppliChem / A5211, 5000 (Darmstadt, Deutschland)

in eigener Arbeitsgruppe isoliert

\subsubsection{Chemikalien und Medikamente}

Die Chemikalien wurden von Biochem AppliChem GmbH (Darmstadt, Deutschland), Invitrogen (Karlsruhe, Deutschland), Roche (Grenzach-Whylen, Deutschland), Roth (Karlsruhe, Deutschland), Merck (Darmstadt, Deutschland), Sigma-Aldrich (Taufkirchen, Deutschland) und Fisher Scientific (Pittsburgh, PA, USA) bezogen und hatten den Reinheitsgrad „zur Analyse“. Narketan und Xylapan wurden von Chassot (Bern, Schweiz) bezogen. 


\subsubsection{Medien, Lösungen und Puffer}

Zusammensetzung und Hersteller der verwendeten Medien, Lösungen und Puffer sind in Tabelle 9 aufgelistetet.

Tabelle 9: Medien, Lösungen und Puffer

\begin{tabular}{|c|c|}
\hline Medium, Lösung, Puffer & Zusammensetzung/Anbieter \\
\hline Acrylamid-Lösung & $\begin{array}{l}30 \mathrm{~g} \text { Acrylamid } \\
0,8 \mathrm{~g} \text { Bis-Acrylamid } \\
100 \mathrm{ml} \text { aqua dest. }\end{array}$ \\
\hline Agarosegel-Elektrophorese Ladepuffer (5x) & $\begin{array}{l}\text { 6,3 g Glycerol } \\
2 \mathrm{ml} 0,5 \mathrm{M} \text { Ethylendiamintetracetat (EDTA) } \mathrm{pH} 8,0 \\
50 \mu \mathrm{l} \text { Trishydroxymethylaminomethan (Tris) } \mathrm{HCl} \mathrm{pH} \mathrm{7,6} \\
0,001 \%(\mathrm{w} / \mathrm{v}) \text { Bromphenolblau } \\
0,001 \%(\mathrm{w} / \mathrm{v}) \text { Xylencyanol FF } \\
\text { mit RNAse freiem aqua dest. auf } 100 \mathrm{ml} \text { aufgefüllt }\end{array}$ \\
\hline Alkalische Phosphatase-Reaktions-Puffer & $\begin{array}{l}20 \mathrm{mM} \text { Tris HCl pH 9,0 } \\
1,65 \mathrm{mg} / \mathrm{ml} \text { 5-bromo-4 chloro-3-indolyl-Phosphat (BCIP) } \\
3,3 \mathrm{mg} / \mathrm{ml} \text { Nitroblau Ietrazolium (NBT) }\end{array}$ \\
\hline Ammoniumpersulfat $\left(\left(\mathrm{NH}_{4}\right)_{2} \mathrm{~S}_{2} \mathrm{O}_{8}\right)$ & Fisher Biotech \\
\hline BSA-Lösung & $1 \%$ bovines Serumalbumin in PBS \\
\hline Citratpuffer & auf $\mathrm{pH} 3,6$ und 8 eingestellt \\
\hline Ethidiumbromid (Stammlösung) & $\begin{array}{l}\text { Sigma / E } 1510 \\
10 \mathrm{mg} / \mathrm{ml} \text { in RNAse freiem aqua dest. }\end{array}$ \\
\hline Ethylendiamintetraacetat (EDTA) & Sigma \\
\hline high salt PBS & $\begin{array}{l}18 \mathrm{~g} \mathrm{NaCl} / 1 \mathrm{l} \text { PBS } \\
\text { mit } 5 \mathrm{M} \mathrm{NaOH} \text { auf } \mathrm{pH} 7,4 \text { eingestellt }\end{array}$ \\
\hline Homogenisierungspuffer & $\begin{array}{l}300 \mathrm{mM} \text { Mannitol } \\
5 \mathrm{mM} \mathrm{EGTA} \text { (ethylen glycol tetracetic acid) } \\
12 \mathrm{mM} \mathrm{Tris-HCl} \\
\text { mit } 5 \mathrm{M} \mathrm{NaOH} \text { auf } \mathrm{pH} 7,4 \text { eingestellt } \\
1 \mathrm{mM} \mathrm{PMSF} \\
0,1 \mathrm{mM} \text { Benzamid } \\
0,1 \mu \mathrm{g} / \mathrm{ml} \text { antipain }\end{array}$ \\
\hline Marker (Agarosegel-Elektrophorese) & $\begin{array}{l}\text { Fermentas / SM0321 } \\
100 \mu \mathrm{l} \text { Marker } \\
100 \mu \mathrm{l} 6 \times \text { Ladepuffer (Fermentas / R0611) } \\
400 \mu \mathrm{l} \text { RNAse freies aqua dest. }\end{array}$ \\
\hline Marker (Agarosegel-Elektrophorese) & $\begin{array}{l}\text { Invitrogen / 15628-050 } \\
10 \mu \mathrm{l} \text { Marker } \\
40 \mu \mathrm{l} 5 \times \text { Agarosegel-Elektrophorese Ladepuffer } \\
150 \mu \mathrm{l} \text { RNAse freies aqua dest. }\end{array}$ \\
\hline Molekulargewichtsmarker (Western Blot) & Fermentas int., Ontario Canada \\
\hline NaCl-Lösung 0,9 \% & $9 \mathrm{~g} \mathrm{NaCl} / 1 \mathrm{l}$ aqua dest. \\
\hline Natriumazid-PFA 0,02 \% & 0,02 g Natriumazid/100 ml PFA-Lösung \\
\hline
\end{tabular}




\begin{tabular}{|c|c|}
\hline Medium, Lösung, Puffer & Zusammensetzung/Anbieter \\
\hline OCT (optimal cutting temperature)-Medium & Tissue-Tek, Sakura, Japan \\
\hline Oligo dt & Eurofins MWG, Operon \\
\hline PBS & $\begin{array}{l}800 \mathrm{ml} \text { aqua dest. } \\
8,0 \mathrm{~g} \mathrm{NaCl} \\
0,2 \mathrm{~g} \mathrm{KCl} \\
1,44 \mathrm{~g} \mathrm{KH}_{2} \mathrm{PO}_{4} \\
0,24 \mathrm{~g} \mathrm{Na}_{2} \mathrm{HPO}_{4} \\
\text { mit } 5 \mathrm{M} \mathrm{NaOH} \text { auf pH } 7,4 \text { eingestellt, auf } 11 \text { mit aqua } \\
\text { dest. aufgefüllt, im Autoklaven sterilisiert }\end{array}$ \\
\hline PFA-Lösung & $\begin{array}{l}90 \mathrm{ml} \text { PBS } \\
4 \mathrm{~g} \text { PFA-Pulver } \\
\text { unter Rühren bei } 60^{\circ} \mathrm{C} \text { gelöst (eventuelle mit Hilfe von } \\
\mathrm{NaOH} \text { ), mit } \mathrm{NaOH} \text { pH } 7,2-7,4 \text { eingestellt, mit aqua } \\
\text { dest. auf } 100 \mathrm{ml} \text { aufgefüllt, Lagerung bei } 4^{\circ} \mathrm{C} \text { in } \\
\text { geschlossenem Gefäß }\end{array}$ \\
\hline RNAlater & Quiagen \\
\hline SDS-Lösung ( Sodium Dodecyl Ślfate) & $1 \%$ SDS in PBS \\
\hline SDS-PAGE Ladepuffer & $\begin{array}{l}1 \% \text { SDS } \\
12 \% \text { Glycerol } \\
30 \mathrm{mM} \text { Tris- } \mathrm{HCl} \\
\text { mit } 5 \mathrm{M} \mathrm{NaOH} \text { eingestellt auf } \mathrm{pH} 6,8\end{array}$ \\
\hline SDS-PAGE Laufpuffer & $\begin{array}{l}25 \mathrm{mM} \text { Tris } \\
0,2 \mathrm{M} \text { Glycin } \\
1 \% \text { SDS }\end{array}$ \\
\hline SDS-PAGE Sammelgelpuffer & 1,5 M Tris- $\mathrm{HCl}, \mathrm{pH} 6,8$ \\
\hline SDS-PAGE Trenngelpuffer & $0,5 \mathrm{M}$ Tris- $\mathrm{HCl}, \mathrm{pH} 8,9$ \\
\hline SDS-Waschpuffer & $\begin{array}{l}5 \% \text { Magermilch } \\
0,15 \mathrm{M} \mathrm{NaCl} \\
1 \% \text { Triton } \mathrm{X}-100 \\
20 \mathrm{mM} \text { Tris- } \mathrm{HCl} \\
\text { mit } 5 \mathrm{M} \mathrm{NaOH} \text { auf } \mathrm{pH} 7,4 \text { eingestellt }\end{array}$ \\
\hline Triton X-100-Lösung & $\begin{array}{l}0,5 \% \text { Triton X-100 in PBS } \\
2 \% \text { Triton } X-100 \text { in PBS }\end{array}$ \\
\hline Vectashield & Vector Laboratories Inc. (Burlingame, CA, USA) \\
\hline
\end{tabular}

\subsubsection{Verbrauchsmaterialien}

Objektträger Superfrost plus Mikroskopobjektträger

Transfermembran Immobilion membran;Millipore (Bedford, MA, USA) 


\subsubsection{Geräte}

Modell und Hersteller der verwendeten Geräte sind in Tabelle 10 aufgelistet.

Tabelle 10: Geräte

\begin{tabular}{|c|c|c|}
\hline Gerät & Modell & Hersteller \\
\hline Elektrophorese & EPS $3500 \mathrm{XL}$ & Pharmacia (Uppsala, Schweden) \\
\hline $\begin{array}{l}\text { Equipment zur SDS- } \\
\text { PAGE }\end{array}$ & Bio-Rad Laboratories & Herkules (CA, USA) \\
\hline Feinwaage & 2002 MP1 & Sartorius (Göttingen, Deutschland) \\
\hline Fluoreszenzmikroskop & $\begin{array}{l}\text { Opton III RS } \\
\text { Fluoreszenzmikroskop }\end{array}$ & $\begin{array}{l}\text { Opton Feintechnik (Oberkochen, } \\
\text { Deutschland) }\end{array}$ \\
\hline Geldokumentation & Gel Print 2000 I & Biophotonics (Ann Arbor, MI, USA) \\
\hline Gelkammer & Midi & $\begin{array}{l}\text { Eurofins MWG Operon (Ebersberg, } \\
\text { Deutschland) }\end{array}$ \\
\hline Gewebeschneider & Leica CM 1850 cryostat & Nussloch GmbH ( Deutschland) \\
\hline Homogenisator & Powergen-125 Homogenisator & Fisher Scientific (New Jersey, NY, USA) \\
\hline Kamera und Software & $\begin{array}{l}\text { Spot RT Slider Kamera und } \\
\text { Software }\end{array}$ & $\begin{array}{l}\text { Diagnostische Geräte (Sterlings } \\
\text { Heights, MI, USA) }\end{array}$ \\
\hline Magnetrührer & KM02 & $\begin{array}{l}\text { IKA Labortechnik (Staufen, } \\
\text { Deutschland) }\end{array}$ \\
\hline Mikrowelle & Privileg 8521 & Quelle Schikedanz (Fürth, Deutschland) \\
\hline Minizentrifuge & C-1200 & Woodbridge (NJ, USA) \\
\hline \multirow{2}{*}{ pH-Meter } & CG 820 & Schott (Mainz, Deutschland) \\
\hline & 611 & Orion Research (Beverly MA, USA) \\
\hline Photometer & Novaspec II & $\begin{array}{l}\text { Pharmacia Biotech (Freiburg, } \\
\text { Deutschalnd) }\end{array}$ \\
\hline Pumpe & Masterflex & Cole-Parmer (Chicago, IL, USA) \\
\hline $\begin{array}{l}\text { Ultrazentrifuge } \\
\text { Rotor }\end{array}$ & $\begin{array}{l}\text { OTD65B } \\
\text { TFT6513 }\end{array}$ & $\begin{array}{l}\text { Thermo Fisher Scientific (Waltham, MA, } \\
\text { USA) }\end{array}$ \\
\hline $\begin{array}{l}\text { Real-time PCR } \\
\text { Thermozykler }\end{array}$ & Mx3005p & Stratagene (Waldborn, Deutschland) \\
\hline $\begin{array}{l}\text { RNS / DNS Kalkulator } \\
\text { (Photometer) }\end{array}$ & GeneQuant II & $\begin{array}{l}\text { Pharmacia Biotech (Freiburg, } \\
\text { Deutschland) }\end{array}$ \\
\hline \multirow{2}{*}{ Thermozykler } & Gene Amp , PCR System 2400 & Perkin Elmer (Waltham, MA, USA) \\
\hline & RoboboCycler, Gradient 96 & Stratagene ( La Jolla, CA, USA) \\
\hline Vortex & MS1 & IKA (Staufen, Deutschland) \\
\hline Waage & LC6215 & Sartorius (Göttingen, Deutschland) \\
\hline \multirow{2}{*}{ Wasserbad } & D8 & Haake (Karlsruhe, Deutschland) \\
\hline & 1083 & GFL (Burgwedel, Deutschland) \\
\hline \multirow{2}{*}{ Zentrifugen } & Biofuge fresco, Labofuge $400 \mathrm{R}$ & Heraeus (Hanau, Deutschland) \\
\hline & $5417 \mathrm{R}, 5415 \mathrm{D}$ & Eppendorf (Hamburg, Deutschland) \\
\hline $\begin{array}{l}\text { Zentrifuge zur } \\
\text { Membranpräparation }\end{array}$ & high-speed Zentrifuge & Sorvall Instruments (Newton, CT USA) \\
\hline
\end{tabular}




\subsubsection{Elektronische Datenanalyse}

In Tabelle 11 ist die Software aufgelistet, die zum Auswerten der Rohdaten, zur Berechnung der Ergebnisse und zur Verwaltung der Literatur verwendet wurde.

Tabelle 11: Software

\begin{tabular}{|l|l|l|}
\hline Programm & Verwendung & Bezug \\
\hline Adobe Photoshop CS2 & Bildbearbeitung & Adobe Systems Incorp. \\
\hline Corel Draw Version 13 & Bildbearbeitung & Corel Corporation \\
\hline End Note X1 & Literaturverwaltung & Thomson Reuters \\
\hline Graph Pad Prism 4 & Signifikanztest und Grafiken & GraphPad Software \\
\hline Microsoft Exel & Auswertung der Rohdaten & Microsoft Corporation \\
\hline Paint Version 6.1 & Bildbearbeitung & Microsoft Corporation \\
\hline Pubmed & Literaturverwaltung & Nat. Library of Med. \\
\hline
\end{tabular}

\subsection{Methoden}

\subsubsection{Einführung}

Alle Arbeitsschritte zur Herstellung von RNS geschahen unter RNAse-freien Bedingungen. Bei der DNS-Herstellung und -Quantifizierung wurden Möglichkeiten für eine Kontamination minimiert, da die verwendeten Materialien und Lösungen auf Eis gelagert wurden.

\subsubsection{Gewebeentnahme und -aufbereitung}

Für die folgenden Versuche wurden Mäuse vom NMRI- und SvJ/129-Stamm aus Göttingen (zentrale Tierexperimentelle Einheit/ZTE, UMG), sowie Ratten vom Stamm Wistar aus der Tierzucht in Zagreb (Institute for Medical Research and Occupational Health) verwendet. Es lag für die Versuche in Göttingen eine Anzeige „Zur Mitteilung von Tötungen von Wirbeltieren zu wissenschaftlichen Zwecken ( $\$ 4$ Abs.3 Tierschutzgesetz)" vor. In Zagreb erfolgte die Tötung ebenfalls tierschutzgerecht nach dortigen gesetzlichen Vorgaben.

\subsubsection{Gewebeentnahme und -aufbereitung bei Mäusen}

Die Mäuse vom Stamm SvJ/129 und NMRI wurden tierschutzgerecht von einem Tierpfleger der ZTE getötet. Anschließend wurde mit einer Schere der Bauchraum V- 
förmig eröffnet, das benötigte Gewebe aufgesucht, freipräpariert und mit einer Schere entnommen. Für die molekularbiologischen Untersuchungen wurden jeweils 30-80 mg Gewebe der Nieren und der Leber in ein 1,5 ml Eppendorfgefäß mit RNAlater gegeben. Je nach weiterem Verarbeitungsplan wurden die Proben in RNAlater bei $4-8^{\circ} \mathrm{C}$ oder bei $-20^{\circ} \mathrm{C}$ konserviert. Die Gewebe wurden in RNAlater nach Angaben des Herstellers gelagert. Zur Gewebehaltbarkeit in Abhängigkeit von der Lagerungstemperatur siehe Tabelle 12 (entsprechend der Angaben des Herstellers Quiagen).

Tabelle 12: Haltbarkeit von Geweben in RNAlater in Abhängigkeit von der Temperatur (entsprechend der Angaben des Herstellers Quiagen)

\begin{tabular}{|c|c|}
\hline Temperatur & Haltbarkeit des Gewebes \\
\hline $37^{\circ} \mathrm{C}$ & 24 Stunden \\
\hline 18 bis $25^{\circ} \mathrm{C}$ & 7 Tage \\
\hline 2 bis $8^{\circ} \mathrm{C}$ & 4 Wochen \\
\hline$-20^{\circ} \mathrm{C}$ bis $-80^{\circ} \mathrm{C}$ & Archivierung \\
\hline
\end{tabular}

Für die Immunhistochemie wurden die Organe kurz in eiskalter 0,9 \% NaCl-Lösung gewaschen und dünne Gewebeschnitte von Nierenkortex und Leberlappen gefertigt. Die Schnitte wurden in ein $15 \mathrm{ml}$ Vial mit PFA-Lösung gegeben und $24 \mathrm{~h}$ bei $4^{\circ} \mathrm{C}$ gelagert. Nach Ablauf der $24 \mathrm{~h}$ wurden die paraffinfixierten Schnitte mehrmals in PBS-Lösung gewaschen und in $0,02 \%$ Natriumazid-PFA bei $4^{\circ} \mathrm{C}$ bis zur Weiterverarbeitung gelagert.

\subsubsection{Gewebeentnahme und -aufbereitung bei Ratten}

Der Exitus der Ratten wurde entweder wie bei den Mäusen durch cervikale Dislokation nach $\mathrm{CO}_{2}$-Narkose herbeigeführt oder durch das Ausbluten der Tiere in vivo unter Narkose (Narketan, 80 mg/kg KG + Xylapan 12 mg/kg KG, i.p.). Hierzu lag eine Masterflex-Pumpe im linken Herzventrikel, über die eine PBS-Lösung perfundiert wurde. Bei der darauffolgenden Fixation wurde PFA-Lösung verwendet (siehe Tabelle 13). Die Versuche an Ratten wurden in Zagreb durchgeführt. Diese Versuche wurden von Mitarbeitern des Institute for Medical Research and Occupational Health in Zagreb durchgeführt. Ich erhielt die entsprechenden Proben zur Aufbereitung. 
Tabelle 13: Perfusion der Tiere

\begin{tabular}{|c|l|}
\hline Perfusionszeit & \multicolumn{1}{|c|}{ Lösung } \\
\hline $2 \mathrm{~min}$ & $\mathrm{PBS}\left(37^{\circ} \mathrm{C}, 95 \% \mathrm{O}_{2}+5 \% \mathrm{CO}_{2}\right)$ \\
\hline $5 \mathrm{~min}$ & $100 \mathrm{ml} 4 \% \mathrm{PFA}$ \\
\hline
\end{tabular}

Die Nieren der perfundierten Tiere für die Immunhistochemie wurden entnommen, entkapselt, in $1 \mathrm{~mm}$ dicke Scheiben geschnitten und die Schnitte in $4 \%$ PFA für $24 \mathrm{~h}$ bei $4^{\circ} \mathrm{C}$ gelagert. Nachfolgend wurden die paraffinfixierten Schnitte mehrmals in PBS-Lösung gewaschen und in $0,02 \%$ Natriumazid-PFA bei $4^{\circ} \mathrm{C}$ bis zur Weiterverarbeitung gelagert.

Die nicht perfundierten Nieren für den Western Blot wurden in Homogenisierungspuffer mit dem Powergen-125 Homogenisator (10 \% Homogenität) bei Maximaleinstellung nach folgendem Schema homogenisiert: 2 min Homogenisierung - 1 min Pause - 2 min Homogenisierung.

\subsubsection{Molekularbiologische Methoden}

\subsubsection{Einführung}

Das Ergebnis der quantitativen reversen Transkriptase-PCR gibt Aufschluss darüber, wie viel mRNS ( $\underline{\text { messenger }} \underline{\mathrm{RNS}}$ ) für ein bestimmtes Protein in den bearbeiteten Zellen vorhanden ist. Aus dem entsprechenden Gewebe wurde zunächst die gesamte RNS isoliert und anschließend die mRNS mittels Oligo dTs separiert, die für alle exprimierten Proteine der Zelle kodiert. Die mRNS wurde unter Zuhilfenahme der reversen Transkriptase in cDNS ( $\underline{c}$ mplementary DNS) umgewandelt und die DNS für die gesuchten Proteine mit der Polymerasen-Kettenreaktion (polymerase chain reaction, PCR) quantifiziert.

\subsubsection{Reinigung und Isolierung der Ribonukleinsäure (RNS)}

Das verwendete Kit SV Total RNA Isolation System (Promega) nutzt eine SiliciumMembran-Methode zur Isolierung und Aufreinigung der RNS. Der verwendete RNALysis-Puffer enthält die Stoffe Guanidiniumthiocyanat (GTC) und $\underline{\beta}$-Mercapotoethanol (BME). GTC denaturiert Proteine effektiv, zersetzt diese in Verbindung mit NatriumLauroylsulfat (sodium dodecyl sulfat, SDS) und schützt gleichzeitig zusammen mit BME die RNS vor dem Abbau durch Ribonukleasen. Das verwendete Ethanol erleichtert die Bindung der RNS an die Silicium-Membran. Der Gebrauch von DNase verhindert die Kontamination durch DNS. In mehreren Waschschritten wird die RNS 
von Salzen, Proteinen und anderen Zellbestandteilen befreit. Mit Hilfe von Nukleasefreiem Wasser wir die aufgereinigte RNS von der Silicium-Membran gelöst.

Die Reinigung und Isolierung der RNS wurde nach Angaben des Herstellers durchgeführt. Um den RNS-Gewinn zu optimieren, wurden die entnommenen Organe pulverisiert. Die in RNAlater bei $-20^{\circ} \mathrm{C}$ gelagerten Gewebestücke wurden in einem Mörser in flüssigem Stickstoff zu Pulver zerstoßen. In einem Eppendorfgefäß wurde das Gewebepulver durch Auf- und Abpipettieren in RNA-Lysis-Puffer (aus dem SVTotal-RNA-Isolation-System-Kit) suspendiert, wobei pro $20 \mathrm{mg}$ Gewebepulver $175 \mu \mathrm{l}$ Puffer eingesetzt wurden. $190 \mu \mathrm{l}$ der Suspension wurden zur RNS-Isolierung in ein weiteres Eppendorfgefäß überführt. Die restliche Suspension wurde bei $-80^{\circ} \mathrm{C}$ eingefroren.

$190 \mu \mathrm{l}$ der Gewebe-Puffer-Suspension wurden mit $350 \mu \mathrm{l}$ SV RNA Dilution Buffer in einem Eppendorfgefäß durch Schwenken gemischt, für 3 min bei $70^{\circ} \mathrm{C}$ im Wasserbad inkubiert und anschließend für $10 \mathrm{~min}$ bei $13 \mathrm{~g}\left(13 \times 9,81 \mathrm{~m} / \mathrm{s}^{2}\right)$ zentrifugiert. Die durch Zentrifugation erhaltene Flüssigkeit wurde in ein neues Eppendorfgefäß überführt und das entstandene Pellet verworfen. Der Überstand wurde mit $200 \mu \mathrm{l} 95 \%$-Ethanol auf- und abpipettiert, in ein Spin Column Asembly (Netz mit 1,5 ml Röhrchen) überführt, bei $13 \mathrm{~g}$ für $1 \mathrm{~min}$ zentrifugiert, die abzentrifugierte Flüssigkeit verworfen, mit $600 \mu \mathrm{l} S V$ RNA Washsolution erneut für 1 min bei $13 \mathrm{~g}$ zentrifugiert und die abzentrifugierte Flüssigkeit abermals verworfen. Pro Probe wurden ein Mastermix mit den in Tabelle 14 angegebenen Mengen und Lösungen zusammengefügt.

Tabelle 14: DNase-Mastermix

\begin{tabular}{|c|l|}
\hline Menge & \multicolumn{1}{|c|}{ Lösung } \\
\hline $40 \mu \mathrm{l}$ & Yellow core buffer \\
\hline $5 \mu \mathrm{l}$ & $0,09 \mathrm{M} \mathrm{MnCl}_{2}$ \\
\hline $5 \mu \mathrm{l}$ & DNase I \\
\hline
\end{tabular}

Dies entspricht $50 \mu \mathrm{l}$ DNase-Mastermix pro Probe. $\mathrm{MnCl}_{2}$ und DNase I wurden vor der Verwendung zentrifugiert. Um eventuell vorhandene DNS zu zersetzen wurden $50 \mu \mathrm{l}$ des DNase-Mastermix direkt auf das Netz pipettiert. Nach einer Inkubation von 15 min bei Raumtemperatur wurde die DNase Aktivität durch $200 \mu \mathrm{l}$ SV DNase Stop- 
Dilution-Lösung gestoppt und das Gefäß bei $13 \mathrm{~g}$ für $1 \mathrm{~min}$ zentrifugiert. Um die im Netz befindliche RNS zu reinigen, wurden im ersten Waschgang $600 \mu \mathrm{l} S V$ RNA Washsolution zugefügt, für 1 min bei $13 \mathrm{~g}$ zentrifugiert und die Flüssigkeit verworfen. Im zweiten Waschgang wurden $250 \mu \mathrm{l} S V$ RNA Washsolution verwendet, die Flüssigkeit wurde nach zwei minütiger high-speed-Zentrifugation abermals verworfen.

Das Netz des Spin Column Asembly wurde in ein neues 1,5 ml fassendes Eppendorf Mikroreaktionsgefäß gesetzt. Die RNS wurde mit $50 \mu \mathrm{l}$ Nuclease freiem Wasser und einminütiger Zentrifugation bei $13 \mathrm{~g}$ in das Reaktionsgefäß überführt. Zum Abschluss wurde die Probe mit Hilfe eines „Vortex“-Gerätes gemischt, die Flüssigkeit auf den Boden des Gefäßes zentrifugiert und auf Eis gelagert.

\subsubsection{Bestimmung der RNS-Konzentration und -Qualität}

Die Konzentration und Qualität der extrahierten RNS wurde durch Messung der Absorption im Spektralphotometer (RNA / DNA Calculator) ermittelt. Die Normierung erfolgte mit $10 \mu \mathrm{I}$ DEPC- $\mathrm{H}_{2} \mathrm{O}$. Unter Verwendung von $1 \mu \mathrm{l}$ RNS-Lösung und $9 \mu \mathrm{l}$ DEPC- $\mathrm{H}_{2} \mathrm{O}$ wurde eine 1:10-Verdünnung hergestellt und in eine Quarzglasküvette überführt. Mit Hilfe des Spektralphotometers wurde die Absorption bei $260 \mathrm{~nm}$ (Absorptionmaximum der Nukleinsäuren) und bei $280 \mathrm{~nm}$ (Absorptionmaximum von Proteinen) bestimmt. Bei einer Absorption von $260 \mathrm{~nm}$ entspricht eine optische Dichte (OD) von 1 einer RNS-Konzentration von $40 \mathrm{mg} / \mathrm{ml}\left(1 \mathrm{OD}_{260}=40 \mathrm{mg} / \mathrm{ml}\right)$. Um ein $\mathrm{Maß}$ für die Reinheit der RNS zu erhalten, kann der Quotient $\mathrm{OD}_{260} / \mathrm{OD}_{280}$ gebildet werden. Optimaler Weise werden für RNS-Reinheitswerte von $\mathrm{OD}_{260} / \mathrm{OD}_{280}$ $\geq 1,8$ angestrebt.

\subsubsection{Isolierung der messenger RNS (mRNS)}

Bei der mRNS-Isolierung wird aus einer genormten Menge an RNS die mRNS heraus gefiltert, indem das zugegebene Oligo dT mit seiner Kette aus Tyrosinen an den Poly-Adenosin-Schwanz der mRNS bindet und sie somit vor der anschließenden Denaturierung durch Hitze schützt, während die restliche RNS zerstört wird.

Zur Isolierung der mRNS wurden $4 \mu \mathrm{g}$ der gewonnen RNS benötigt. Aus der gemessenen Konzentration $(\mu \mathrm{g} / \mathrm{ml})$ wurde das Volumen $(\mathrm{ml})$ errechnet, in dem $4 \mu \mathrm{g}$ RNS enthalten waren, und mit DEPC- $\mathrm{H}_{2} \mathrm{O}$ auf $14 \mu \mathrm{l}$ aufgefült. Wenn die RNSKonzentration so gering war, dass in $14 \mu \mathrm{l}$ RNS-Lösung keine $4 \mu \mathrm{g}$ RNS enthalten 
waren, wurde mit $14 \mu \mathrm{l}$ reiner RNS-Lösung gearbeitet. Die $14 \mu \mathrm{RNS}$-Lösung wurden mit $2 \mu$ l Oligo dT (verdünnt auf $20 \mathrm{pmol}$ ) $10 \mathrm{~min}$ bei $70^{\circ} \mathrm{C}$ und anschließend 10 bis 15 $\min$ bei $4^{\circ} \mathrm{C}$ inkubiert.

\subsubsection{Umwandlung der mRNS in complementary DNS (cDNS) (reverse Transkription)}

Bei der reversen Transpkription wird mRNS mit Hilfe einer DNS-Polymerase (reverse Transkriptase) in complementary DNS (cDNS) umgewandelt. In dieser Arbeit dient als reverse Transkriptase eine veränderte Enzymvariante aus dem Retrovirus Moloney Maus Leukämievirus (M-MLV). Zugesetzte RNase $\mathrm{H}$ baut spezifisch die RNS aus RNS/DNS-Hybriden ab. Die entstandene cDNS dient als Matrize für die anschließende Polymerase-Ketterreaktion (siehe Abbildung 11).

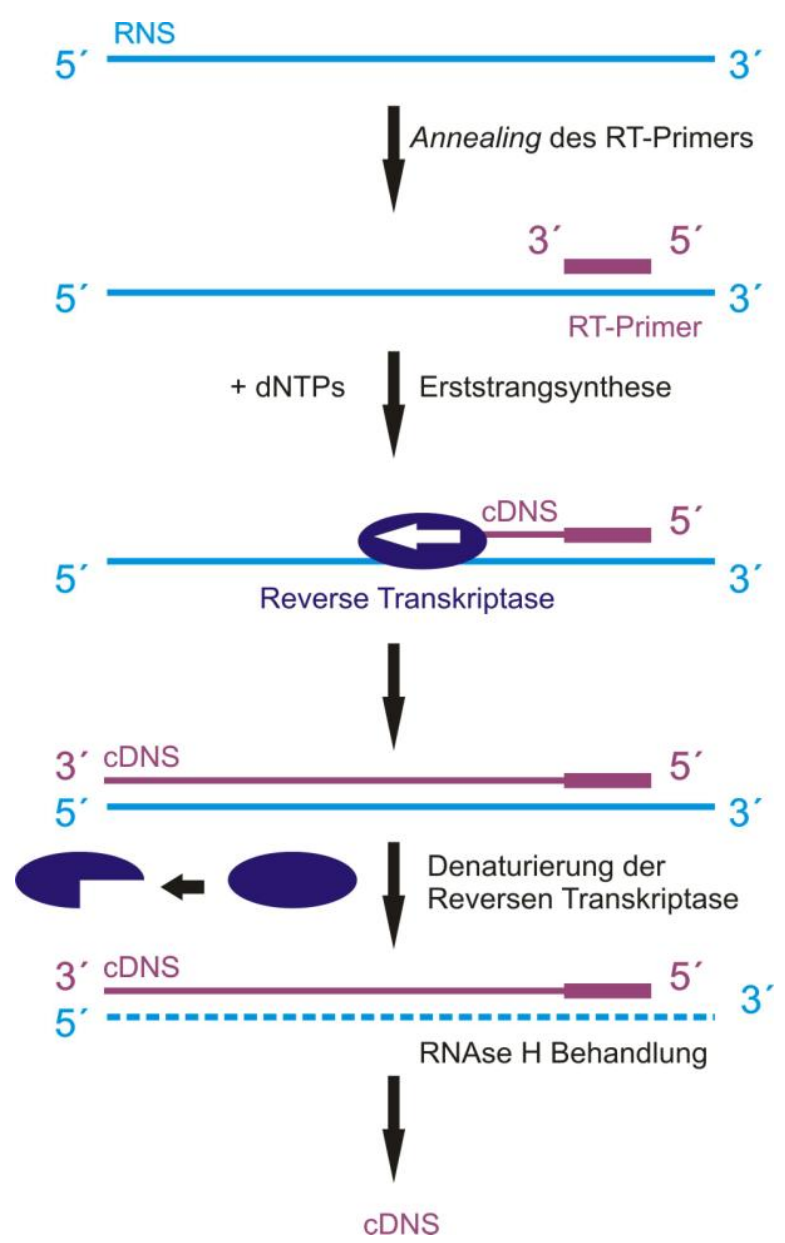

\section{Abbildung 11: Reverse Transkription}

An den RNS-Strang lagert sich der Primer der reversen Transkriptase (RT-Primer) an (Annealing). Anschließend synthetisiert das Enzym reverse Transkriptase den komplementären DNS-Strang (cDNS) aus dNTPs (Erststrangsynthese). Nach Fertigstellung des cDNS Stranges denaturiert die reverse Transkriptase. Die RNS wird durch RNAse-H-Behandlung abgebaut. 
Zur reversen Transkription wurden pro Probe mit isolierter mRNS die in Tabelle 15 angegebenen Mengen und Lösungen verwendet.

Tabelle 15: Mastermix für die reverse Transkription

\begin{tabular}{|c|l|}
\hline Menge & \multicolumn{1}{c|}{ Lösung } \\
\hline $8 \mu \mathrm{l}$ & $5 \times$ Puffer \\
\hline $2 \mu \mathrm{l}$ & M-MuLV (200 Unit/ml) \\
\hline $2 \mu \mathrm{l}$ & dNTPs $(10 \mathrm{mM})$ \\
\hline $6 \mu \mathrm{l}$ & DEPC- $\mathrm{H}_{2} \mathrm{O}$ \\
\hline
\end{tabular}

Es wurden jeweils $24 \mu \mathrm{l}$ Mastermix und $14 \mu \mathrm{l}$ mRNS-Lösung in einem Eppendorfgefäß gemischt und bei $13 \mathrm{~g}$ kurz zentrifugiert. Anschließend wurde im Thermozykler (Robocycler Gradient 96, Stargene) die reverse Transkription durchgeführt (Temperaturprofil in Tabelle 16).

Tabelle 16: Temperaturprofil für die reverse Transkription

\begin{tabular}{|c|c|}
\hline Zeit & Temperatur \\
\hline $60 \mathrm{~min}$ & $37^{\circ} \mathrm{C}$ \\
\hline $10 \mathrm{~min}$ & $70^{\circ} \mathrm{C}$ \\
\hline$\infty$ & $4^{\circ} \mathrm{C}$ \\
\hline
\end{tabular}

\subsubsection{Polymerase-Kettenreaktion (PCR)}

Bei der Polymerase-Ketterenreaktion (polymerase chain reaction, PCR) werden beliebige DNS-Abschnitte unter Zuhilfenahme von zwei Oligonukleotiden (Forwardund Reverse-Primer), den vier Desoxynukleosidphosphaten und dem hitzestabilen Enzym Polymerase vermehrt. Die PCR läuft in Zyklen ab, wobei sich die Menge der amplifizierten DNS in jedem Zyklus ungefähr verdoppelt. Jeder Zyklus besteht aus drei Schritten. Zunächst werden die DNS-Stränge durch Denaturierung getrennt, anschließend lagern sich im Annealing die Primer an, sodass die Polymerase im letzten Schritt, der Elongation, neue DNS-Stränge synthetisieren kann. Die verschiedenen Reaktionschritte benötigen unterschiedliche Temperaturen, um optimal ablaufen zu können (siehe Abbildung 12). 


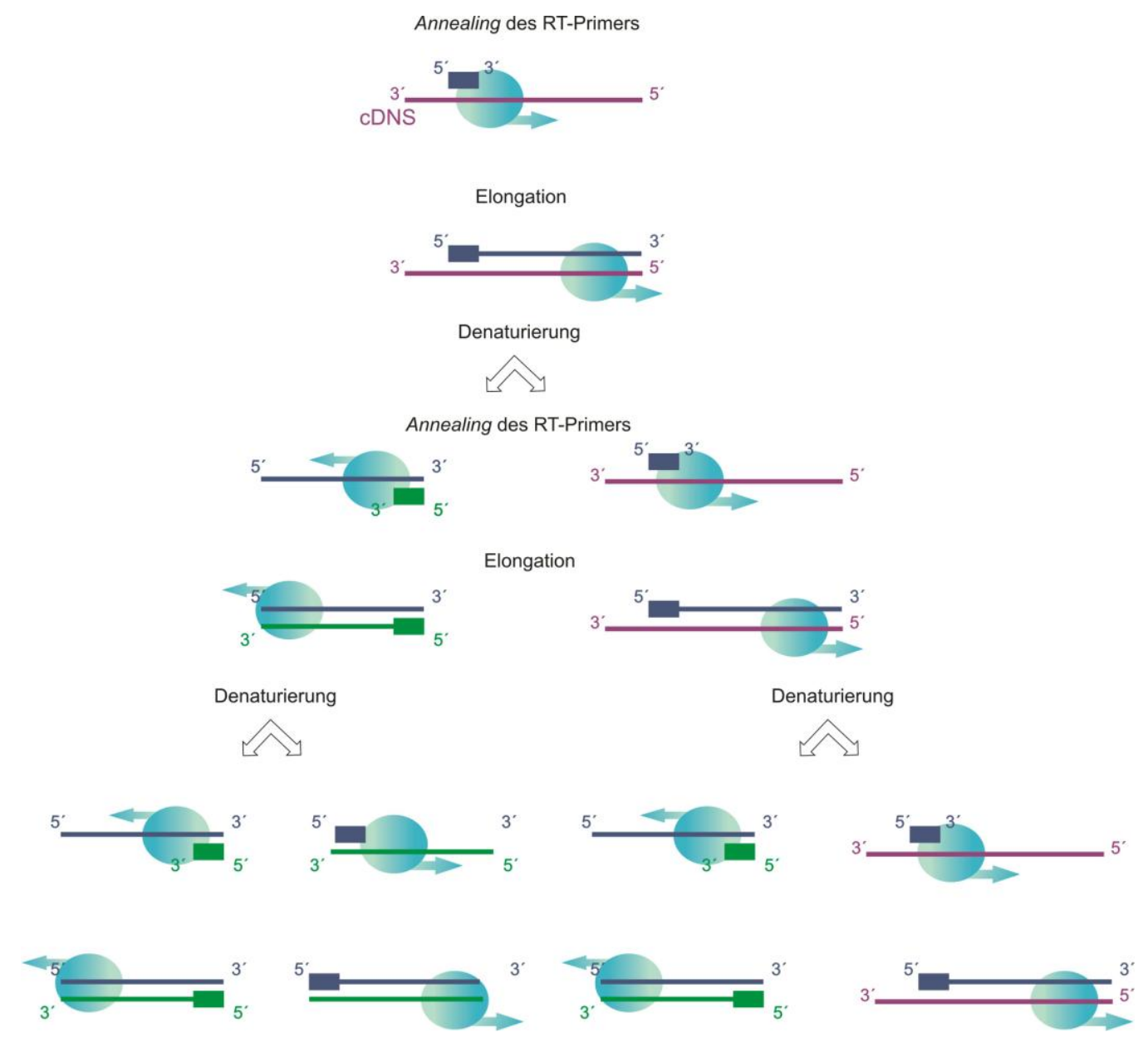

\section{Abbildung 12: Polymerase-Kettenreaktion}

Die DNS-Doppelstränge werden durch Hitzedenaturierung getrennt, sodass sich die Primer an die Einzelstränge anlagern können. Das Enzym Polymerase synthetisiert den komplementären Strang und es liegt ein neuer DNS-Doppelstrang vor.

Mittels reverser Transkription und der oben beschriebenen PCR wurde vor der Durchführung der real-time PCR das Vorhandensein der DNS nachgewiesen, die den gesuchten Proteinen entspricht. In der ersten Versuchsreihe wurden sowohl die DNS von GAPDH als auch die der Transporter NaS1 und sat1 untersucht, um festzustellen, ob die jeweilige DNS in den Nieren der beiden Mäusestämme vertreten ist. In den darauffolgenden Versuchsreihen wurde zum Beweis der erfolgreichen reversen Transkription nur noch die DNS des housekeeping Gens GAPDH nachgewiesen, um anschließend die real-time PCR durchführen zu können. Für den Nachweis der DNS von GAPDH, sowie der Transporter NaS1 und sat1 wurde jeweils ein PCR-Mastermix hergestellt. Für jede Probe wurden die in Tabelle 17 angegebenen Mengen und Lösungen verwendet. 
Tabelle 17: Mastermix für die PCR

\begin{tabular}{|c|l|}
\hline Menge & \multicolumn{1}{c|}{ Lösung } \\
\hline $29 \mu \mathrm{l}$ & DEPC- $\mathrm{H}_{2} \mathrm{O}$ \\
\hline $8 \mu \mathrm{l}$ & dNTPs $(1,25 \mathrm{mM})$ \\
\hline $5 \mu \mathrm{l}$ & $10 \times$ Puffer \\
\hline $1 \mu \mathrm{l}$ & Forward-Primer \\
\hline $1 \mu \mathrm{l}$ & Reverse-Primer \\
\hline $1 \mu \mathrm{l}$ & Taq-Polymerase \\
\hline
\end{tabular}

Es wurden $45 \mu \mathrm{l} \mathrm{PCR}$-Mastermix und $5 \mu \mathrm{l}$ DNS gemischt und herunter zentrifugiert. Die PCR wurde mit dem in Tabelle 18 folgende Temperaturprofil durchgeführt.

Tabelle 18: Temperaturprofil für die PCR

\begin{tabular}{|c|c|c|}
\hline Zeit & Temperatur & Zyklen \\
\hline $3 \mathrm{~min}$ & $94^{\circ} \mathrm{C}$ & 1 \\
\hline $40 \mathrm{~s}$ & $94^{\circ} \mathrm{C}$ & \multirow{2}{*}{25} \\
\hline $50 \mathrm{~s}$ & $58^{\circ} \mathrm{C}$ & \\
\hline $1 \mathrm{~min}$ & $72^{\circ} \mathrm{C}$ & \\
\hline $5 \mathrm{~min}$ & $72^{\circ} \mathrm{C}$ & 1 \\
\hline$\infty$ & $4^{\circ} \mathrm{C}$ & \multicolumn{1}{|c}{} \\
\hline
\end{tabular}

\subsubsection{Agarosegel-Elektrophorese}

Die Agarosegel-Elektrophorese ist eine Methode zur Auftrennung von DNS-Strängen nach ihrer Länge. Durch Anlegen einer elektrischen Spannung wandern Moleküle durch das Gel, wobei kleine Moleküle auf Grund der Siebstruktur des Gels schneller wandern als große. Durch den Vergleich mit Größenmarkern lässt sich ein Rückschluss auf die Größe der DNS-Fragmente ziehen. Durch den im Gel enthaltenen Fluoreszenzfarbstoff Ethidiumbromid, der an die DNS-Fragmente bindet, können diese unter UV-Licht sichtbar gemacht werden.

Der Agarosegehalt der Gele wurde jeweils der Sequenzlänge der amplifizierten DNS angepasst. Für GAPDH und NaS1 wurden 1,5\% Ethidiumbromid-haltige Gele, für sat1 $2 \%$ Ethidiumbromid-haltige Gele hergestellt. Mit $100 \mathrm{ml}$ TBE 1× Puffer wurden $1,5 \mathrm{~g}$ oder $2 \mathrm{~g}$ Agarose in einen Erlenmeyerkolben eingewogen. Die Agarose wurde durch Erhitzen der Flüssigkeit in der Mikrowelle vollständig gelöst. Der Siedeverzug 
wurde durch erneutes Wiegen ermittelt und mit aqua dest. ausgeglichen. Nach Beimengen von 4,5 $\mu \mathrm{l}$ Ethidiumbromid wurde die Flüssigkeit in die Gelkammer mit Gelschlitten eingefüllt, 20 min abgekühlt und im Kühlschrank gelagert. Nachdem das Gel auspolymerisiert war, wurden $12 \mu \mathrm{l}$ des amplifizierten Produktes jeweils mit $3 \mu \mathrm{l}$ Auftragspuffer (5× DNA Stopp) gemischt und in die Geltaschen eingefüllt. Zusätzlich zu den Proben und der amplifizierten Negativkontrolle wurde das Gel mit einer Positivkontrolle und einer Wasserkontrolle so wie $5 \mu \mathrm{l}$ „Lighter" beschickt. Das Gel wurde in der Elektrophoresekammer für mindestens $1,25 \mathrm{~h}$ bei $100 \mathrm{~V}$ angeschlossen. Die Banden der aufgetrennten DNS wurden unter UV-Bestrahlung sichtbar gemacht und fotografiert (siehe Abbildung 13).

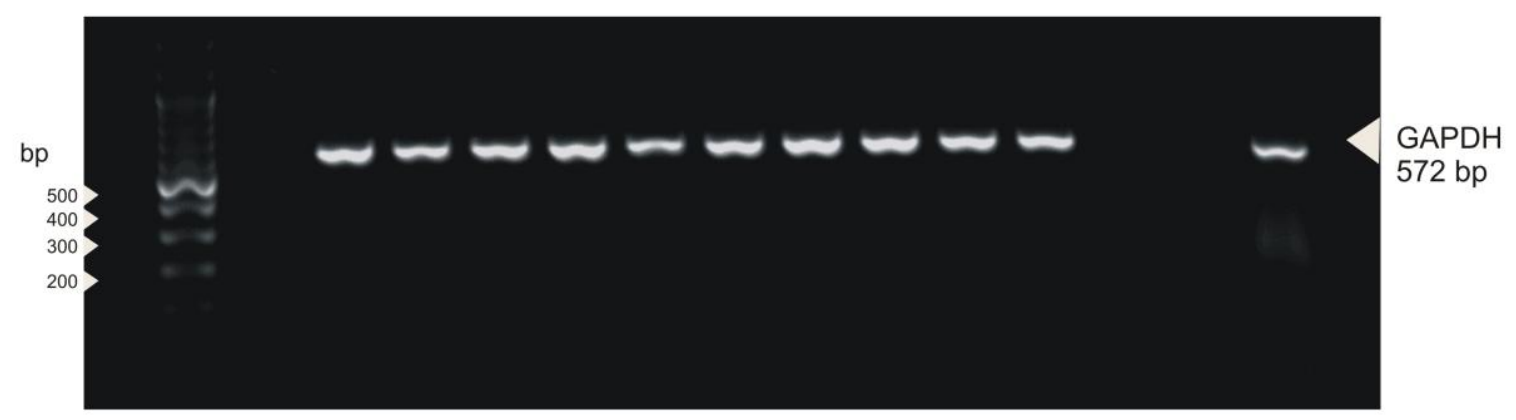

\section{Abbildung 13: Beispielhafte Darstellung einer Agarosegel-Elektrophorese für GAPDH in Nierengewebe von Mäusen}

Die Gesamt RNS wurde isoliert, mittels reverser Traskriptase in cDNS umgeschrieben und als „Template“ für die PCR mit GAPDH-spezifischen Primern verwendet. Die PCR Produkte wurden durch Elektrophorese auf einem Agarosegel getrennt und durch Ethidiumbromid sichtbar gemacht. Die Abbildungen zeigten ein repräsentatives Experiment. Vergleichbare Ergebnisse wurden auch mit NaS1- und sat1-spezifischen Primern erzielt.

Da bei jeder PCR und der dazugehörenden Gelelektrophorese die Banden für das gesuchte Protein zu sehen waren, konnte im Anschluss alle Proben mittels real-time PCR quantifiziert werden.

\subsubsection{Real-time PCR}

Mit der real-time PCR, auch quantitative Echtzeit-PCR, werden Nukleinsäuren nach dem Prinzip der PCR vervielfältigt und die gewonnene DNS gleichzeitig quantifiziert. Die Detektion der DNS Menge geschieht mit Hilfe von Fluoreszenzmessungen, das heißt in Echtzeit. Die in dieser Arbeit verwendeten TaqMan-Sonden besitzen an ihrem einen Ende ein Reporter-Fluorophor, das durch Anregung mit Licht bestimmter Wellenlänge Licht einer anderen Wellenlänge emittiert, und an ihrem anderen Ende 
einen sogenannten Quentscher, der die Lichtemission des Reporters unterdrückt. Nach dem Ablauf jedes PCR-Zyklus wird die Reporter-Fluoreszenz durch die Polymerase abgespalten. Dabei werden Reporter und Quentscher voneinander getrennt, sodass der Quentscher die Lichtemission des Reporters nicht mehr unterdrückt und die Lichtproduktion der spezifischen Wellenlänge steigt. Je mehr DNS synthetisiert wird, umso mehr Fluorochrome werden abgespalten, sodass die Signalstärke proportional zur DNS-Menge zunimmt (siehe Abbildung 14).
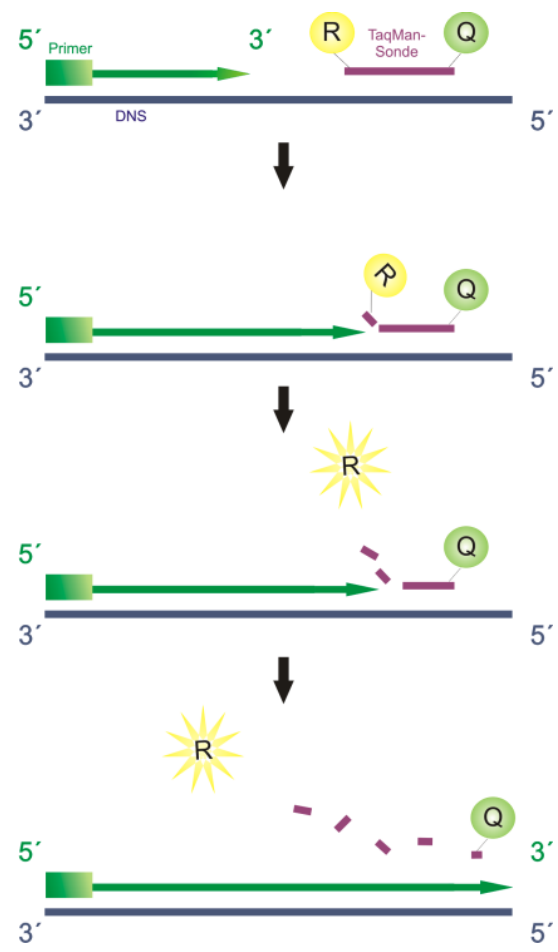

\section{Abbildung 14: Real-time PCR}

An die Ausgangs-DNS (blau) lagert sich die TaqMan-Sonde mit Reporter $(R)$ und Quentscher $(Q)$ an. Der Quentscher unterdrückt die Fluoreszenz des Reporters. Bei der Synthese des komplementären DNS-Strangs (grün) wird die Reporter-Sequenz abgespalten und beginnt zu fluoreszieren (Stern).

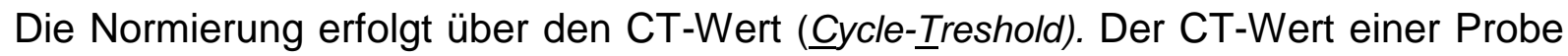
entspricht der Anzahl der schon gelaufenen Zyklen bei Erreichen einer bestimmten Signalstärke. Der Schwellenwert wird früher erreicht, wenn vor der Amplifikation mehr Ausgangs-DNS und somit mehr mRNS des spezifischen Proteins vorhanden war. Demnach bedeuten kleinere CT-Werte eine stärkere Expression der mRNS 
eines Proteins und hohe CT-Werte umgekehrt eine geringe Menge proteinspezifischer mRNS.

Um die Verunreinigungen von verwendeten Materialien auszuschließen, wurde bei jeder real-time PCR eine Negativkontrolle quantifiziert, in der Wasser anstelle von DNS eingesetzt wurde. Um die Menge der eingesetzten DNS zu standardisieren, wurde als endogene Kontrolle das housekeeping Gen GAPDH quantifiziert und zur Normierung der Ergebnisse verwendet. Jede Probe wurde für jedes Protein doppelt amplifiziert, um einen Mittelwert bilden zu können. In der 96-Well-Platte wurden jeweils zwei "Wells“ mit demselben Ansatz DNS und Mastermix beschickt. Für ein Well wurden pro Probe die in Tabelle 19 aufgeführten Lösungen verwendet.

\section{Tabelle 19: Mastermix für die real-time $P C R$}

\begin{tabular}{|c|l|}
\hline Menge & \multicolumn{1}{|c|}{ Lösung } \\
\hline $8,75 \mu \mathrm{l}$ & DEPC- $\mathrm{H}_{2} \mathrm{O}$ \\
\hline $12,5 \mu \mathrm{l}$ & $2 \times$ Puffer (Taqman) \\
\hline $1,25 \mu \mathrm{l}$ & Spezifischer Primer \\
\hline
\end{tabular}

In jedes Well wurde 2,5 $\mu$ I DNA und 22,5 $\mu$ Mastermix pipettiert. Die Wellplatte wurde mit einer Klebefolie abgedichtet, die Flüssigkeit herunter zentrifugiert und im real-time-PCR-Thermozykler (M×3005p, Stargene) amplifiziert. Die real-time PCR wurde mit dem in Tabelle 20 folgenden Temperaturprofil durchgeführt.

Tabelle 20: Temperaturprofil für die PCR

\begin{tabular}{|c|c|c|}
\hline Zeit & Temperatur & Zyklen \\
\hline $2 \mathrm{~min}$ & $50^{\circ} \mathrm{C}$ & 1 \\
\hline $10 \mathrm{~min}$ & $95^{\circ} \mathrm{C}$ & 1 \\
\hline $15 \mathrm{~s}$ & $95^{\circ} \mathrm{C}$ & \multirow{2}{*}{\}} \\
\hline $1 \mathrm{~min}$ & $60^{\circ} \mathrm{C}$ & 40 \\
\hline
\end{tabular}

Mit der komparativen $\triangle \mathrm{CT}$-Methode wurde die relative Expression der RNS errechnet und signifikante Unterschiede mit dem T-Test nach Student geprüft. 


\subsubsection{Immunhistochmische Methoden}

\subsubsection{Einführung}

Das Prinzip der immunhistochemischen Fluoreszenz beruht darauf, vorbehandelte Gewebeschnitte mit einem Primärantikörper gegen ein Protein (AK1) zu inkubieren, um anschließend diesen AK1 mit einem sekundären fluoreszierenden Antikörper (AK2), der an AK1 bindet, zu markieren (siehe Abbildung 15).

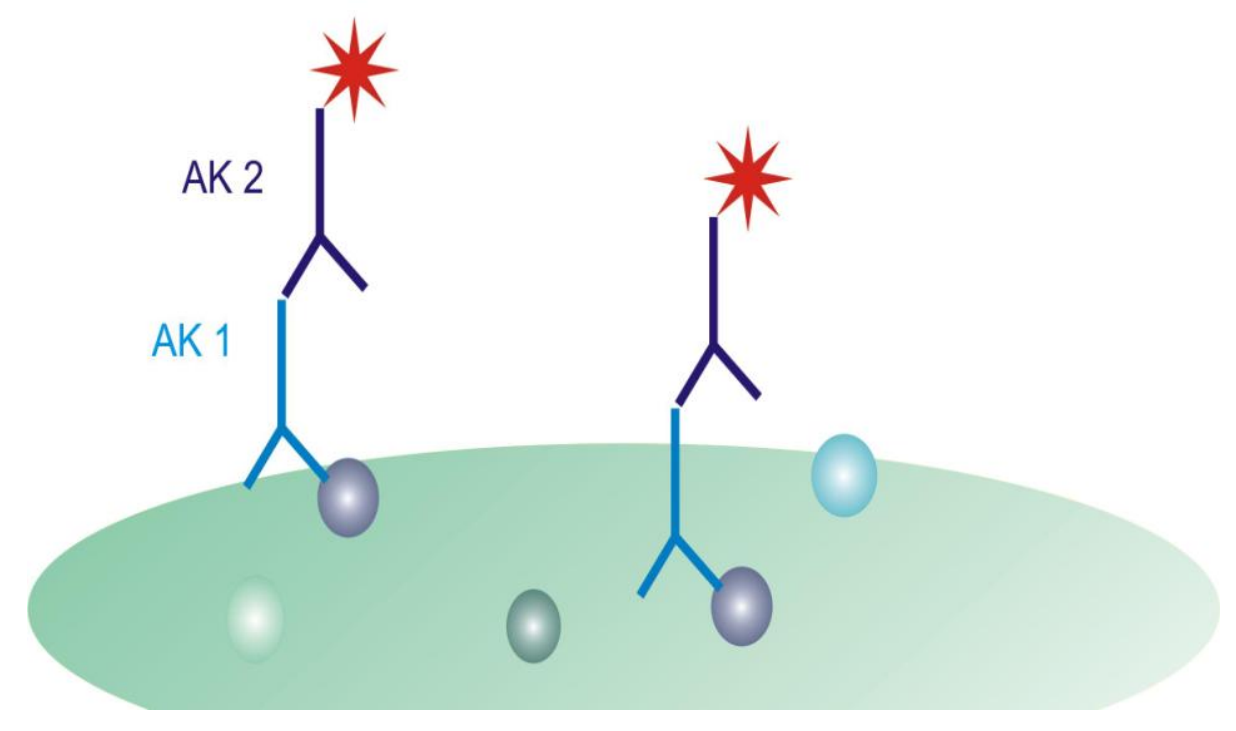

\section{Abbildung 15: Prinzip der immunhistochemischen Antikörperfärbung}

Antikörper 1 (AK1) bindet an das zu markierende Protein. Der fluoreszierende (Stern) Antikörper 2 (AK2) bindet an AK1.

Es gibt verschiedene Methoden um die Antikörperbindungsstellen (Antigene) zu demaskieren. Für jeden Versuchsaufbau ist, abhängig vom verwendeten Antikörper, Antigen und Gewebe, die optimale Vorbehandlung zu eruieren.

Zur Optimierung der Färbung von Nieren- und Leberschnitten wurden die Gewebeschnitte mit unterschiedlichen Methoden vorbereitet und anschließend mit einem der zwei Primärantikörper, dem polyklonalen Antikörper (Santa Cruz) oder dem monoklonaler Antikörper (Karniski et al., 1998), gegen eine antigene Sequenz des sat 1 behandelt. Schließlich wurden die restlichen Schnitte mit der Methode, bei der die beste Färbung resultierte, gefärbt. 


\subsubsection{Kryosektion}

Zur immunhistochemischen Färbung werden die Gewebe oder Zellen zunächst durch Fixation (0,02\% Natriumazid-PFA) denaturiert und anschließend gefroren und kryosektioniert. Das Gewebe wurde über Nacht in $30 \%$-Saccharose in PBS gelagert und anschließend vollständig mit OCT-Medium bedeckt bei $-25^{\circ} \mathrm{C}$ gefroren. Nach 30 60 min wurden mit einem Gewebeschneider (Leica CM 1850) $4 \mu \mathrm{m}$ dicke Gewebeschnitte angefertigt und auf einen Objektträger aufgebracht. Um den Proben Wasser und Gewebeflüssigkeit zu entziehen, folgte eine zweistündige Trocknung bei Raumtemperatur. Bis zum Gebrauch wurden die Schnitte bei $4^{\circ} \mathrm{C}$ gelagert.

\subsubsection{Gewebevorbereitung}

\subsection{Methoden zur Gewebevorbereitung}

Es wurden verschiedene Methoden angewandt, um die Antikörperbindungsstellen (Antigene) zu demaskieren. Um den optimalen Versuchsaufbau zu ermitteln, wurde die immunhistochemische Färbung an einem unbehandelten Kryoschnitt mit den Färbungen von vorbehandelten Schnitten verglichen. Die Behandlung der Schnitte vor der Inkubation mit dem Primärantikörper erfolgte entweder mit SDS-Lösung (Sodium Dodecyl Sulfate/Natrium-Laurylsulfat) (siehe SDS-Methode), oder durch Kochen der Schnitte in Citratpuffer bei pH-Werten von 3, 6 und 8, ohne Alkoholvorbehandlung (Citratpuffer-Methode) und mit Alkoholvorbehandlung (Deparaffinierungs-Citratpuffermethode).

\subsection{Methode mit unbehandelten Proben}

Die Objektträger mit den Gewebeschnitten wurden für $15 \mathrm{~min}$ in PBS-Lösung rehydriert und 30 min mit BSA (1 \% bovines Serumalbumin in PBS) inkubiert, um unspezifische Bindungen des Antikörpers zu verhindern.

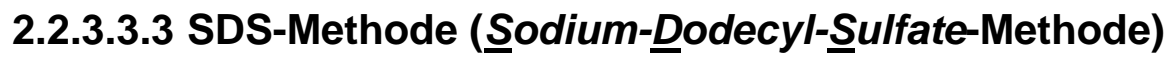

Nach einer 15-minütigen Rehydratation in PBS wurden die Gewebeschnitte 5 min in SDS-Lösung ( $1 \%$ SDS in PBS) inkubiert, $4 \times 5$ min mit PBS gewaschen und $30 \mathrm{~min}$ mit BSA inkubiert.

\subsection{Citratpuffer-Methode}

Die Gewebeschnitte wurden $15 \mathrm{~min}$ in PBS rehydriert und in $10 \mathrm{mmol} / \mathrm{l}$ Citratpuffer mit pH-Werten von 3, 6 und 8 für $4 \times 5$ min bei $800 \mathrm{~W}$ erhitzt. Nach 20-minütigem Abkühlen wurden die Proben $3 \times 5$ min in PBS gewaschen, 15 min in 0,5\% Triton X- 
100 in PBS und 30 min in $2 \%$ Triton X-100 in PBS inkubiert, $2 \times 5$ min in PBS gewaschen und 30 min mit BSA inkubiert.

\subsection{Deparaffinisierungs-Citrat-Methode}

Zur Entfettung der Gewebeschnitte wurden die Proben vor der Rehydratation (siehe Citrat-Methode) mit verschiedenen Alkoholen behandelt (siehe Tabelle 21).

Tabelle 21: Alkoholbehandlung bei der Deparaffinisierungs-Citrat-Methode

\begin{tabular}{|l|c|}
\hline \multicolumn{1}{|c|}{ Alkohol } & Zeit \\
\hline $100 \%$ Xylol & $30 \mathrm{~min}$ \\
\hline $100 \%$ Propanol & $5 \mathrm{~min}$ \\
\hline $96 \%$ Ethanol & $5 \mathrm{~min}$ \\
\hline $75 \%$ Ethanol & $5 \mathrm{~min}$ \\
\hline $60 \%$ Ethanol & $5 \mathrm{~min}$ \\
\hline
\end{tabular}

Nach 5 min Waschen in aqua dest. wurden die Proben wie in 2.2.3.3.4 CitratpufferMethode beschrieben behandelt.

\subsubsection{Immunhistochemische Färbung}

Die vorbehandelten Gewebeschnitte wurden über Nacht mit dem Primärantikörper bei $4^{\circ} \mathrm{C}$ inkubiert. Nach Ablauf der Inkubationszeit wurden die Gewebeschnitte gewaschen (siehe Tabelle 22).

Tabelle 22: Wäsche der Gewebeschnitte

\begin{tabular}{|c|l|}
\hline Anzahl $\times$ Zeit & \multicolumn{1}{c|}{ Waschlösung } \\
\hline $2 \times 5 \mathrm{~min}$ & High-salt PBS (PBS mit 1,8 \% NaCl) \\
\hline $2 \times 5 \mathrm{~min}$ & PBS \\
\hline
\end{tabular}

Die Schnitte wurden $1 \mathrm{~h}$ mit dem Sekundärantikörper bei Raumtemperatur in feuchtem Milieu inkubiert, erneut wie in Tabelle 22 beschrieben gewaschen, mit „Vectashield“ behandelt, um das Ausbleichen des Fluoreszenzfarbstoffes zu verzögern, abschließend mit einem Deckglas abgedeckt und mit Nagellack versiegelt. Die immunhistochemischen Färbungen der Mäusenieren und -lebern, sowie der Rattennnieren wurden mit einem Opton-III-RS-Fluoreszenzsmikroskop ausgewertet. Zum Fotografieren der rot fluoreszierenden Gewebeschnitte wurde eine Spot-RT-Slider-Kamera und dazugehörige Computersoftware verwendet. Die 
fotografierten Gewebeschnitte wurden mit dem Computerprogram Adobe Photoshop bearbeitet.

\subsubsection{Proteinbiochemische Methoden}

\subsubsection{Membranpräparation}

Nach der Homogenisierung der Gewebe (siehe 2.2.1.2) wurden die Membranpräparation von Mitarbeitern des Instituts in Zagreb durchgeführt. Dabei wurden Basalmembranen aus dem Nierenhomogenat und Zellmembranen aus dem Leberhomogenat isoliert. Die Membranen wurden vom Gewebehomogenat durch Trennungszentrifugation in einer gekühlten Zentrifuge (Sorvall Instruments) isoliert. Das entstandene Pellet mit Homogenisierungspuffer resuspendiert und bis zum Gebrauch bei $-70^{\circ} \mathrm{C}$ gelagert.

\subsubsection{SDS-Polyacrylamid-Gelelektropherese}

Mit Hilfe der Natrium-Dodecylsulfat-Polyacrylamid-Gelelektropherese (sodium dodecyl sulfate polyacrylamide gel electrophoresis, SDS-PAGE) wird das Proteingemisch aus dem verwendeten Homogenat durch Elektropherese in der netzartigen Gelstruktur nach seiner Molekülgröße aufgetrennt. Das verwendete Gel unterteilt sich in zwei Abschnitte - das oben liegende grobporigere Sammelgel und das unten liegende feinporigere Trenngel. Ammoniumpersulfat und Tetramethylethylendiamin bewirken eine Polymerisation des Acrylamids, sodass ein Netz aus Polyacrylamiden entsteht. Durch die Behandlung des Proteingemisches mit SDS und $\beta$-Mercaptoethanol werden Sekundär- und Primärstruktur der Proteine aufgelöst und Disulfidbrücken gespalten, sodass die Proteine als vollständig entfaltete, negativ geladene Polypetidketten vorliegen. Durch hydrophobe Wechselwirkungen mit den freilegenden Aminoresten binden die SDS-Moleküle an die Proteine. Die Proteine liegen somit als gleichmäßig negativ geladene Moleküle vor und wandern beim Anlegen einer Spannung zur Anode. Dabei werden die Proteine alleine nach ihrer Molekülgröße aufgetrennt.

Für das diskontinuierliche SDS-Polyacrylamidgel wurde ein Sammelgel auf ein Trenngel gegossen und der Probenkamm luftblasenfrei eingesetzt. Die Zusammensetzung der Gele ist in Tabelle 23 aufgelistet. 
Tabelle 23: Zusammensetzung des Sammel- und des Trenngels für die SDSPAGE

\begin{tabular}{|l|c|c|}
\hline & Trenngel 10\% & Sammelgel 3,9\% \\
\hline Acrylamid-Lösung & $3 \mathrm{ml}$ & $0,52 \mathrm{ml}$ \\
\hline Trenngel-Puffer & $2,25 \mathrm{ml}$ & - \\
\hline Sammelgel-Puffer & - & $1 \mathrm{ml}$ \\
\hline $10 \%$ SDS & $90 \mu \mathrm{l}$ & $40 \mu \mathrm{l}$ \\
\hline Ammoniumpersulfat & $0,45 \mu \mathrm{l}$ & $0,24 \mu \mathrm{l}$ \\
\hline Aqua dest. & $3,21 \mu \mathrm{l}$ & $2,2 \mu \mathrm{l}$ \\
\hline Tetramethylethylendiamin & $2,4 \mu \mathrm{l}$ & $1,6 \mu \mathrm{l}$ \\
\hline
\end{tabular}

Die Proben wurden mit Ladepuffer mit oder ohne $\beta$-Mercaptoethanol gemischt, bei verschiedenen Temperaturen denaturiert $\left(37^{\circ} \mathrm{C} / 30 \mathrm{~min}, 65^{\circ} \mathrm{C} / 15 \mathrm{~min}\right.$ oder $95^{\circ} \mathrm{C} / 5$ min) und nach vollständiger Polymerisation des Gels mit einem Molekulargewichtsmarker aufgetragen. Die Proteine wurden mittels Gelelektrophorese auf $10 \%$ SDS-Minigels unter einem konstanten Strom bei einer Spannung von $100 \mathrm{~V}$ über $2 \mathrm{~h}$ bis zum "drop off" aufgetrennt.

\subsubsection{Proteintransfer auf die PVDF (Polyyinylidenfluorid) -Membran}

Der sogenannte Western Blot dient dem Nachweis eines bestimmten Proteins in einem Proteingemisch, wobei die Auftrennung mittels SDS-Gelelektropherese nach der Molekülröße der Proteine erfolgt. Mit Hilfe eines primären und sekundären Antikörpers und eines bei Katalyse lichtemittierenden Enzyms wird das Protein sichtbar gemacht.

Die Imobilion-Transfermembran wurde beschriftet, kurz in Methanol getaucht und anschließend zusammen mit dem zugeschnittenen Gel in Transferpuffer gelegt. Gel und aktivierte Membran wurden zwischen Faserpads und Filterpapiere geschichtet. Das geschichtete und mit Blot-Puffer getränkte Gel-Blot-Sandwich wurde im Kasettenhalter in die mit Puffer gefüllte Western-Blot-Kammer gesetzt und für $2 \mathrm{~h}$ bei 100 V Spannung angeschlossen. Für den Proteintransfer wurde das Eqiupment von Bio Rad Laboratories verwendet. Um die Effizienz des Proteintransfers zu Überprüfen wurde die Membran mit 0,1 \% Coomasie Brilliant Blue gefärbt und anschließend solange mit Entfärbungsmittel gewaschen, bis der Hintergrund von Farbrückständen befreit war. 


\subsubsection{Proteindetektion auf Western Blots}

Nach dem Transfer der Proteine auf die PVDF-Membran wurde die Membran mit magermilchhaltigem Waschpuffer $1 \mathrm{~h}$ bei Raumtemperatur inkubiert, um die unspezifischen Bindungen abzusättigen und die Proteine mittels einer Immunfärbung spezifisch nachzuweisen. Über Nacht erfolgte die Inkubation mit dem Primärantikörper (polyklonaler anti-sat1-Ak 1:500 in Waschpuffer verdünnt) bei $4^{\circ} \mathrm{C}$. Am folgenden Tag wurde die Membran $4 \times 10 \mathrm{~min}$ in Waschpuffer gewaschen, $1 \mathrm{~h}$ mit $0,1 \mu \mathrm{g} / \mathrm{ml}$ GAM-AP (goat anti- $\underline{m o u s e} / Z i e g e$ anti-Maus alkalische Phosphatase) in Waschpuffer inkubiert und $4 \times 10 \mathrm{~min}$ in Waschpuffer sowie $2 \times 10 \mathrm{~min}$ in PBS gewaschen. Die Proteinbanden wurden mittels der alkalischen-PhosphataseReaktion visualisiert, wobei ein Puffer verwendet wurde, der 5-bibromo-4-chhloro-3indolyl-phosphat (BCIP) und nitro-b-blue-tetrazolium (NBT) enthält. Zur Abschätzung der relativen molekularen Masse der markierten Proteinbanden wurde ein Molekulargewichtsmarker eingesetzt.

\subsubsection{Statistik}

Die Signifikanz wurde durch den Signifikanztest nach Student ermittelt. Alle Ergebnisse werden als Mittelwerte +/- Standardabweichung des Mittelwerts angegeben. Der Unterschied der RNS-Expression zwischen zwei Gruppen wird als nicht signifikant angegeben, wenn das Signifikanzniveau von $p<0,05$ nicht eingehalten wird. Im Folgenden gilt: Das Signifikanzniveau $p<0,05$ wird bezeichnet mit ${ }^{*}$ und $p<0,01$ mit ${ }^{* * *}$. Diese Verfahrensweise wird bei allen künftigen Abbildungen zur RNS-Expression angewende und deshalb in den Legenden nicht mehr erwähnt. 


\section{Ergebnisse}

\subsection{Einführung}

In dieser Arbeit wurde die Expression der Sulfattransporter NaS1 und sat1 bei zwei verschiedenen Stämmen von Mäusen untersucht. Einerseits wurden Experimente zur geschlechtsabhängigen Expression von NaS1 und sat1 in den Nieren und von sat1 in der Leber von 7,5 Wochen alten NMRI-Mäusen durchgeführt, andererseits zur geschlechts- und altersabhängigen Expression der Sulfattransporter in den Nieren der sogenannten „Alport-Maus“, die auf dem Hintergrund des SvJ/129-Stammes generiert worden war.

Aus dem SvJ/129-Stamm wurden Mäuse untersucht, die $\operatorname{COL} 4 A 3^{+/+}$und somit Wildtyp-Tiere waren, sowie Mäuse, die COL4A3 $3^{-1-}$ und somit am Alport-Syndrom erkrankte Tiere waren. Um die altersabhängige Expression der Transporter der Mäuse untersuchen zu können, wurden vier Gruppen unterschiedlichen Alters gebildet $(4,5 ; 6 ; 7,5$ und 9 Wochen alte Tiere beiderlei Geschlechts).

In den Grafiken zur RNS-Expression wurde folgende Farbwahl getroffen: Für NMRIMäuse gilt, dass die Balken für weibliche Mäuse in Violett dargestellt sind, männliche in Anthrazit-Blau. Für die Mäuse vom SvJ/129-Stamm gilt, dass die Daten für weibliche Tiere in Rosa, die für männliche in Blau dargestellt sind. Wildtyp-Tiere $\left(\mathrm{COL} 4 \mathrm{~A}^{+/+}\right)$sind in einem, für die jeweilige Farbe dunkleren, erkrankte Tiere $\left(\mathrm{COL} 4 \mathrm{~A}^{-1}{ }^{-}\right)$in einem helleren (hellrosa und hellblau) Farbton dargestellt (siehe Abbildung 16).

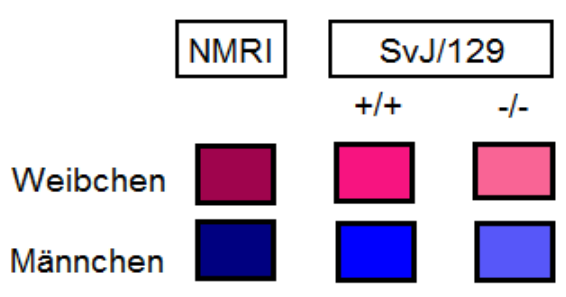

Abbildung 16: Farbwahl in den Grafiken zur RNS-Expression 


\subsection{Untersuchung der Sulfattransporter NaS1 und sat1 auf Transkriptionsebene}

\subsubsection{Nachweis von mNaS1- und msat1-RNS in Leber und Nieren von NMRI- Mäusen}

An vier männlichen und vier weiblichen NMRI-Mäusen wurde die geschlechtsabhängige Expression der Sulfattransporter NaS1 und sat1 untersucht. Es wurden beide Nieren verwendet, sodass sowohl für die männliche als auch für die weibliche Gruppe ein Mittelwert aus den Ergebnissen von acht Nieren gebildet werden konnte. Zusätzlich wurde die geschlechtsspezifische Expression der RNS von sat1 in der Leber untersucht, um einen Vergleich zur Expression bei Ratten anstellen zu können (Brzica et al., 2009a).

Bevor die RNS, die für NaS1 und sat1 kodierte mittels real-time PCR quantifiziert wurde, wurde zunächst eine RT-PCR (reverse Iranskriptions $\underline{P C R}$ ) mit anschließender Agarosegel-Elektrophorese durchgeführt, um das Vorhandensein der entsprechenden RNS zu belegen.

Alle Gewebe von Nieren und Leber wurden pulverisiert und die RNS nach Anleitung des Kits SV Total RNA Isolation System (Promega) isoliert. Mit Hilfe von Oligo dTs wurde die RNS separiert und mit rerverser Transkriptase in cDNS umgeschrieben. Durch die PCR wurde die cDNS für das housekeeping Gen GAPDH, sowie für NaS1 und sat1 vervielfältigt und mittels Agarosegel-Elektrophorese nachgewiesen.

\subsubsection{Geschlechtsabhängige RNS-Expression von NaS1 und sat1 in den Nieren und sat1 in der Leber von NMRI-Mäusen}

Nachdem die RNS von NaS1, sat1 und GAPDH nachgewiesen war, wurde zur Quantifizierung selbiger eine real-time PCR durchgeführt. Hierzu wurde die durch reverse Transkription produzierte cDNS als Ausgangsmaterial verwendet. Die DNS wurde für jedes Protein und jede Probe im doppelten Ansatz amplifiziert und aus den zwei Werten ein Mittelwert gebildet. Um eventuelle individuelle Ungleichheiten der absoluten Expression auszugleichen, wurden $\Delta$ CT-Werte gebildet, indem die Werte für das housekeeping-Gen von den Werten für die Transporter abgezogen wurden. Zur Normung wurde der $\Delta \mathrm{CT}$-Wert für ein beliebiges Tier gleich „0“ gesetzt und die $\Delta C T$-Werte der übrigen Proben daran normiert ( $\triangle C T$ (Maus $\mathrm{x}$ ) - $\Delta C T$ (NormungsMaus) $=\triangle \triangle C T$ ). Als Wert der relativen Expression von NaS1- und sat1-RNS wird der Durchschnitt der $\mathrm{x}$-fachen Änderung $\left(2^{-\triangle \Delta C T}\right)$ angegeben. Mit dem Durchschnitt der $x$-fachen Änderung wird demnach das Verhältnis der Genexpression im Bezug auf 
ein beliebig gewähltes Grundniveau angegeben. Dieser $\Delta \Delta C T$-Wert wird in den Abbildungen als „Relative Expression“ angegeben.

Die real-time PCR zeigte, dass männliche NMRI-Mäuse eine signifikant $(p<0,01)$ niedrigere NaS1-RNS-Expression aufweisen als gleichaltrige weibliche Tiere (siehe Abbildung 17).

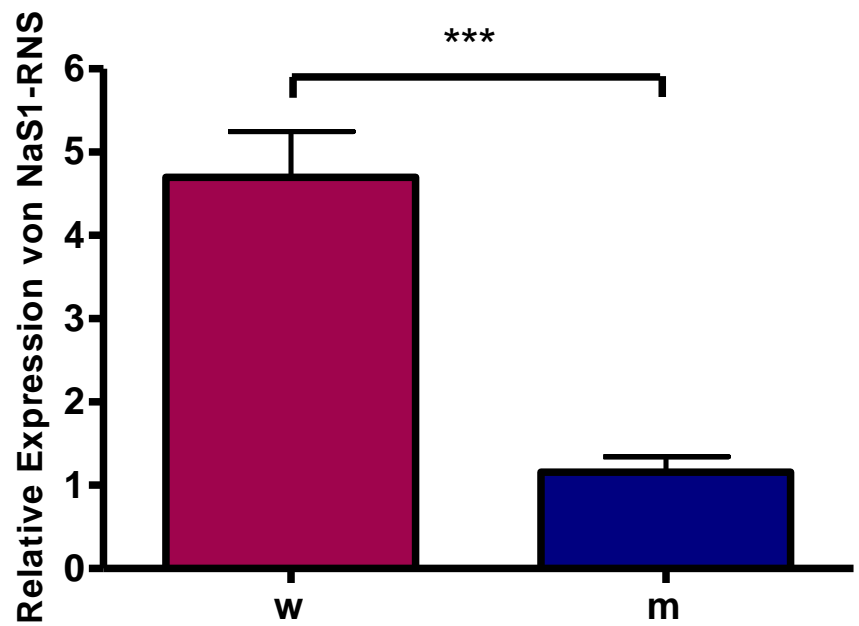

Abbildung 17: Relative Expression der NaS1-RNS in je acht Nieren von vier weiblichen (w) und vier männlichen $(m)$ 7,5 Wochen alten NMRI-Mäusen.

Für sat1 zeigte sich ebenfalls eine signifikant $(p<0,01)$ niedrigere Expression bei männlichen Mäusen (siehe Abbildung 18).

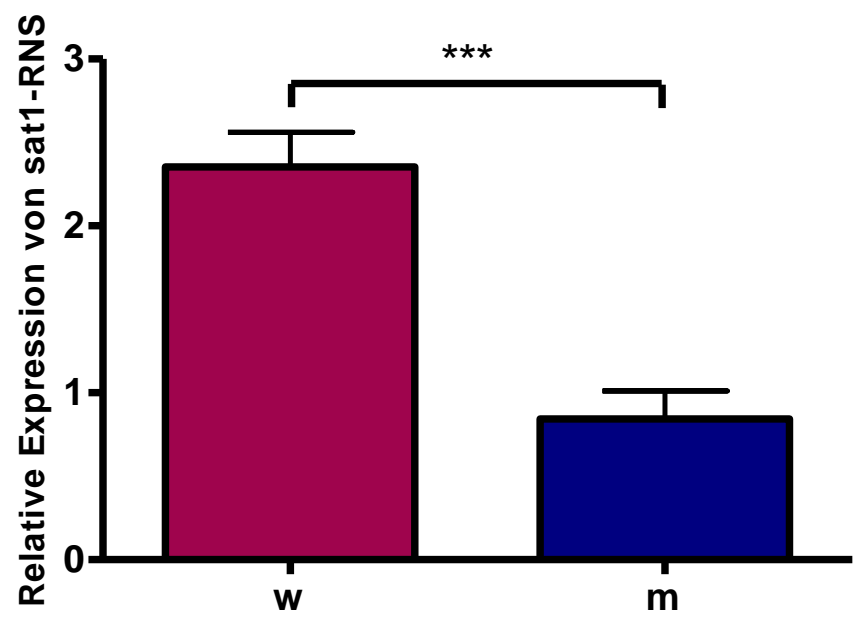

Abbildung 18: Relative Expression der sat1-RNS in je acht Nieren von vier weiblichen ( $w$ ) und vier männlichen $(m)$ 7,5 Wochen alten NMRI-Mäusen. 
Der Gehalt an sat1-RNS in der Leber ist ebenfalls tendenziell bei Männchen niedriger als bei Weibchen, doch erreichte der Unterschied kein angestrebtes Signifikanzniveau (siehe Abbildung 19).

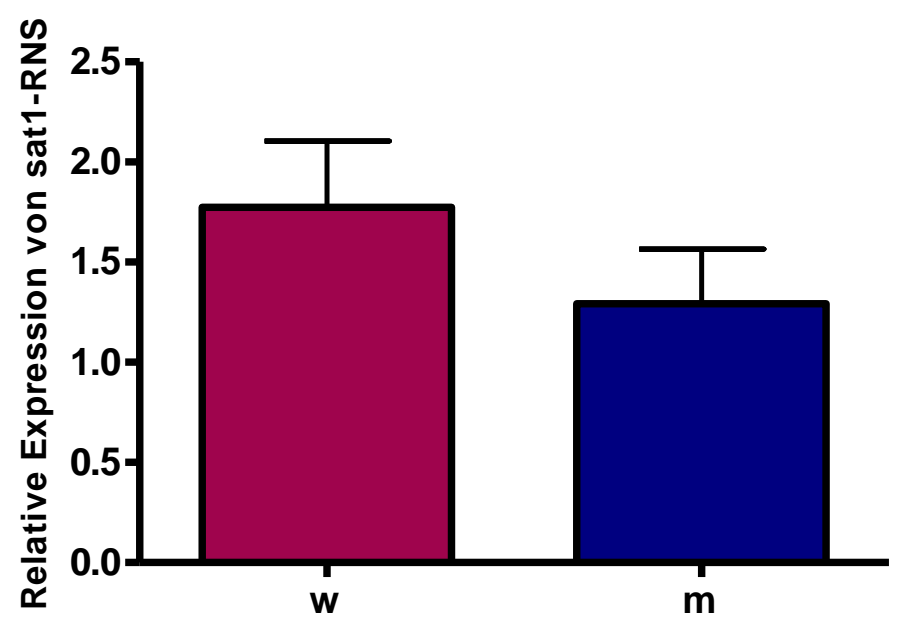

Abbildung 19: Relative Expression der sat1-RNS in der Leber von vier weiblichen $(w)$ und vier männlichen $(m)$ 7,5 Wochen alten NMRI-Mäusen.

\subsubsection{Nachweis von mNaS1 und msat1 in den Nieren von $\mathrm{COL}_{4} \mathrm{A3}^{+/+}$- und $\mathrm{COL}_{4 \mathrm{~A}} 3^{-/}$- Mäusen}

Bei der Untersuchung der „Alport-Tiere“ wurden verschiedene Vergleiche im Hinblick auf die Expression der Sulfattransporter angestellt. Es wurde untersucht, in wie fern sich die RNS-Menge in Abhängigkeit vom Geschlecht, dem Alter und dem Stadium der Alporterkrankung verhält. Außerdem wurden die Ergebnisse der $\mathrm{COL} 4 \mathrm{~A}^{+/+}$Tiere denen der NMRI-Tiere gegenübergestellt.

Für die Versuche wurden männliche und weibliche $\mathrm{COL} 4 \mathrm{~A}^{+/+}$- und $\mathrm{COL} 4 \mathrm{~A} 3^{-1-}$-Tiere unterschiedlichen Alters verwendet. Es wurden vier Altersgruppen gebildet (siehe Tabelle 24).

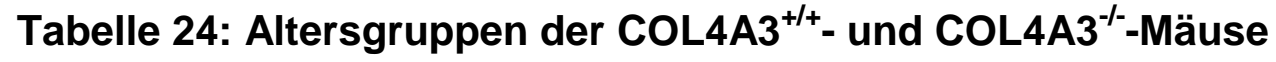

\begin{tabular}{|c|c|}
\hline Altersgruppe & Alter in Tagen \\
\hline 4,5 Wochen & $31-36$ \\
\hline 6 Wochen & $39-45$ \\
\hline 7,5 Wochen & $47-57$ \\
\hline 9 Wochen & $63-66$ \\
\hline
\end{tabular}


$\mathrm{Da}$ das Geschlecht der Geschwistertiere in den einzelnen Altersgruppen stark variierte, stand für die Untersuchungen teilweise nur ein weibliches Tier pro Gruppe zu Verfügung. Aus diesem Grund sind die Gruppen der weiblichen Tiere zum Teil nicht groß genug, um valide Ergebnisse zu erzeugen (siehe Tabelle 25).

Tabelle 25: Anzahl der untersuchten Mäuse

\begin{tabular}{|c|c|c|c|c|}
\cline { 5 - 5 } \multicolumn{1}{c|}{} & \multicolumn{2}{c|}{ Weibchen } & \multicolumn{2}{c|}{ Männchen } \\
\cline { 1 - 1 } Alter in Wochen & COL4A 3 & COL4A 3 & COL4A 3 & COL4A 3 \\
\hline 4,5 & 1 & 4 & 5 & 4 \\
\hline 6 & 3 & 3 & 3 & 6 \\
\hline 7,5 & 3 & 1 & 5 & 4 \\
\hline 9 & 0 & 3 & 4 & 4 \\
\hline
\end{tabular}

Die RT-PCR wies für alle Tiere GAPDH-, NaS1- und sat1-DNS nach, sodass die RNS-Quantität der Proteine mittels real-time PCR getestet werden konnte.

\subsubsection{NaS1- und sat1-RNS-Expression in den Nieren von COL4A3 ${ }^{+/+}$-Männchen in Abhängigkeit vom Alter}

Bei männlichen $\mathrm{COL} 4 \mathrm{~A}^{+/+}$-Mäusen zeigte die real-time PCR einen tendenziellen Abfall der relativen Expression von NaS1-RNS zwischen 4,5 und 6 Wochen alten Tieren und einen signifikanten $(p<0,05)$ Anstieg zwischen den Altersgruppen von 6 und 7,5 Wochen. Zwischen 7,5 und 9 Wochen ist erneut ein leichter Abfall zu beobachten. Der Vergleich der verschiedenen Altersgruppen untereinander zeigte für NaS1 keine weiteren Signifikanzen auf dem 5 \%-Signifikanzniveau (siehe Abbildung 20). 


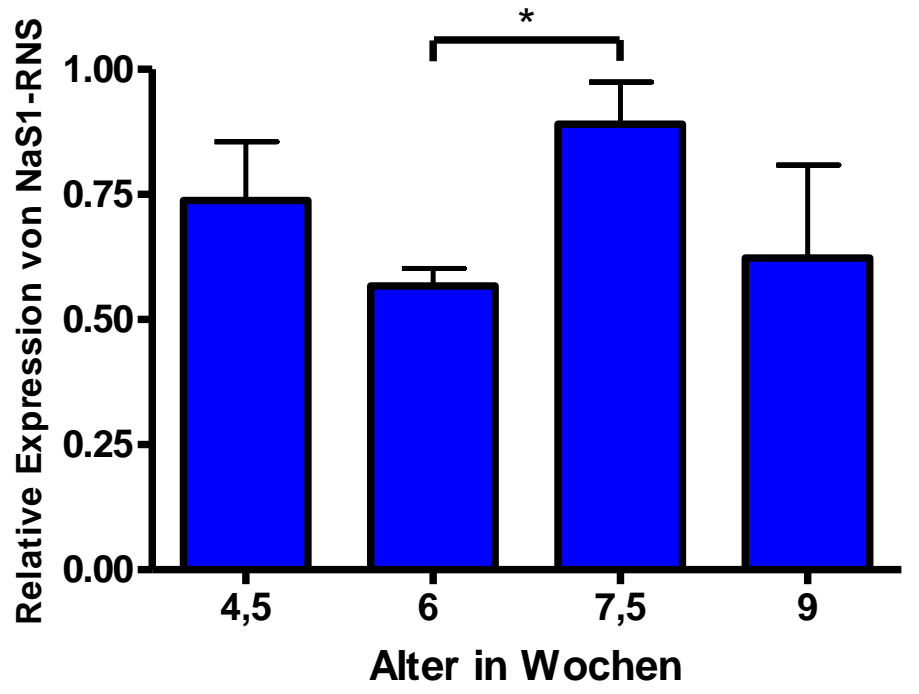

Abbildung 20: Relative Expression von NaS1-RNS in Nieren von männlichen $\mathrm{COL} 4 \mathrm{A3}^{+++}$-Mäusen in Abhängigkeit vom Alter.

Für sat1 wurde wie bei NaS1 eine tendenziell geringere RNS-Expression bei 6 Wochen alten im Vergleich zu 4,5 Wochen alten Tieren sowie eine signifikant $(p<$ $0,05)$ geringere Expression bei 6 Wochen alten Tieren im Vergleich zu 9 Wochen alten Tieren detektiert. Der Vergleich der verschiedenen Altersgruppen untereinander zeigte für sat1 keine weiteren Signifikanzen auf dem $5 \%$-Signifikanzniveau (siehe Abbildung 21).

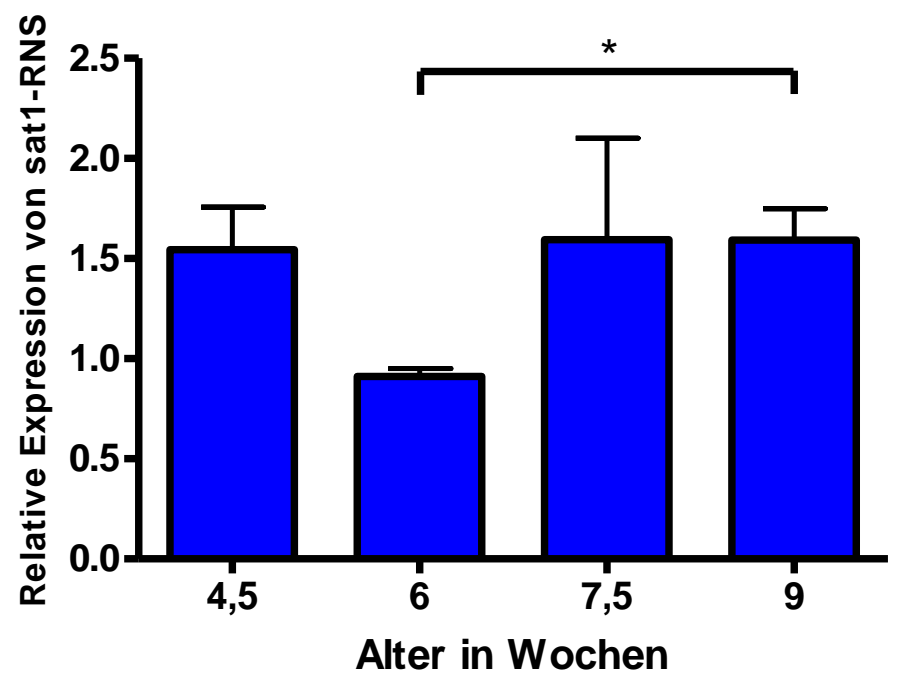

Abbildung 21: Relative Expression von sat1-RNS in Nieren von männlichen $\mathrm{COL}_{4} \mathrm{A3}^{+/+}$-Mäusen in Abhängigkeit vom Alter. 


\subsubsection{NaS1- und sat1-RNS-Expression in den Nieren von COL4A3 ${ }^{-1-}$-Männchen in Abhängigkeit vom Alter}

Da ein 9 Wochen altes COL4A3 ${ }^{-1}$-Tier für sat1 eine circa 60 -fach erhöhte Expression aufwies, wurden die Werte dieses Tieres nicht mit in die Versuchsreihe aufgenommen.

Bei männlichen am Alport-Syndrom erkrankten $\left(\mathrm{COL} 4 \mathrm{~A} 3^{--}\right)$Tieren exprimiert die Gruppe der 4,5 Wochen alten Tiere signifikant $(p<0,01)$ mehr NaS1-RNS als die Gruppe der 6 Wochen alten Tiere. Tendenziell sind zwischen der Gruppe der 6 Wochen und 7,5 Wochen alten Tiere ein Anstieg und danach ein Abfall der Expression zu erkennen, der allerdings aufgrund der großen Schwankungen innerhalb der Gruppe der 7,5 Wochen alten Tiere kein Signifikanzniveau erreicht (siehe Abbildung 22).

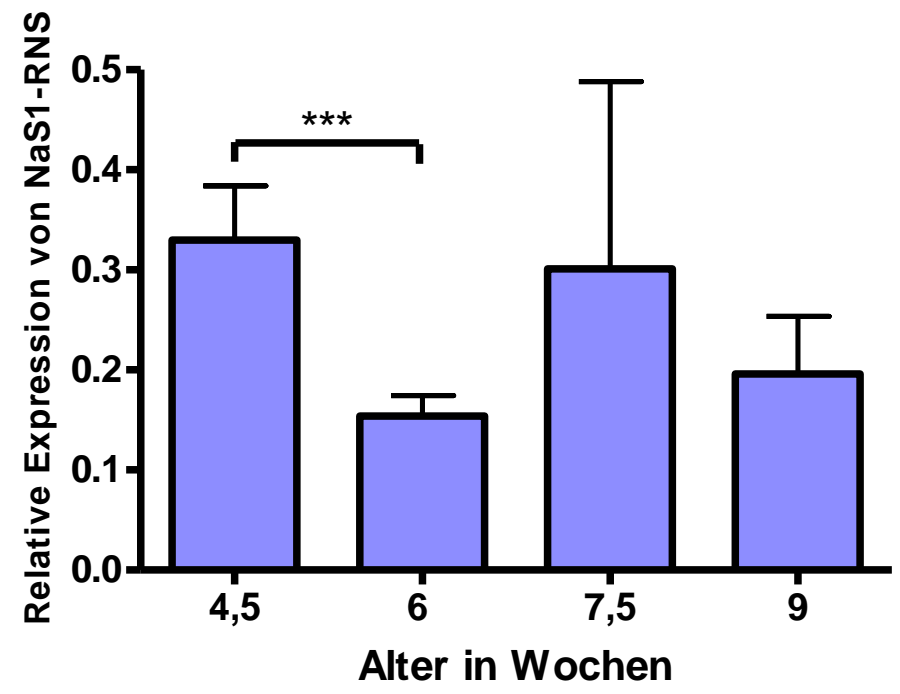

Abbildung 22: Relative Expression von NaS1-RNS in den Nieren von männlichen $\mathrm{COL}_{4} \mathrm{A3}^{-/-}$-Mäusen in Abhängigkeit vom Alter.

Für sat1 wurde eine signifikant $(p<0,01)$ höhere Expression bei 9 Wochen alten Tieren als bei 6 Wochen alten Tieren gefunden. Wie bei den COLAA3 ${ }^{+/+}$-Tieren scheint es als würde die Expression von 4,5 zu 6 Wochen hin abfallen, um danach wieder anzusteigen (siehe Abbildung 23). 


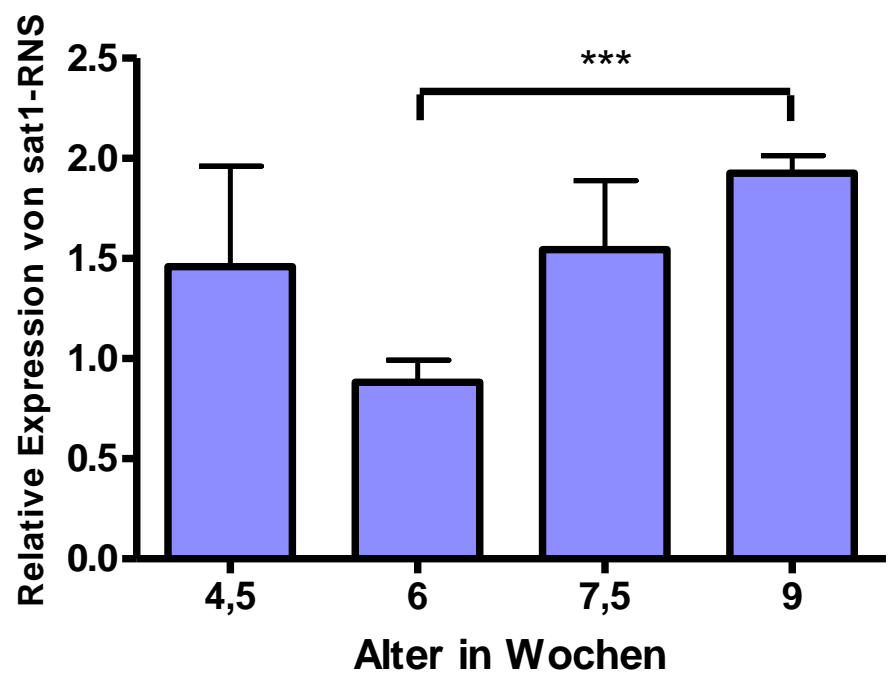

Abbildung 23: Relative Expression von sat1-RNS in den Nieren von männlichen $\mathrm{COL} 4 \mathrm{A3}^{-/-}$-Mäusen in Abhängigkeit vom Alter.

3.2.6 NaS1- und sat1-RNS-Expression in den Nieren von $\mathrm{COL}_{4 \mathrm{~A}} 3^{+/+}$- und $\mathrm{COL}_{4} \mathrm{A3}^{-1-}$-Weibchen in Abhängigkeit vom Alter

Wie bei den männlichen Tieren konnte auch ein weibliches COL4A3 $3^{-/}$-Tier nicht in die Versuchsreihe aufgenommen werden, da es eine circa 10-fach erhöhte Expression für NaS1 und eine circa 150-fach erhöhte Expression für sat1 aufwies.

Weder bei weiblichen $\mathrm{COL} 4 \mathrm{~A}^{+/+}$-Mäusen noch bei weiblichen $\mathrm{COL} 4 \mathrm{~A} 3^{-1-}$-Mäusen ist mittels real-time PCR eine altersabhängige Veränderung der RNS-Expression von NaS1 oder sat1 zu erkennen (siehe Abbildung 24). 
a)

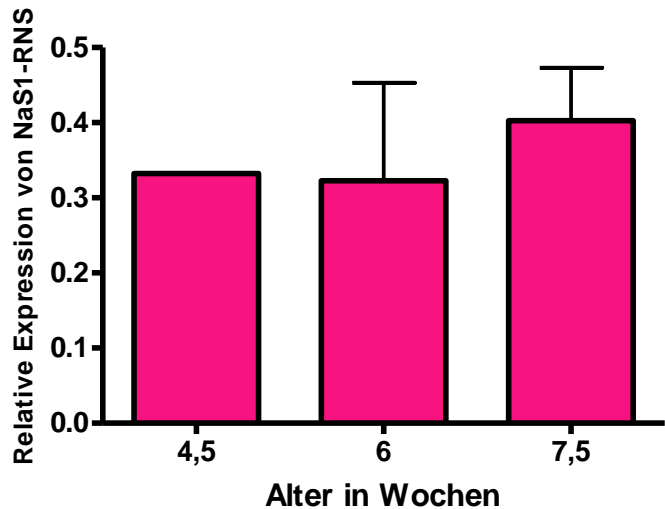

c)

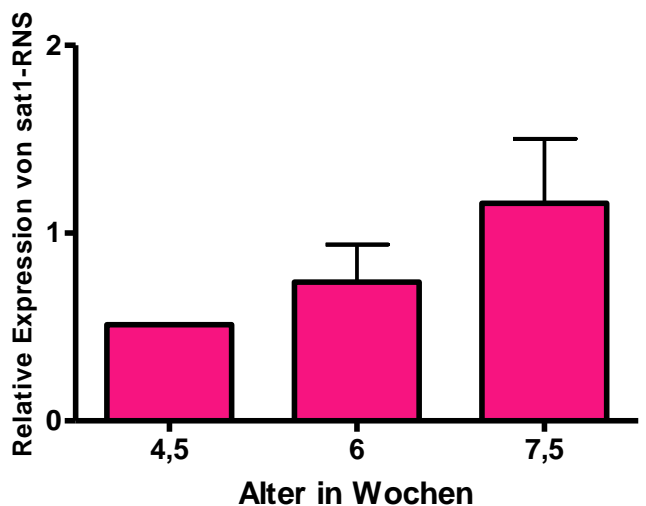

b)

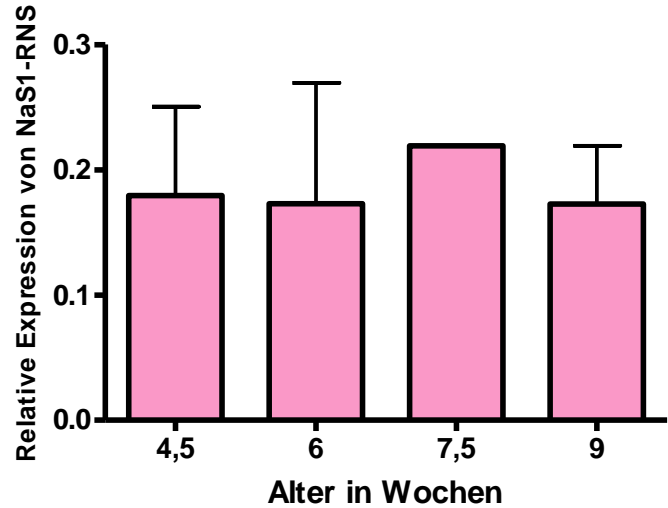

d)

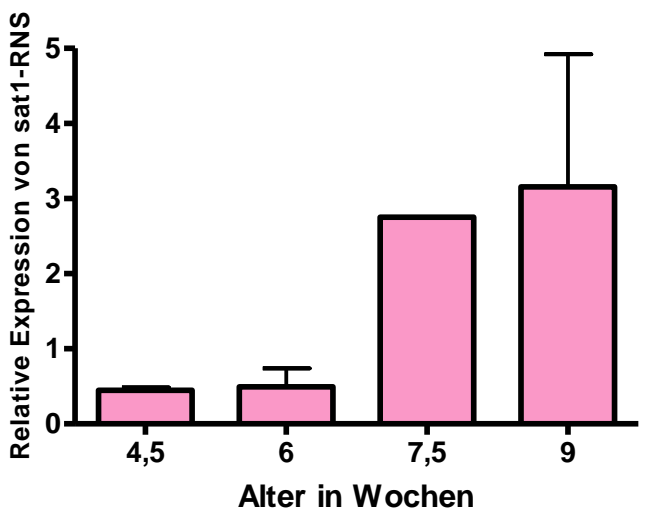

Abbildung 24: Relative Expression von NaS1-RNS in den Nieren von weiblichen a) $\mathrm{COL}_{4 \mathrm{~A}} 3^{+/+}$und b) $\mathrm{COL}_{4 \mathrm{A3}} 3^{-/-}$-Mäusen und sat1-RNS in den Nieren von weiblichen c) $\mathrm{COL}_{4 \mathrm{~A}} 3^{+/+}$- und d) $\mathrm{COL}_{4 \mathrm{~A}}{ }^{-/-}$-Mäusen in Abhängigkeit vom Alter.

3.2.7 Geschlechtsabhängige RNS-Expression von NaS1 und sat1 in den Nieren von COL4A3 $3^{++}$- und COL4A3 $3^{-/-}$-Mäusen

Vergleicht man die RNS-Konzentration für NaS1 von weiblichen und männlichen 7,5 Wochen alten COL4A3 $3^{+/+}-$Mäusen ist, wie auch bei den Mäusen des NMRIStammes, zu erkennen, dass Männchen signifikant $(p<0,01)$ mehr NaS1-RNS exprimieren als Weibchen. Tendenziell ist dies auch bei den anderen Altersgruppen zu beobachten (siehe Abbildung 25). 


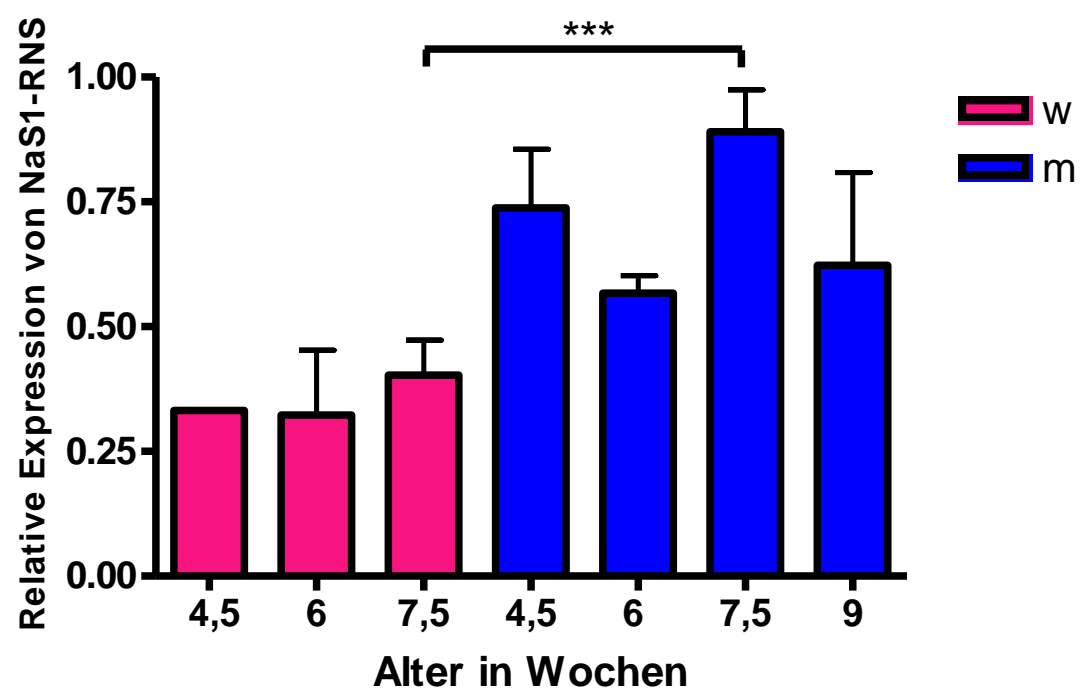

Abbildung 25: Relative Expression von NaS1-RNS in den Nieren von weiblichen (w) und männlichen (m) $\mathrm{COL} 4 \mathrm{~A}^{+/+}$-Mäusen.

Für die Expression von sat1 bei gesunden Tieren kann keine Aussage hinsichtlich signifikanter Unterschiede im Geschlechtervergleich gemacht werden. Für erkrankte Tiere ist weder für NaS1 noch für sat1 eine Signifikanz im Geschlechtervergleich erkennbar (siehe Abbildung 26).

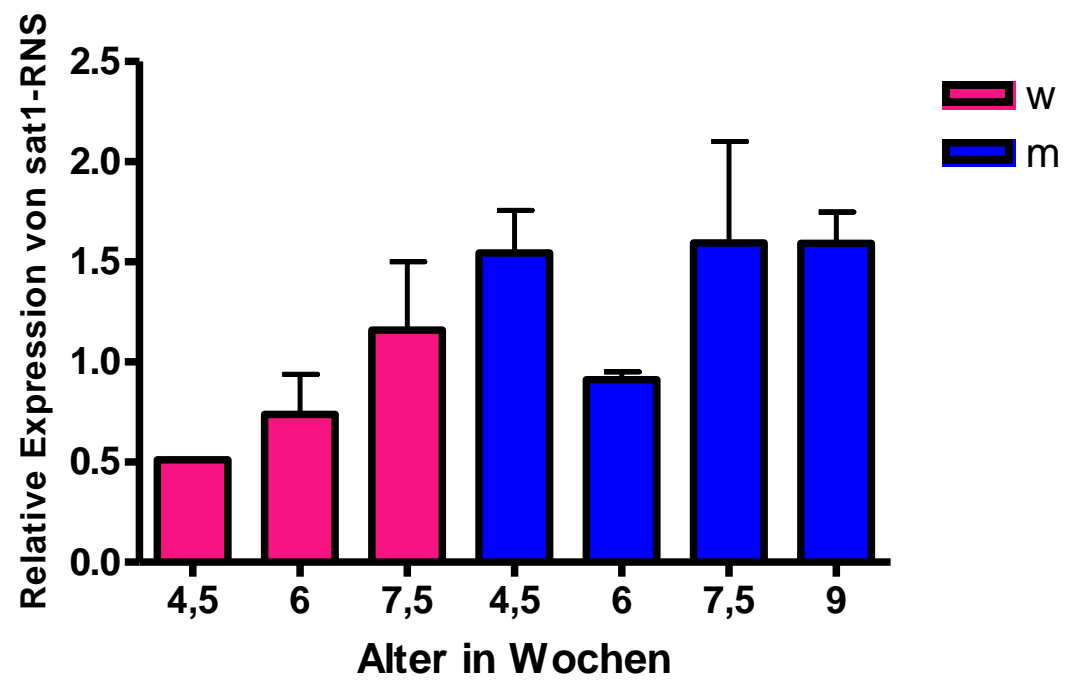

Abbildung 26: Expression von sat1-RNS in den Nieren von weiblichen (w) und männlichen (m) COL4A3 ${ }^{+/+}$-Mäusen. 
3.2.8 Expression von NaS1- und sat1-RNS in den Nieren von männlichen $\mathrm{COL}_{4} \mathrm{A3}^{\mathrm{t}}{ }^{+}$- im Vergleich zu COL4A3 ${ }^{-/}$-Mäusen

Vergleicht man die Expression der NaS1-RNS von männlichen gesunden $\mathrm{COL}_{4 \mathrm{~A}} 3^{+/+}$-Mäusen mit der von männlichen $\mathrm{COL} 4 \mathrm{~A} 3^{-/-}$-Tieren, zeigt sich eine deutlich höhere Konzentration bei den $\mathrm{COL} 4 \mathrm{~A} 3^{+/+}$-Tieren. Signifikant ist dieser Unterschied bei 4,5 Wochen $(p<0,05), 6$ Wochen $(p<0,001)$ und 7,5 Wochen $(p<$ $0,05)$. Auch bei den 9 Wochen alten Tieren ist eine deutliche Tendenz zu erkennen (siehe Abbildung 27).

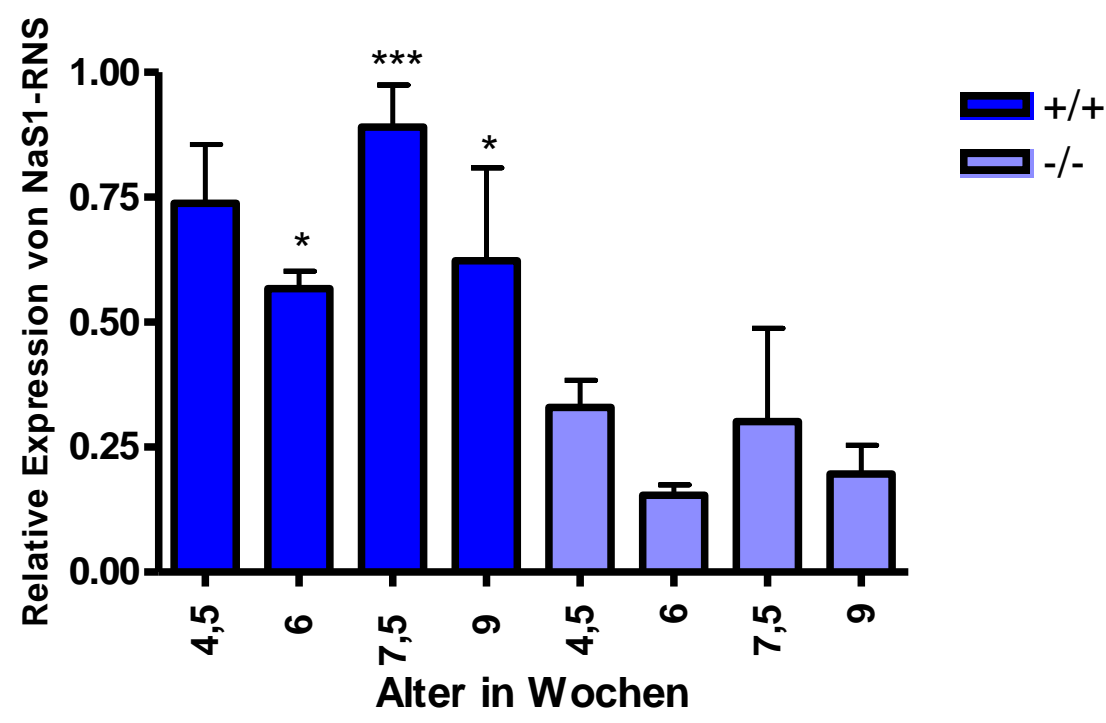

Abbildung 27: Relative Expression von NaS1-RNS in den Nieren von männlichen COL4A3 ${ }^{+/+}$- im Vergleich zu COL4A3 ${ }^{-/}$-Mäusen.

Für sat1 zeigen sich keine Signifikanzen beim Vergleich von gesunden und kranken Tieren. Da die Expression nicht verändert scheint, wurde auf eine entsprechende Abbildung verzichtet.

3.2.9 Expression von NaS1- und sat1-RNS in den Nieren von weiblichen $\mathrm{COL}_{4} \mathrm{A3}^{+/+}$- im Vergleich zu COL4A3 ${ }^{-/}$-Mäusen

Die Expression von NaS1-RNS scheint bei weiblichen COL4A3 ${ }^{+/+}$-Tieren höher zu sein, als bei $\mathrm{COL} 4 \mathrm{~A} 3^{-/}$, es sind jedoch keine Signifikanzen feststellbar (siehe Abbildung 28). 


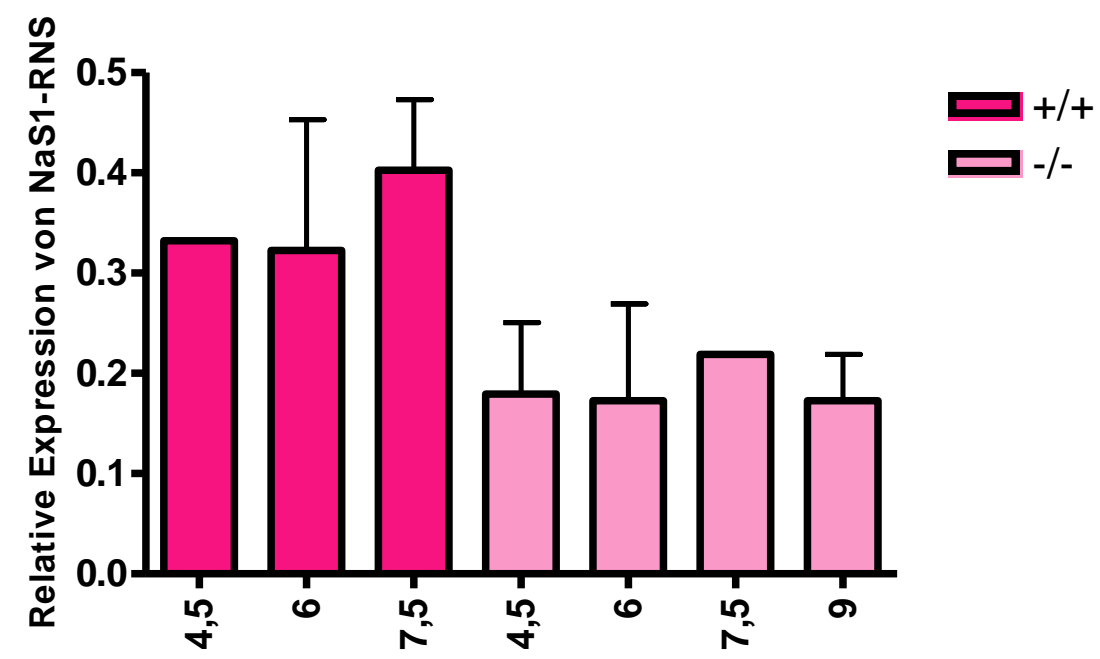

Alter in Wochen

Abbildung 28: Relative Expression von NaS1-RNS in den Nieren von weiblichen $\mathrm{COL} 4 \mathrm{A3}^{+/+}$- im Vergleich zu COL4A3 ${ }^{-/-}$-Mäusen.

Der sat1-RNS-Gehalt scheint bei COL4A3 ${ }^{-/}$-Tieren ab 7,5 Wochen stark anzusteigen. Dieses Phänomen ist bei gesunden Tieren nicht zu erkennen (siehe Abbildung 29).

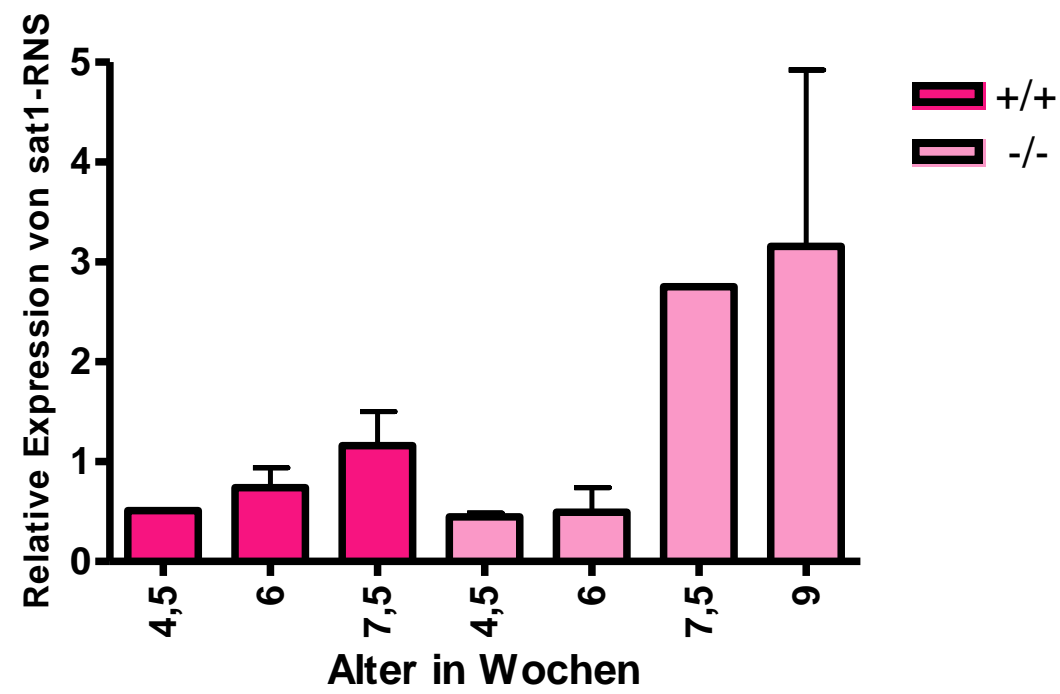

Abbildung 29: Relative Expression von sat1-RNS in den Nieren von $\mathrm{COL}_{4} \mathrm{A3}^{+/+}$im Vergleich zu COL4A3 ${ }^{-1-}$-Mäusen. 


\subsubsection{Expression von NaS1- und sat1-RNS in den Nieren von NMRI- und SvJ/129-Mäusen}

Ein Vergleich der RNS-Expression zwischen Mäusen unterschiedlicher Stämme des gleichen Alters (7,5 Wochen alte NMRI- und SvJ/129-Mäuse) ergab folgende Resultate (siehe Abbildung 30).

a)

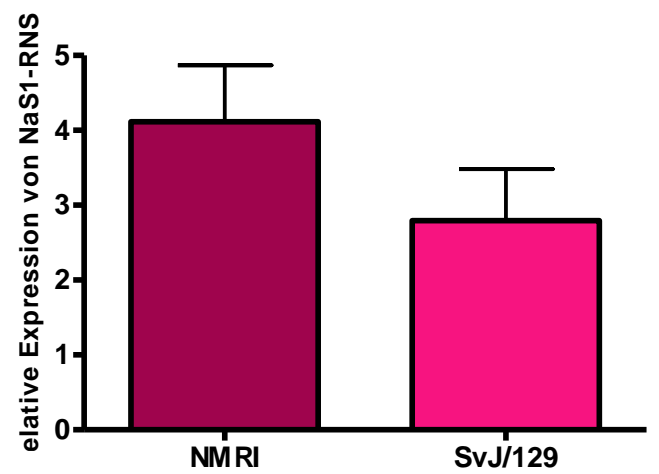

c)

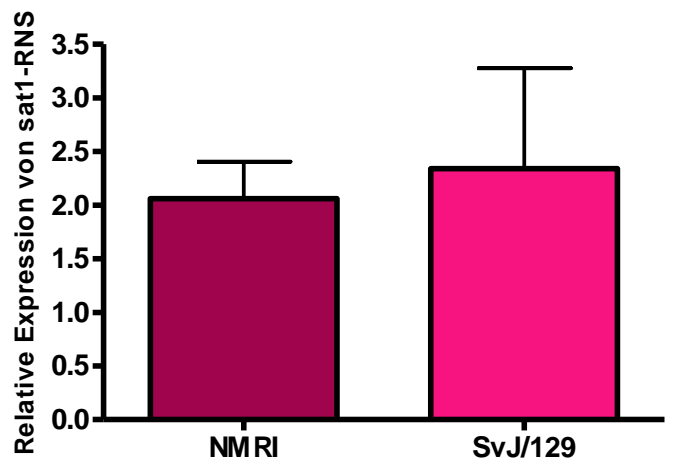

b)

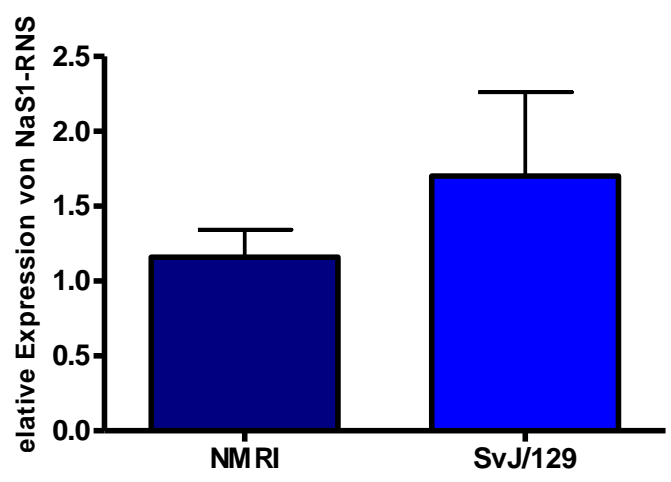

d)

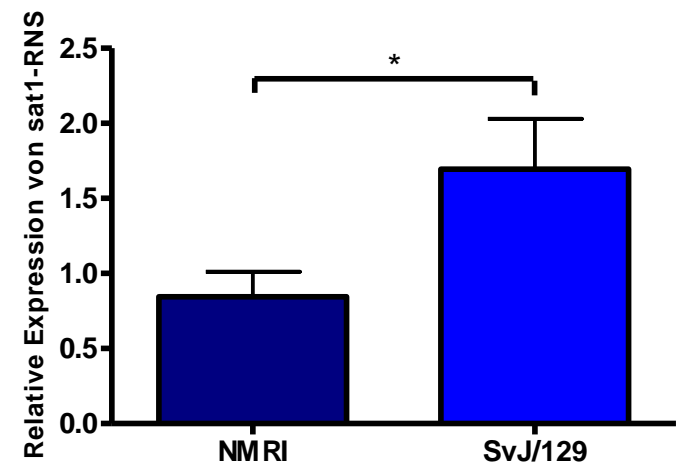

Abbildung 30: Relative Expression von RNS bei NMRI- im Vergleich zu SvJ/129Mäusen. NaS1-RNS in den Nieren von a) weiblichen und b) männlichen und sat1-RNS in den Nieren von c) weiblichen und d) männlichen Tieren.

Die Ergebnisse belegen eindeutig, dass männliche Tiere des Stammes SvJ/129 deutlich mehr sat1-RNS besitzen als Vergleichstiere des Stammes NMRI.

\subsection{Untersuchung des sat1 auf Proteinebene}

\subsubsection{Testung des polyklonalen anti-sat1-Antikörpers an Nieren und Leber von Mäusen und Ratten}

Die immunhistochemische Färbung von Nieren und Leber sollte sowohl an NMRIMäusen als auch an SvJ/129-Mäusen angewendet werden. Bei beiden Tierstämmen war mittels real-time PCR RNS für NaS1 und sat1 nachgewiesen worden. Als anti- 
sat1-Antikörper wurde zunächst ein polyklonales anti-Maus IgG verwendet. Dieser Ak wurde zuerst zur Evaluation an Nieren und Leber von NMRI-Mäusen getestet. In Mäusenieren befindet sich sat1 an der basolateralen Membran der proximalen Tubuluszellen (Lee et al., 2003).

Für die weiteren Untersuchungen wurde ein käuflich erworbener anti-sat1-Ak von Santa Cruz verwendet, der nach Angaben des Herstellers gegen bestimmte Epitope des sat1 der Maus gerichtet ist. Da weitere Angaben zu dem Ak fehlten, sollte er zunächst evaluiert werden, d.h. mit inm sollte die schon aus der Arbeit von Lee et al. (2003) bekannte Lokalisation des sat1 in den Nieren von Mäusen überprüft werden. Sowohl in Schnitten aus den Nieren der NMRI- als auch aus denen der Alport-Maus konnte in unseren Händen keine sat1-spezifische Färbung nachgewiesen werden (Daten nicht gezeigt).

Da die Sequenzhomologie zwischen dem sat1 der Maus und der Ratte hoch ist, wurde eine zweite Evaluation des Ak an Schnitten aus der Nierenrinde und der Leber von erwachsenen Wistar-Ratten vorgenommen. Bei dieser Spezies wurde der sat1 mit dem von Karniski generierten anti-sat1-Ak in der basolateralen Membran der proximalen Tubuluszellen (Karniski et al., 1998) und der sinusoidalen Membran von Hepatozyten (Brzica et al., 2009a) nachgewiesen.

Mit dem polyklonalen Ak von Santa Cruz konnte allerdings keine Färbung und damit kein Nachweis des sat1 in der basolateralen Membran der Tubuli erbracht werden. Der Ak färbte viele Strukturen innerhalb der Zelle an, wobei die Zellkerne allerdings ausgespart wurden (siehe Abbildung 31). Diese angefärbten, teilweise wolkigen Strukturen beschränken sich auf den submembranären Bereich der basolateralen Membran. Die basolaterale Membran ist als feine, ungefärbte Linie zu erkennen. Die luminale Membran ist ebenfalls erkennbar. Sie ist schwach angefärbt. Unter der luminalen, apikalen Membran sind im Zytosol ebenfalls keine Färbungen auszumachen. Während in Abbildung 31 die Schnitte mit Citrat bei $\mathrm{pH} 3,0$ vorbehandelt waren, zeigt die Vorbehandlung mit Citrat bei $\mathrm{pH}$ 6,0 folgendes Bild (Abbildung 32). Die Veränderungen des pH-Wertes veränderte auch das Muster angefärbter Zellbereiche. Die Färbung ist über die gesamte Zelle unter Aussparung der Zellkerne verteilt. Im Gegensatz zu Abbildung 31 sind allerdings die apikalen Bereiche stärker angefärbt. Basolaterale und luminale Membran sind deutlich zu erkennen, sind aber nicht angefärbt. Das Glomerulus und umgebende Strukturen 
reagierenten nicht mit dem Ak. Die Tatsache, dass mit demselben Ak bei unterschiedlichen Behandlungen verschiedenartige Anfärbungen erzielt wurden, spricht für einen unspezifischen Nachweis.

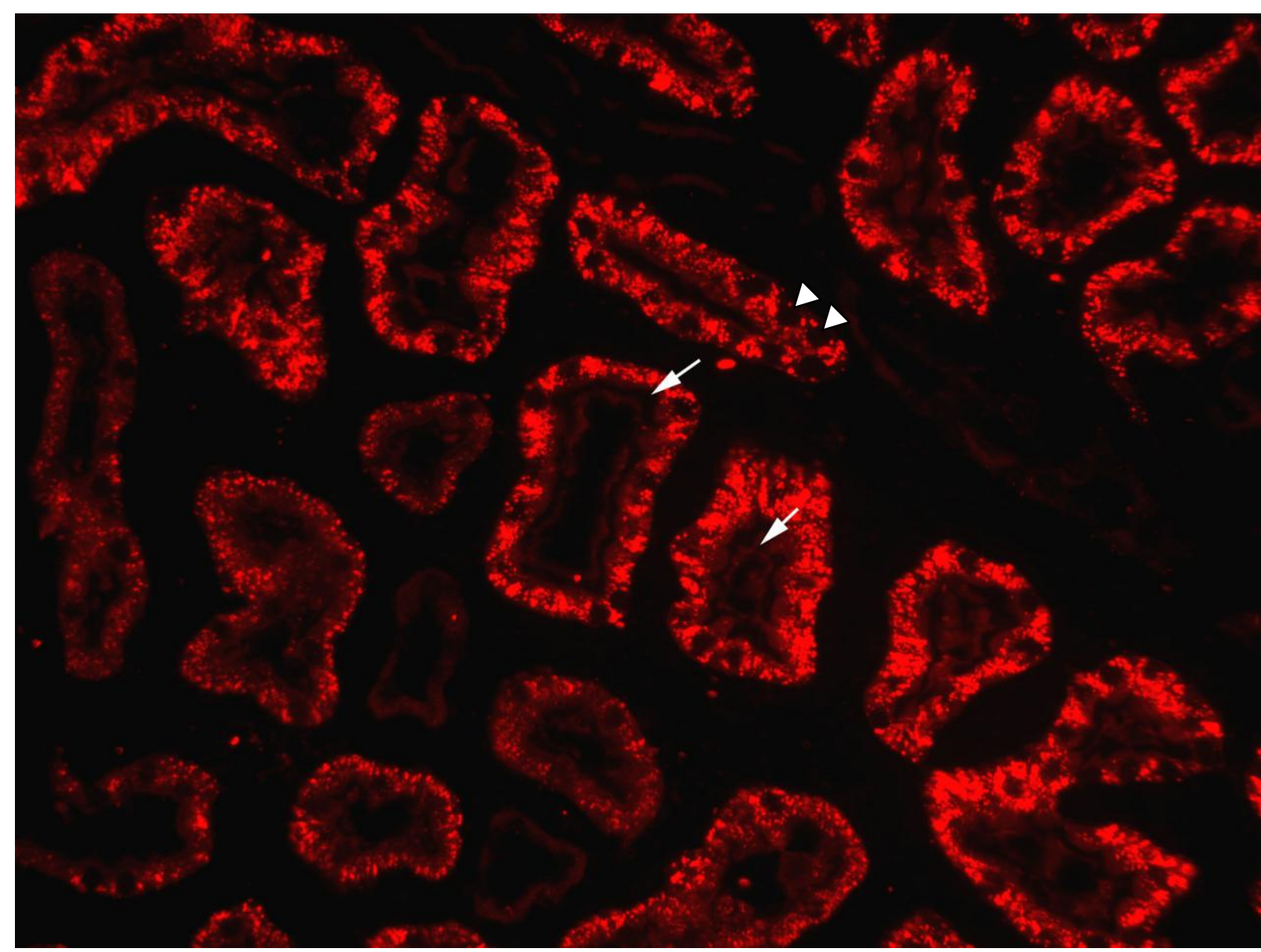

Abbildung 31: Immunhistochemische Färbung mit polyklonalem anti-sat1-Ak in der Nierenrinde von Ratten mit der Citratmethode bei pH3: Schwache apikale Färbung (Pfeile) der Tubuluszellen im ersten und zweiten Segment. Keine Färbung von Zellkernen (Pfeilköpfe). Erläuterungen im Text. 


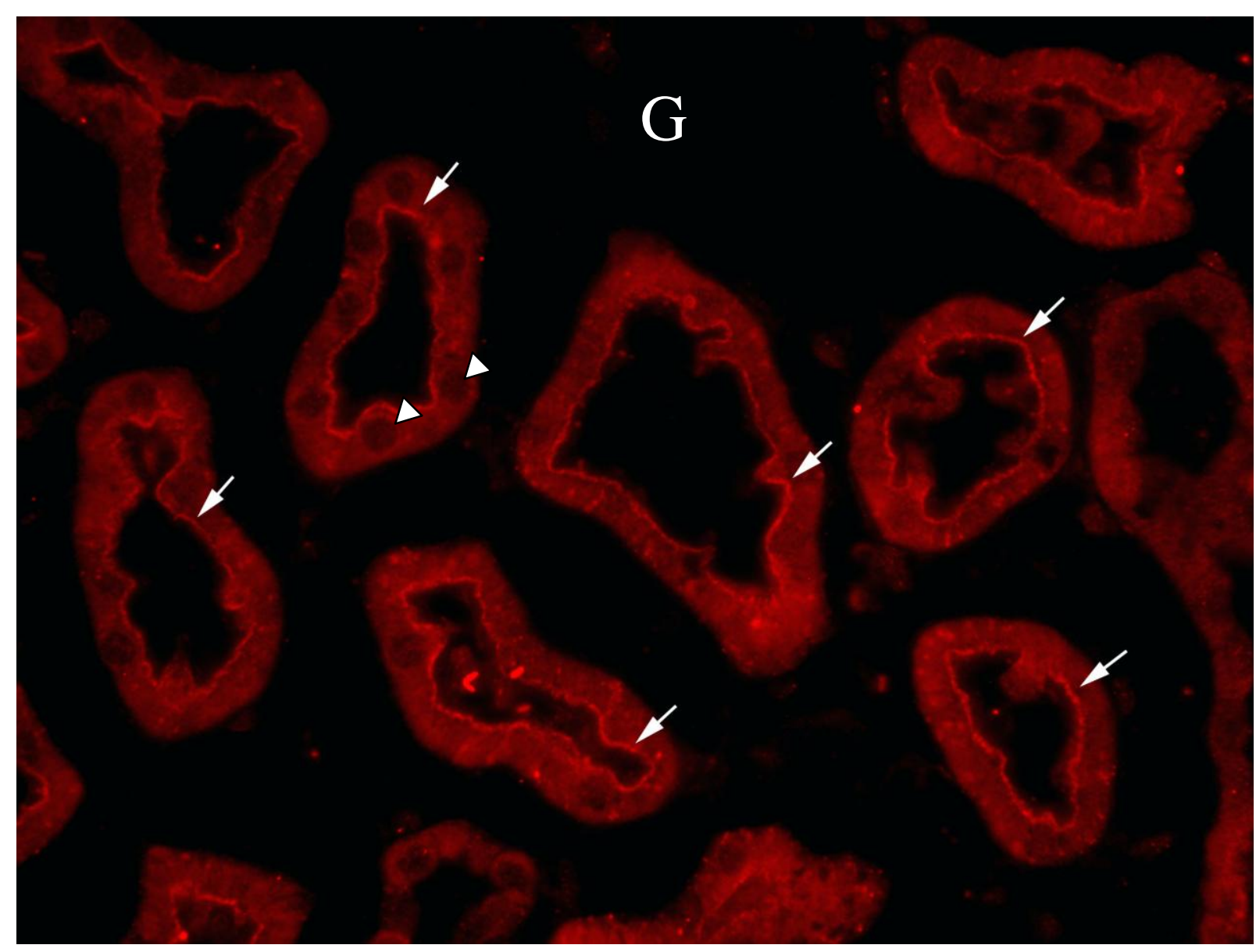

Abbildung 32: Immunhistochemische Färbung mit polyklonalem anti-sat1-Ak in der Nierenrinde von Ratten mit der Citratmethode bei pH6: Deutliche apikale bis subapikale Färbung der Tubuluszellen (Pfeile). Keine Färbung von Glomerulus (G) und Zellkernen (Pfeilköpfe). Erläuterungen im Text.

\subsubsection{Testung des polyklonalen anti-sat1-Antikörpers an Rattengewebe}

Da die immunhistochemischen Detektionen von sat1 mit dem polyklonalen Ak (Santa Cruz) weder bei Mäusen noch bei Ratten eindeutige Ergebnisse lieferte, wurde zusätzlich eine Proteindetektion von sat1 mittels Western Blot durchgeführt. Die Western-Blot-Analyse mit dem polyklonalem Antikörper gegen sat1 an Rattengewebe lieferte folgende Befunde (siehe Abbildung 33): In Nierengewebe wurde sowohl in An- als auch in Abwesenheit von B-Mercaptoethanol $( \pm \beta)$ Banden mit einem Molekulargewicht von $50 \mathrm{kDa}$ detektiert. In Anwesenheit von B-Mercaptoethanol konnte zusätzlich noch eine sehr schwache Bande bei 35 kDa nachgewiesen werden. In Lebergewebe konnte unter ß-Mercaptoethanol ausschließlich diese 35 kDa-Bande gefunden werden. 

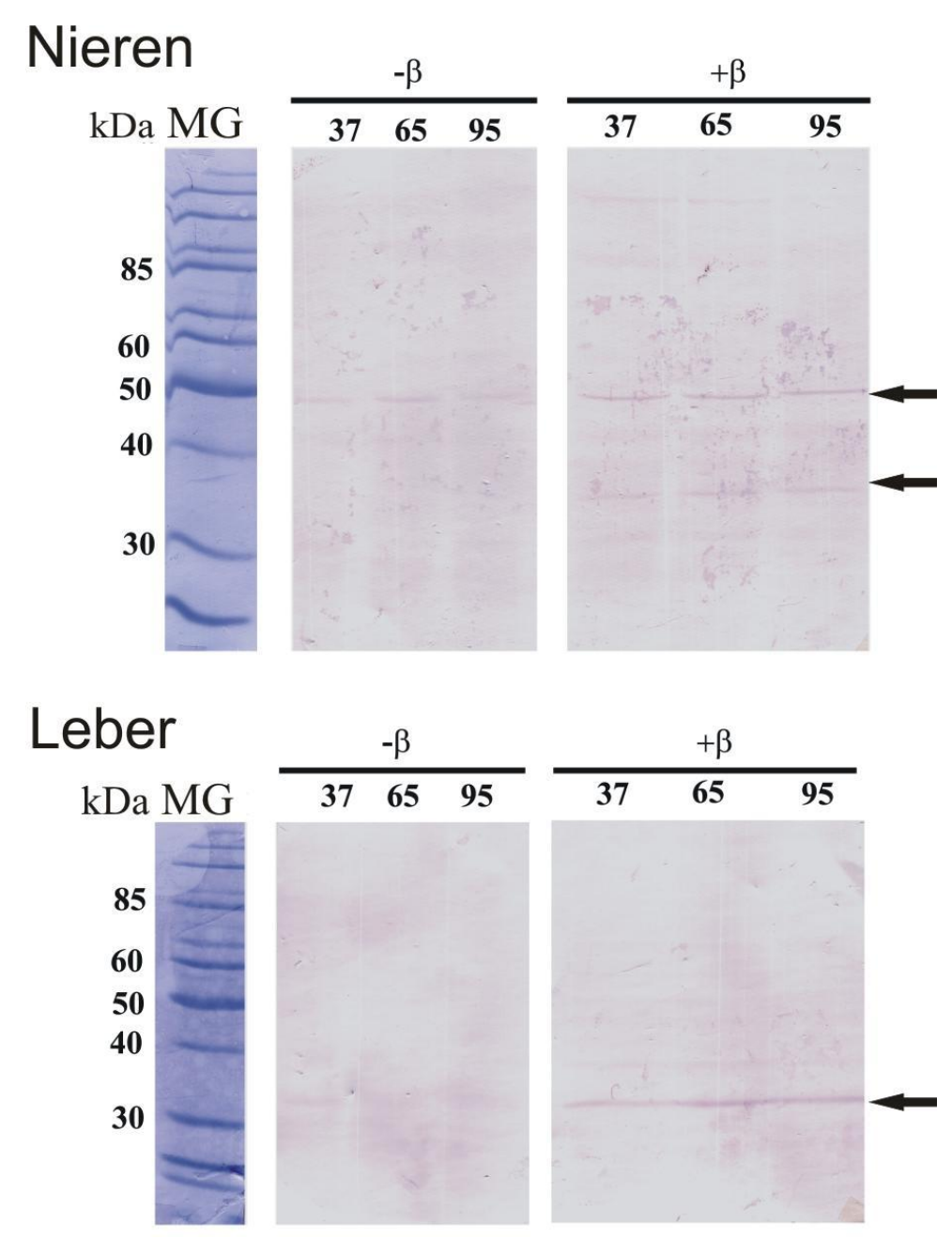

Abbildung 33: Western-Blot-Analyse an Nieren und Leber von Ratten mit polyklonalem anti-sat1-Ak mit $(+B)$ und ohne (-B) B-MecaptoethanolVorbehandlung bei 37,65 und $95^{\circ} \mathrm{C}$ denaturiert. MG, Molekulargewicht in kDa.

\subsubsection{Testung des monoklonalen anti-sat1-Antikörpers an Nieren und Leber von Mäusen}

\subsubsection{Spezifische immunhistochemische Färbungen von sat1 in Nieren- und Lebergewebe von Mäusen}

Da der polyklonale Ak von Santa Cruz weder an Gewebe von Mäusen noch von Ratten sat1-spezifische Färbungen lieferte und auch die Proteindetektion mittels Western Blot keine Spezifität zeigte, wurde eine weitere Färbung der Mäusegewebe mit dem monoklonalen Antikörper (Karniski et al., 1998), den bereits Karniski und Brzica an Rattengewebe verwendet hatten, durchgeführt. Die Vorbehandlung der Schnitte mit der Citratpuffermethode bei pH 6 ergab eine Färbung der basolateralen Membran von proximalen Tubuli (siehe Abbildung 34), sowie der sinusoidalen Membran der Hepatozyten in Lebern von NMRI-Mäusen (siehe Abbildung 38). Die alleinige Inkubation mit dem sekundären Ak ergab keine spezifische Färbung (siehe 
Abbildung 37 und Abbildung 39), sodass davon ausgegangen werden kann, dass die Färbung mit dem monoklonalen Primärantikörper spezifisch für das sat1-Protein ist.

\subsubsection{Geschlechtsabhängige Proteinexpression von sat1 in den Nieren von NMRI-Mäusen}

Im Nierenkortex ist eine deutliche Färbung der basolaterlaen Tubulusmembranen bei beiden Geschlechtern zu erkennen. Die Färbung fällt bei Weibchen (siehe Abbildung $34 \mathrm{a}$ und b) stärker aus, als bei den gleichaltrigen Männchen (siehe Abbildung $34 \mathrm{c}$ und d).
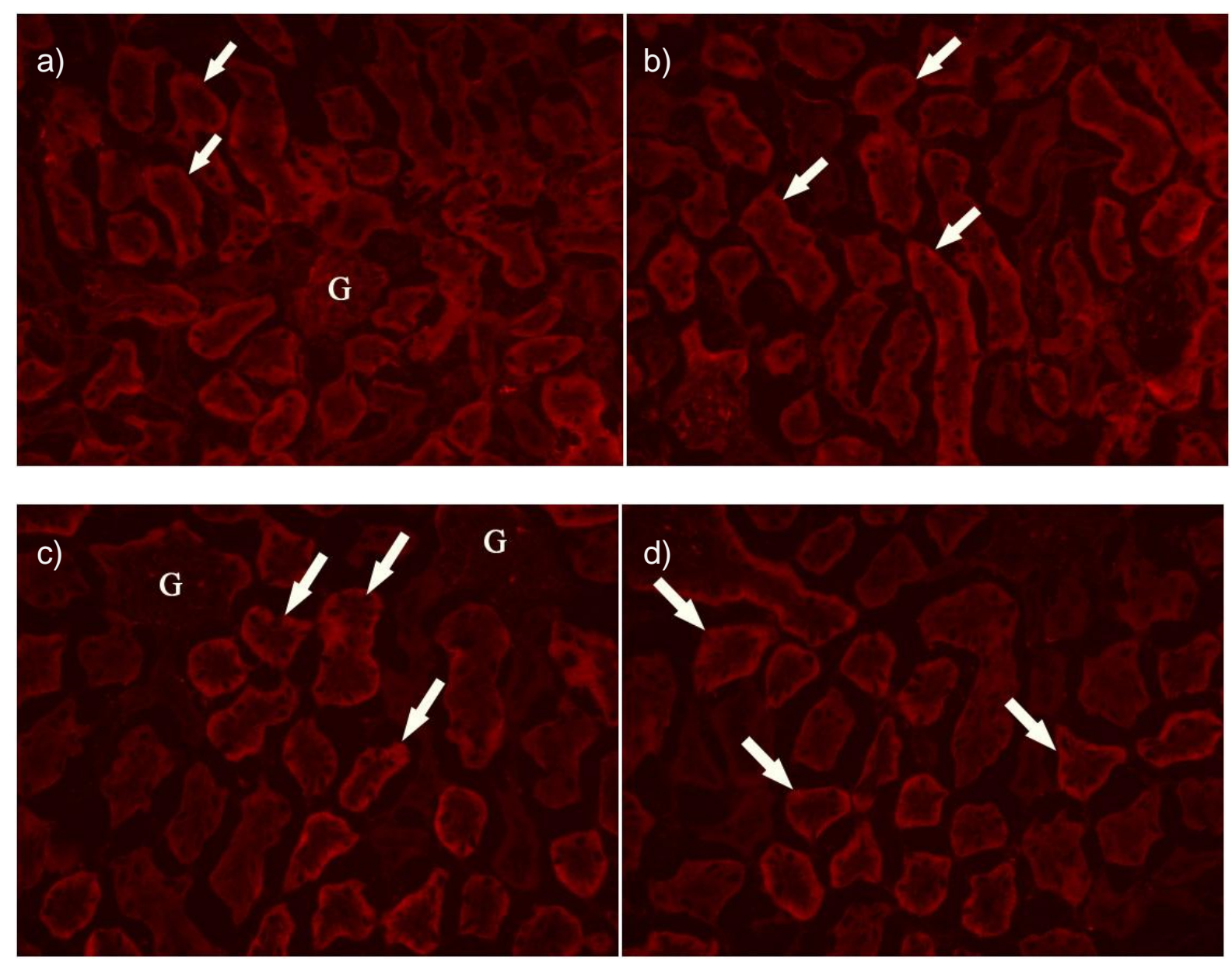

Abbildung 34: Immunhistochemische Färbung mit monoklonalem Ak gegen sat1 in der Nierenrinde von NMRI-Mäusen mit der Citratmethode bei pH6: Spezifische Färbung von sat1 an der basolateralen Membran von proximalen Tubulszellen (Pfeile). Keine Färbung des Glomerulus (G). Stärkere Färbung bei weiblichen Tieren ( $a$ und $b$ ), als bei männlichen Tieren (c und d).

In den Schnitten des äußeren Markstreifen ist sat1, wie zu erwarten, kaum markiert. Die Tubuli, die eine Färbung der basolateralen Membran tragen, sind vermutlich Anschnitte der proximalen Anteile. Die stark fluoreszierenden extratubulären 
Färbungen sind unspezifisch (siehe Abbildung 35). Der Vergleich von Schnitten weiblicher und männlicher Tiere erbringt keine geschlechtsspezifischen Unterschiede (Vergleiche Abbildung 35 a und $b$ mit $c$ und $d$ ).
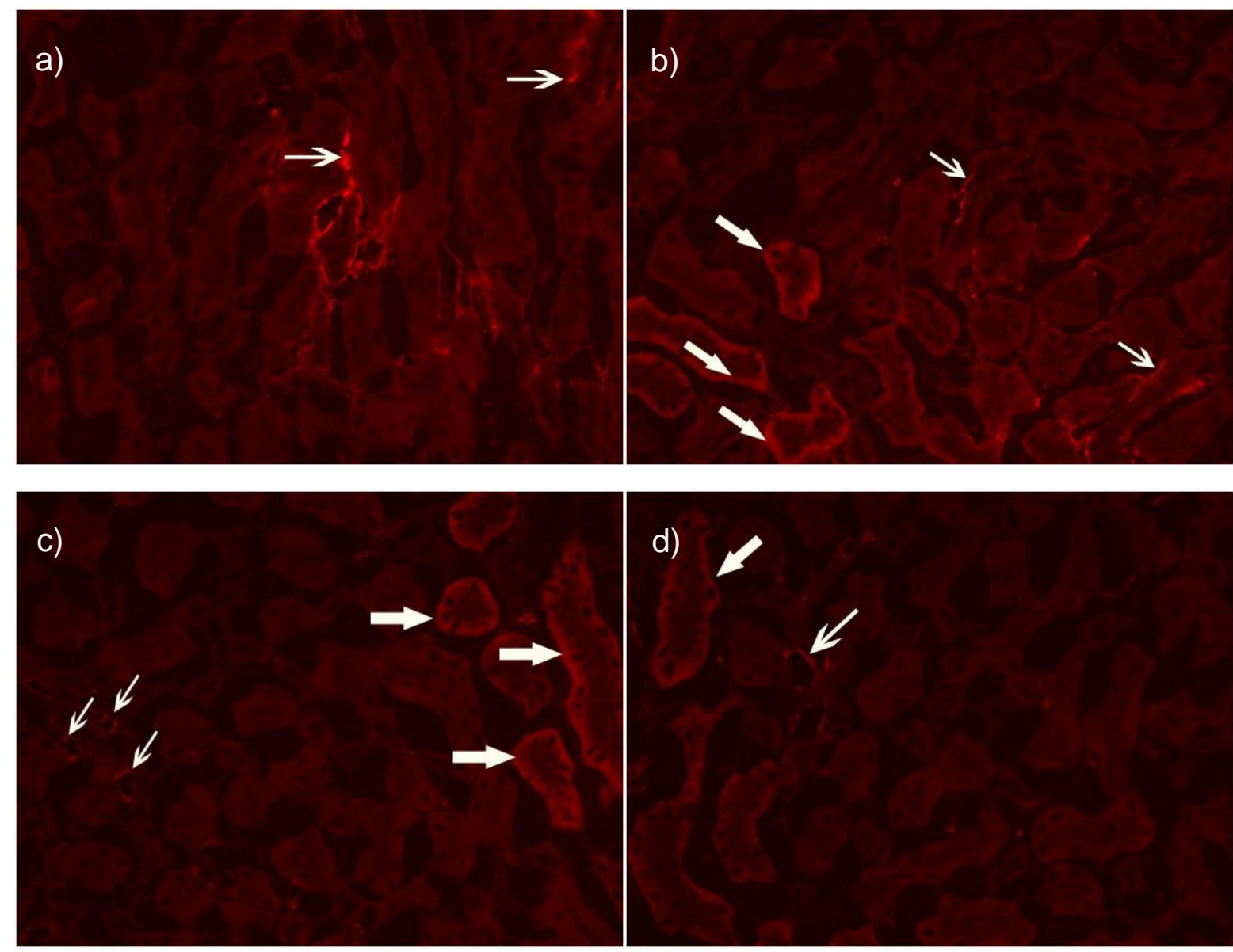

Abbildung 35: Immunhistochemische Färbung mit monoklonalem Ak gegen sat1 im äußeren Markstreifen der Nieren von NMRI-Mäusen mit der Citratmethode bei pH6: Anschnitte der proximalen Tubulusanteile mit sat1Färbung an der basolateralen Membran (Pfeile mit geschlossenem Pfeilkopf -). Unspezifische interstitielle Färbung (Pfeile mit offenem Pfeilkopf $>$ ). Kein Unterschied in der Intensität der Färbung zwischen weiblichen ( $a$ und $b$ ) und männlichen (c und d) Tieren.

Die Schnitte der Papille, in der sat1 nicht vertreten ist, zeigen keine spezifische Färbung. Zwischen den Färbungen bei weiblichen und männlichen Tieren ist kein Unterschied auszumachen (vergleiche Abbildung 36 a mit b). 


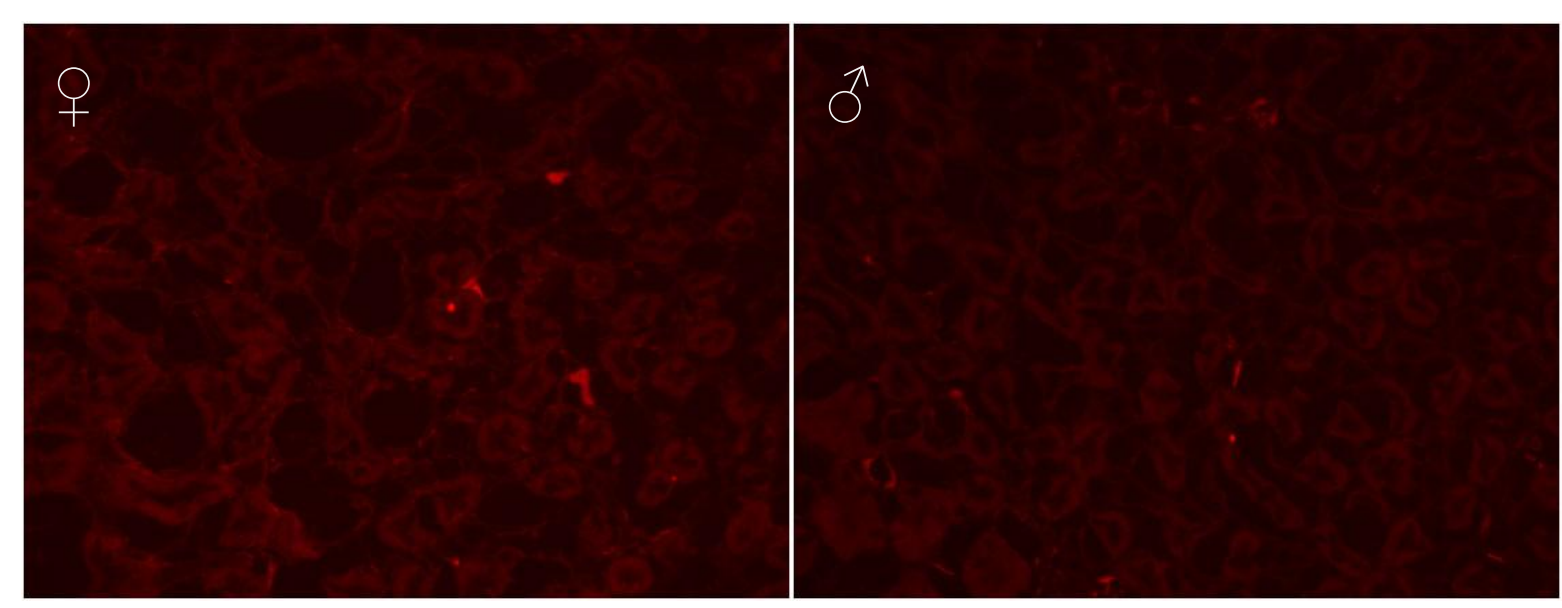

Abbildung 36: Immunhistochemische Färbung der Nierenpapille von NMRIMäusen mit monoklonalem Ak gegen sat1 mit der Citratmethode bei pH6: Spezifische Färbung weder bei weiblichen $(+)$ noch bei männlichen $(\hat{)})$ Tieren erkennbar.

Auch Schnitte der Nieren von männlichen NMRI-Mäusen, die zur Kontrolle alleine mit dem sekundären Ak inkubiert wurden, zeigen keine spezifische Färbung (siehe Abbildung 37).

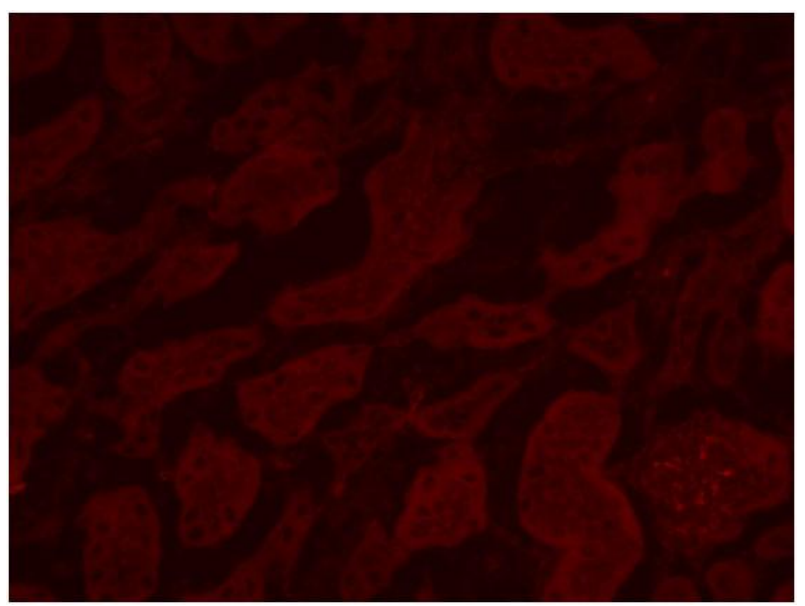

Abbildung 37: Immunhistochemische Färbung ohne Verwendung des monoklonalen primären Ak gegen sat1 mit der Citratmethode bei pH6: Keine spezifischen Markierungen von sat1 in der Nierenrinde von männlichen NMRIMäusen bei alleiniger Inkubation mit dem sekundären Ak.

3.3.3.3 Geschlechtsabhängige Proteinexpression von sat1 in der Leber von NMRI-Mäusen

In Leberschnitten konnte eine spezifische Färbung der sinusoidalen Membran von Hepatozyten bei weiblichen und männlichen NMRI-Mäusen erlangt werden. Dabei 
wurde bei weiblichen Tieren mehr sat1-Protein detektiert als bei männlichen Tieren (vergleiche Abbildung 38 a und $b$ mit $c$ und $d$ ).
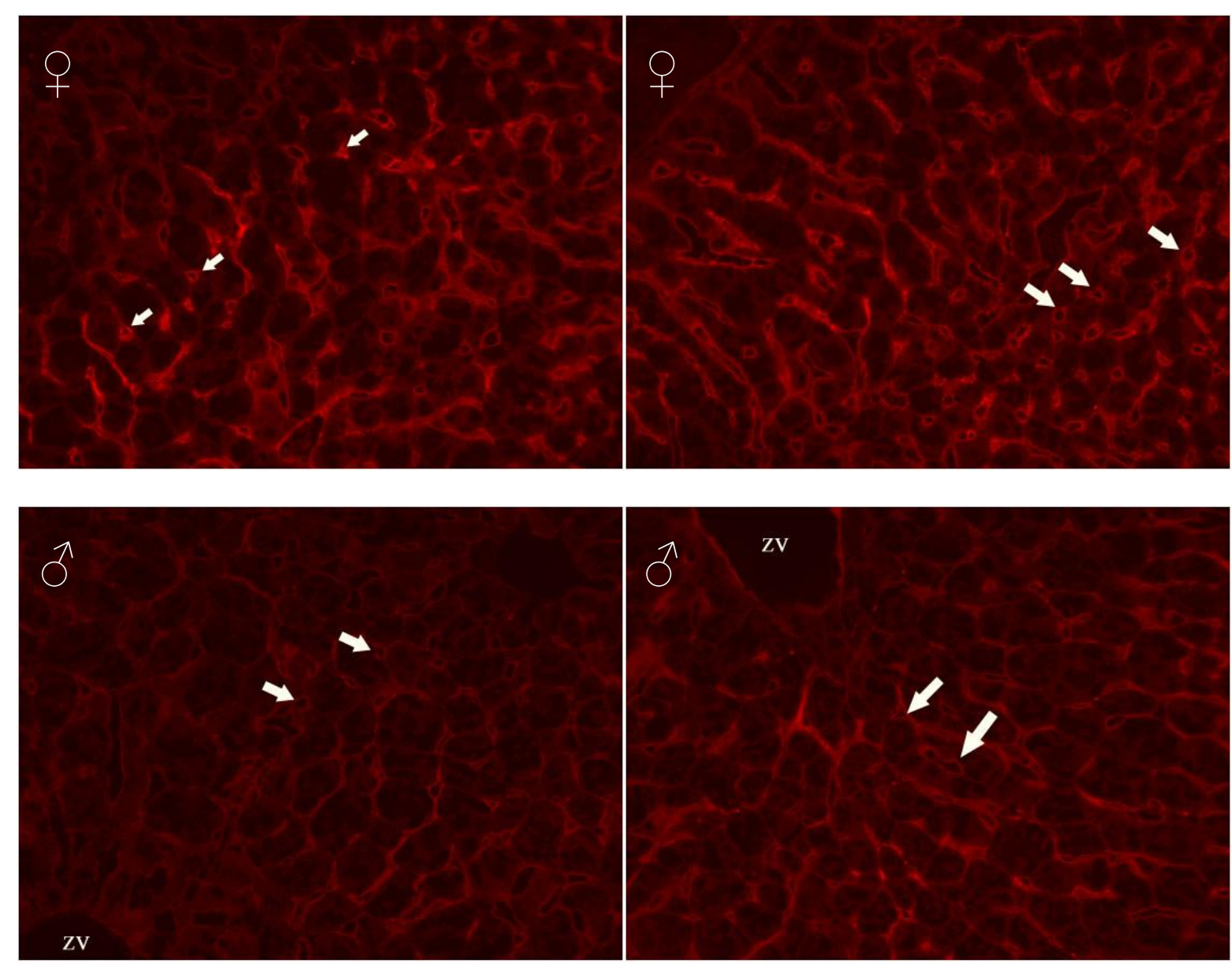

Abbildung 38: Immunhistochemische Färbung der Leber von NMRI-Mäusen mit monoklonalem Ak gegen sat1 mit der Citratmethode bei pH6: Spezifische sat1Färbung der sinusoidalen Membran der Hepatozyten (Pfeile). Deutlichere Färbung bei weiblichen Tieren $(+)$ als bei männlichen Tieren $\left({ }^{\lambda}\right) . Z V$, Zentralvene.

Die alleinige Inkubation der Leberschnitte von männlichen NMRI-Mäusen mit dem sekundären Ak ergab keine spezifische Färbung (siehe Abbildung 39). 


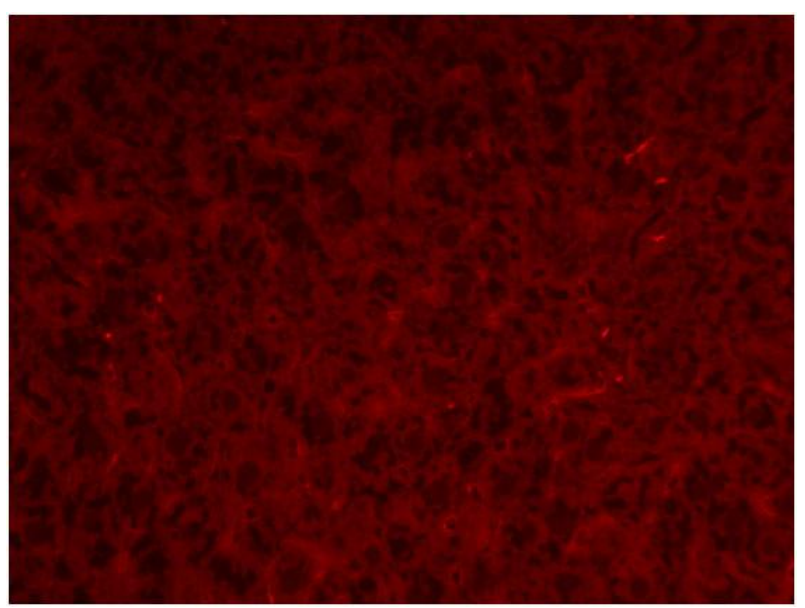

Abbildung 39: Immunhistochemische Färbung ohne Verwendung des monoklonalem primären Ak gegen sat1 mit der Citratmethode bei pH6: Keine spezifischen Markierungen von sat1 in der Leber von männlichen NMRIMäusen bei alleiniger Inkubation mit dem sekundären Ak.

\subsubsection{Proteinexpression von sat1 in den Nieren von $\mathrm{COL}_{4} \mathrm{A3}^{+/+}$- und COL4A3 $^{-1-}$ - Weibchen}

Es wurden Schnitte aus Nierengewebe von $\mathrm{COL} 4 \mathrm{~A}^{+/+}$- und $\mathrm{COL} 4 \mathrm{~A}^{-/-}$-Weibchen und -Männchen angefertigt. Alle Gewebeschnitte zeigen eine spezifische Färbung der basolateralen Tubulusmembran. Die Glomeruli der Nieren sind nicht angefärbt (siehe Abbildung 40).

Beim Vergleich der Schnitte von weiblichen COL4A3 ${ }^{-/-}$und weiblichen COL4A3 ${ }^{+/+}$ Mäusen ist kein Unterschied in der Fluoreszenzstärke zu erkennen (vergleiche Abbildung $40-/$ - und $+/+$ ). 

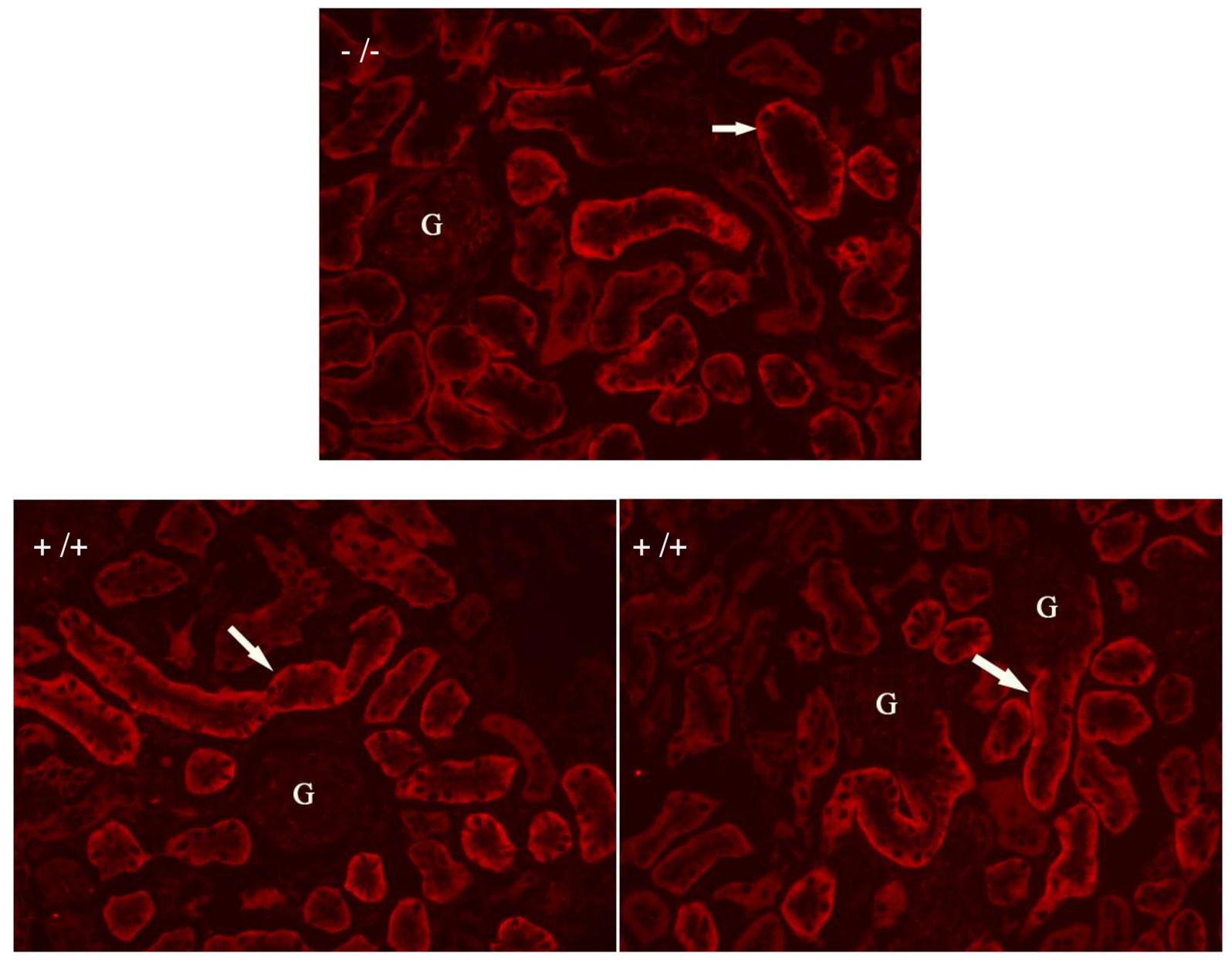

Abbildung 40: Immunhistochemische Färbung mit monoklonalem Ak gegen sat1 in der Nierenrinde von weiblichen Mäusen mit der Citratmethode bei pH6: Spezifische Färbung von sat1 an der basolateralen Membran von proximalen Tubuluszellen (Pfeile). Keine Färbung der Glomeruli (G). Keine signifikant unterschiedliche Färbung von sat1 zwischen weiblichen $\operatorname{COL}_{4} \mathrm{~A}^{-/-}(-/-)-$und $\mathrm{COL} 4 A 3^{+/+}(+/+)-$Mäusen.

\subsubsection{Proteinexpression von sat1 in den Nieren von COL4A3 ${ }^{-/-}$-Weibchen und -Männchen}

Beim Vergleich der Schnitte von COL4A3 ${ }^{-/-}$-Weibchen und -Männchen ist bei den weiblichen Tieren eine tendenziell schwächere Färbung zu erkennen (vergleiche Abbildung $41+$ und $\precsim$ ). 


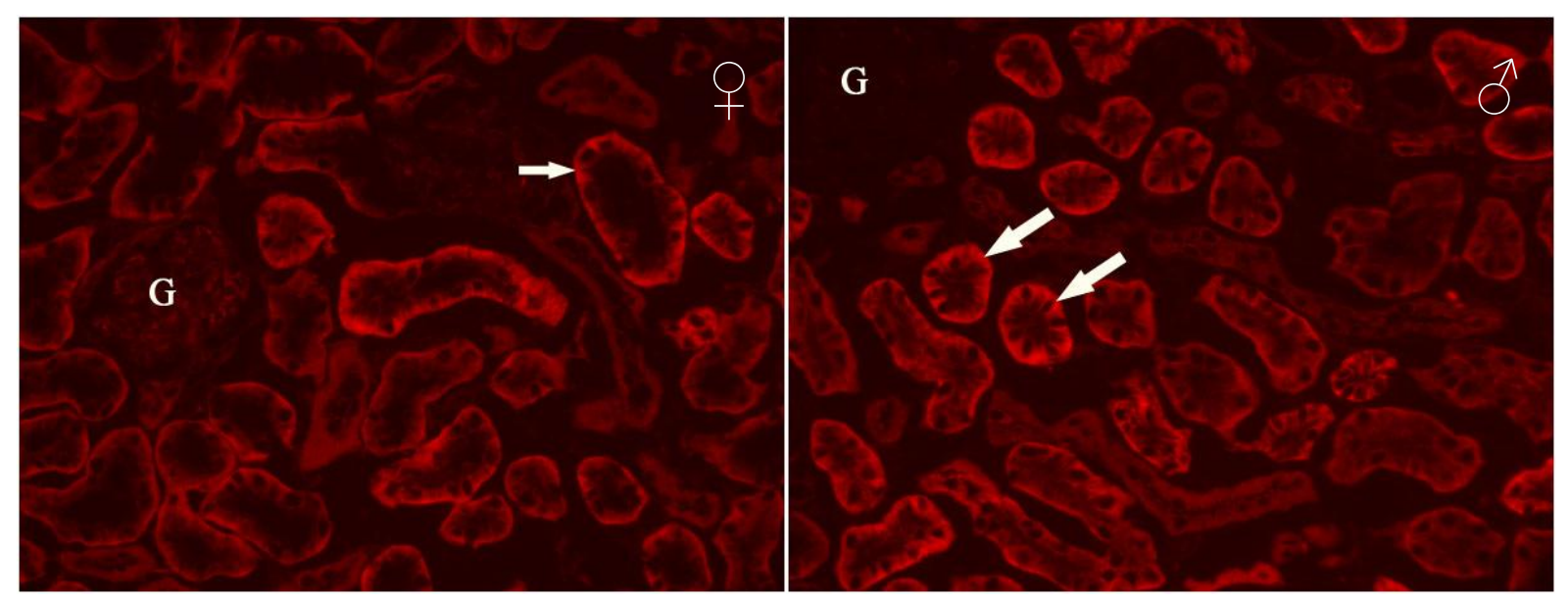

Abbildung 41: Immunhistochemische Färbung mit monoklonalem Ak gegen sat1 in der Nierenrinde von COL4A3 ${ }^{-/-}$-Mäusen mit der Citratmethode bei pH6: Spezifische Färbung von sat1 an der basolateralen Membran von proximalen Tubulszellen (Pfeile). Keine Färbung des Glomerulus (G). Nach der immunhistochemischen Färbung tendenziell schwächere Expression von sat1Protein bei weiblichen Tieren $(+)$ als bei männlichen Tieren $\left({ }^{\top}\right)$.

\subsubsection{Vergleich der Proteinexpression von sat1 in den Nieren von weiblichen} Mäusen des NMRI- und des SvJ/129-Stammes

Die immunhistochemische Markierung von sat1 mit monoklonalem Antikörper in Nierenrinden von weiblichen Mäusen scheint bei Tieren vom NMRI-Stamm eine stärkere sat1-Proteinexpression zu präsentieren als bei Tieren vom SvJ/129-Stamm (vergleiche Abbildung $42 \mathrm{NMRI}$ mit SvJ/129).

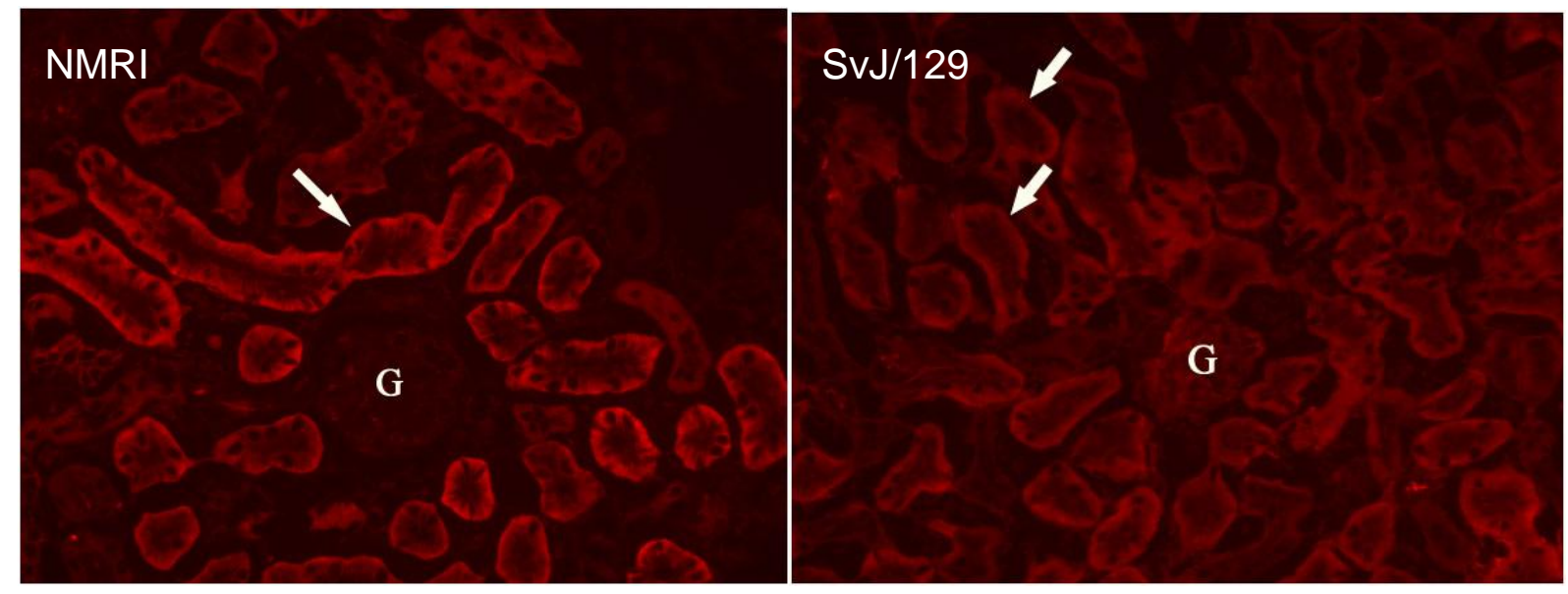

Abbildung 42: Immunhistochemische Färbung mit monoklonalem Ak gegen sat1 in der Nierenrinde von weiblichen Mäusen des Stammes NMRI und SvJ/129 mit der Citratmethode bei pH6: Spezifische Färbung von sat1 an der basolateralen Membran von proximalen Tubulszellen (Pfeile). Keine Färbung der Glomeruli (G). Nach der immunhistochemischen Färbung tendenziell stärkere sat1-Protein-Expression bei Tieren vom NMRI-Stamm als bei Tieren vom SvJ/129-Stamm. 


\section{Diskussion}

\subsection{Diskussion der Methoden}

\subsubsection{Real-time PCR und Immunhistochemie als geeignete Methoden für den Nachweis und die Quantifizierung von NaS1 und sat1}

Im Rahmen dieser Arbeit wurde die Expression von Sulfattransportern auf RNS- und Proteinebene untersucht. Zum einen wurde die RNS des natriumabhängigen Sulfattransporters NaS1 in den Nieren von Mäusen unterschiedlicher Stämme und bei Mäusen, die am Alport-Syndrom litten, quantifiziert. Zum anderen wurde der Sulfat-Anionen-Austauscher sat1 auf RNS- und Proteinebene in Nieren und Leber eben dieser Mäuse untersucht. Zusätzlich wurden einige Versuche zu sat1 auf Proteinebene an Rattengewebe gefertigt. Der Nachweis auf RNS-Ebene erfolgte mittels real-time PCR. Der Nachweis auf Proteinebene geschah an Hand immunhistochemischer Methoden, wobei zwei verschiedene Antikörper gegen das sat1-Protein getestet wurden. Die Anwendung verschiedener Untersuchungsmethoden für den Nachweis und die Quantifizierung der Sulfattransporter auf RNS- und Proteinebene erzeugt Ergebnisse, die in ihrer Wertigkeit als sehr valide eingestuft werden können. Es zeigte sich jedoch auch, dass bei der immunhistochemischen Untersuchung mit Antikörpern verschiedene Schwierigkeiten auftreten können.

\subsubsection{Darstellung der molekularbiologischen Methoden}

Ein Problem bei der Entnahme von Gewebeproben ist der rasch beginnende Abbau von RNS durch Ribonukleasen. RNasen sind sehr stabile und aktive Enzyme, die schwer zu inaktivieren sind und in kurzer Zeit große Mengen an RNS abbauen können. Aus diesem Grund ist die Zeit zwischen Gewebeentnahme und Isolation der RNS eine empfindliche Phase, in der die Zuverlässigkeit quantitativer Genexpressions-Analysedaten und die Integrität der RNS gestört werden kann. Eine zeitliche Orientierung hierfür bieten Studien von Eikmans et al. (2001), die die Integriät und den Abbau von RNS aus menschlichen Nieren unter Autolyse untersuchten. Demnach ist bei Lagerung unterhalb von $4^{\circ} \mathrm{C}$ und ohne RNaseinhibierende Detergenzien bereits nach circa sieben Stunden ein messbarer Abbau von RNS zu verzeichnen. Um den RNS-Abbau möglichst gering zu halten, wurden die Gewebeproben in dieser Arbeit vom Zeitpunkt der Entnahme bis zur RNSIsolation in RNase-inhibierendem RNAlater gelagert. Die Lagerung von 
Nierengewebe in RNAlater bei $-70^{\circ} \mathrm{C}$ gewährleistet nach Untersuchungen von Roosvan Groningen et al. (2004) eine unveränderte RNS-Integrität bis zu einem Zeitraum von mindestens drei Monaten. Selbst nach einer Einlagerung bei $-70^{\circ} \mathrm{C}$ von bis zu 10 Jahren zeigte sich bei Eikmans et al. (2001) keine Degradierung der untersuchten RNS. Um das Risiko des RNS-Abbaus auch während der Pulverisierung der Gewebe gering zu halten, wurden diese Arbeitsschritte in flüssigem Stickstoff bei ca. $-180^{\circ} \mathrm{C}$ durchgeführt. Das pulverisierte Gewebe wurde anschließend in RNS-Abbau hemmenden RNA-Lysis-Buffer gelagert, der, wie die übrigen Reagenzien des SV Total RNA Isolation System-Kits (Promega), RNAse frei war. Um die RNAse-Freiheit des Kits zu gewährleisten, wurden extra hierfür eingerichtete Arbeitsplätze mit RNAse-freiem Arbeitsmaterial genutzt. Mit dem SV-Total-RNA-Isolation-System-Kit wurde die RNS an einer Silicium-Membran isoliert und gereinigt. Der Gebrauch von DNase I verringerte das Risiko der Kontamination der Proben mit DNS. Der Reinheitsgrad der RNS wurde mittels Ratiowerten (Quotient der Absorption bei 260nm / Absorption bei $280 \mathrm{~nm}$ ) überprüft. Die ermittelten Ratiowerte lagen zwischen 1,7 und 2,0, wobei ein Wert von $\geq 1,8$ als ein Wert für eine hohe RNS-Qualität gilt. Die Konzentration der extrahierten RNS wurde ebenfalls spektrophotometrisch überprüft und anschließend für die weiteren Arbeitsschritte eine normierte Menge an RNS eingesetzt. Sowohl zur Überprüfung der Reinheit der RNS, als auch zu ihrer Quantifizierung wurden dasselbe Gerät und gleiche Verdünnungsverhältnisse verwendet. In den weiteren Arbeitsschritten wurde mRNS mit Hilfe von Oligo dTs aus RNS isoliert und mit dem Enzym reverse Transkriptase in cDNS ungeschrieben. Zur Isolierung von mRNS können wahlweise Random Primer, Oligo dTs oder spezifische Primer genutzt werden. Die Verwendung von Oligo dTs ist die bessere Methode im Vergleich zu Random Primern, da sie spezifischere Ergebnisse liefert. Im Vergleich zur Verwendung von spezifischen Primern, bei der mehrere Lösungsansätze nötig sind, bieten Oligo dTs bei limitierten RNS-Mengen die bessere Alternative, da nur ein Lösungsansatz benötigt wird (Bustin und Nolan, 2004). Bei den folgenden Arbeitsschritten der DNS-Vervielfältigung wurde besonders auf Kontaminationsfreiheit geachtet. Fremde DNS, die in die Proben gelangt sein könnte, könnte Ergebnisse verfälschen. Um einer Kontamination des verwendeten Materials und der verwendeten Lösungen auszuschließen, wurde ständig eine Wasserprobe mitgeführt. 
Die reverse Transkription mit anschließender Polymerase-Kettenreaktion (PCR) kann wahlweise in einem oder nacheinander in zwei Reaktionsgefäßen statt finden. Nachteilig bei der Verwendung eines einzelnen Reaktionsgefäßes ist, dass durch die hohe Anzahl von Inhaltsstoffen die Wahrscheinlichkeit von Interaktionen und Inhibitionen steigt, wodurch Artefakte entstehen können (Suslov und Steindler, 2005). Um diese Artefaktbildung zu vermeiden, wurden die reverse Transkription und die PCR nacheinander in zwei verschiedenen Reaktionsgefäßen durchgeführt. Auch die der reversen Transkription vorangehende mRNS-Isolierung mittels Oligo dTs wurde in einem separaten Arbeitsschritt durchgeführt, um Interaktionen der Inhaltsstoffe zu vermeiden. Zudem gelten für die Verwendung von Oligo dTs und für die reverse Transkriptase unterschiedliche Optimaltemperaturen, sodass eine Trennung der Arbeitsschritte als sinnvoll erachtet werden kann (Bustin und Nolan, 2004). In der PCR wurde die Quantifizierung der Genexpression von NaS1 und sat1 relativ zu dem housekeeping-Gen GAPDH, als interner Standard ermittelt. Hierfür ist eine konstante Expression des housekeeping-Gens eine wichtige Vorraussetzung, ohne die eine valide Darstellung über quantitative Messungen der Genexpression nicht möglich ist. GAPDH eignete sich in dieser Arbeit als interner Standard, da von einer konstanten Expression in den Nieren ausgegangen werden kann.

Da die Extraktion der RNS mit dem SV-Total-RNA-Isolation-Kit in der photometrischen Messung hohe RNS-Konzentrationen und eine hohe Reinheit aufwies und die Agarosegelelektropherse für NaS1, sat1 und GAPDH Banden zeigte, konnte davon ausgegangen werden, dass sich die erzeugte cDNS für die präzise Quantifizierung mittels real-time PCR eignete. Auch bei der Vorbereitung der realtime PCR wurde auf Kontaminationsfreiheit geachtet: Die Ansätze wurden in doppelter Ausführung gefertigt, außerdem wurde eine Wasserprobe als Negativkontrolle mitgeführt. Die doppelt geführten Probenansätze zeigten alle vergleichbare CT-Wert. Keine der Wasserproben enthielt messbare Amplifikationsprodukte, sodass von einer genauen und kontaminationsfreien Quantifizierung ausgegangen werden kann. Die Auswertung der real-time PCR wurde mit Hilfe der komparativen CT-Methode nach Pfaffl (2004) durchgeführt. Diese Analysemethode ist ein valides Berechnungsmodell um Serien von quantifizierten Zielgenen (im Falle dieser Arbeit NaS1 und sat1), normiert an einem Standard (housekeeping-Gen GAPDH), zu vergleichen (Cikos et al., 2007). 
Für die übermäßig hohen Expressionswerte der Transporter bei zwei Tieren im Endstadium der Erkrankung sind Fehler im Versuchsablauf oder eine krankheitsbedingte erhöhte Expression der Sulfattransporter denkbar. Aus der isolierten RNS der Proben wurde, nachdem die außergewöhnlichen Werte auftraten, ein zweites Mal mRNS isoliert und in cDNS umgeschrieben. Es erfolgte eine zweite real-time PCR, die Werte in der gleichen Größenordnung wie zuvor lieferte. Damit ist davon auszugehen, dass eine krankheitsbedingte abnorm hohe relative Expression der Transporter möglich ist.

\subsubsection{Darstellung der proteinbiochemischen Methoden}

Durch Sauerstoffmangel kommt es leicht zu Strukturveränderungen im Gewebe. Zellen sterben $a b$, verlieren ihre ursprüngliche Form und zerfallen nach und nach. Deshalb ist bei der Verarbeitung von Geweben für histologische Zwecke auf eine rasche Fixierung der Gewebe sofort nach Organentnahme zu achten.

Die proteinbiochemischen Versuche wurden in einem Labor des Institute for Medical Research and Occupational Health in Zagreb unter der Leitung von Dr. Ivan Sabolic durchgeführt. Die Mitarbeiter des Labors besitzen einen großen Erfahrungsschatz in der Methodik der Immunhistochemie und haben bereits Studien zur Versuchsoptimierung durchgeführt (Brzica et al., 2009b). Vor der immunhistochemischen Färbung wurde die Vorbehandlung der Gewebe nach Brzica et al. (2009b) optimiert und damit die bestmögliche Methode zur Demaskierung der Antikörperbindungsstellen eruiert. Die Vorbehandlung, die der Markierung des sat1Proteins am dienlichsten war, wurde als Standardmethode zur Vorbereitung der Schnitte gewählt. Es wurde für jeden der beiden anti-sat1-Antikörper (Ak) die optimale Vorbehandlung ermittelt. Als Ak wurde zunächst ein polyklonaler Ak genutzt. Dieser sollte laut Hersteller Santa Cruz das sat1-Protein in Mäusen spezifisch markieren. Allerdings war der Ak vor dem Verkauf nur mittels Western Blot, nicht mittels Immunhistochemie, getestet worden. Demnach war nur gesichert, dass der Ak ein Protein markiert, das ein Molekulargewicht in der Größenordnung des sat1-Proteins hat. Obwohl die zu färbenden Gewebeschnitte auf unterschiedliche Weise vorbehandelt wurden, um die Antikörperbindungsstellen zu demaskieren und somit die Wahrscheinlichkeit für eine erfolgreiche Proteindetektion zu erhöhen, waren spezifische Färbungen weder bei den Mäuse- noch bei den Rattengeweben möglich. In den Gewebeschnitten von Rattennieren fand sich sowohl eine Färbung von in den 
proximalen Tubulszellen basal gelegenen Vesiklen, als auch eine subapikale Färbung (Abbildung 31 und Abbildung 32). Beide Lokalisationen sind nicht mit den bisherigen Erkenntnissen zur Lokalisation des Transporters vereinbar, da sich der Transporter mehreren Studien zufolge basolateral in der Zellmembran der Tubuluszellmembran befindet (Karniski et al., 1998). Es ist also davon auszugehen, dass der verwendete polyklonale Antikörper unspezifisch an andere Proteine bindet. Um diese Vermutung zu überprüfen, wurde ein Western Blot gemacht, bei dem der polyklonale Antikörper an Gewebe von Rattennieren und Rattenleber eingesetzt wurde. Die Western-Blot-Analyse lieferte eine stärke Bande bei $~ 50 \mathrm{kDa}$ und eine schwächere bei $\sim 35 \mathrm{kDa}$ in der Leber, sowie eine Bande bei $\sim 32 \mathrm{kDa}$ in den Nieren. Es liegen verschiedene Arbeiten vor, in denen das sat1-Protein im Western Blot Banden bei $\sim 85 \mathrm{~kb}$ und bei $\sim 65 \mathrm{~kb}$ liefert (Brzica et al., 2009a, Karniski et al., 1998). Die Bande bei $\sim 65 \mathrm{~kb}$ entspricht der Molekülgröße des sat1 und könnte somit die unglykolisierte Form des Transporters dasstellen, sodass anzunehmen ist, dass der polyklonale Antikörper sat1 nicht spezifisch bindet. Im Folgenden wurde eine zweite Versuchsreihe mit einem monoklonalen Ak von Karniski an Gewebe von NMRIMäusen (Leber und Nieren) und an $\mathrm{COL} 4 \mathrm{~A}^{+/+}$- und $\mathrm{COL} 4 \mathrm{~A}^{-\sigma_{-}}$-Mäusen angefertigt. Mit dem verwendeten $\mathrm{AK}$, den Dr.Ivan Sabolic freundlicherweise zur Verfügung stellte, waren bereits in mehreren Arbeiten spezifische Markierungen von sat 1 in Nieren und Leber gelungen (Brzica et al., 2009a, Dawson et al., 2010, Karniski et al., 1998, Quondamatteo et al., 2006). Auch in dieser Arbeit konnten spezifische Färbungen erzielt werden.

\subsection{Diskussion der Ergebnisse}

\subsubsection{Physiologische Wirkungen von Sulfat}

Anorganisches Sulfat wird in Form von schwefelhaltigen Aminosäuren, als Sulfoester, oder als freies Sulfat über den Magen-Darm-Trakt aufgenommen. Außerdem entsteht es beim Abbau der Aminosäuren Methionin und Cystein (Cole und Evrovski, 2000). Sulfat ist in viele physiologische Prozesse involviert, die die normale Zellfunktion garantieren. Es wird in den Nieren frei filtriert und zum Großteil resorbiert. Der kleinere nicht resorbierte Anteil wird ausgeschieden, sodass die Nieren die wesentlichen Regulatoren der Sulfathomöostase sind (Cole und Evrovski, 2000). Die Hauptverwendung von Sulfat im Körper findet sich in der Sulfatierung 
einer Reihe exogener und endogener Substanzen. In einigen Fällen dient die Konjugation mit Sulfat zur Aktivierung von Stoffen, in anderen erleichtert sie deren renale Ausscheidung. Nicht zuletzt ist Sulfat für die Synthese struktureller Membranund Gewebebestandteile, wie den sulfatierten Glykosaminoglycanen der Proteoglykane, notwendig (Beck und Silve, 2001). Proteoglykane sind ein wesentlicher Bestandteil von Bindegewebe, das bei Fibrosen vermehrt gebildet wird.

Es gibt Vermutungen, dass der Sulfatierungsgrad der Protoglykane mit dem Stadium der Nierenfibrose einhergeht. Die Sulfatierung aller von Natur aus zu sulfatierenden Stoffe, inklusive der bei Fibrose vertretenen Proteoglykane, hängt von der Höhe der intrazellulären anorganischen Sulfatskonzentration ab. Anorganisches Sulfat ist der Vorläufer von 3'-Phosphoadenosin 5'-Phosphosulfat (PAPS), welches die aktivierte Form von Sulfat darstellt und als Substrat für Sulfotransferasen dient (Krijgsheld et al., 1980, Mulder und Keulemans, 1978). In Nieren von Mäusen wurden eine signifikant höhere RNS-Expression für die PAPS-Synthase (PAPSs)-Isoformen PAPSs1 und PAPSs2 bei Weibchen gefunden (Alnouti und Klaassen, 2006). Die intrazelluläre Sulfatkonzentration und somit das Sulfatierungspotenzial der Zellen steht in direktem Zusammenhang mit der extrazellulären Verfügbarkeit von Sulfat, der Plasmasulfatkonzentration und der Anwesenheit von spezifischen Transportern, wie NaS1 und sat1, die für den Transport von Sulfat über die Zellmembran hinweg verantwortlich sind (Beck und Silve, 2001).

Beim Menschen beträgt die Sulfatkonzentration im Blutserum ca. $300 \mu \mathrm{mol} / /$, wobei die Messwerte in verschiedenen Studien von 240-420 $\mu \mathrm{mol} / \mathrm{l}$ reichen. Im Blut von Frauen und Männern sind keine signifikant unterschiedlichen Konzentrationen von Sulfat zu finden (Cole und Evrovski, 2000). Mäuse besitzen eine Serumsulfatkonzentraion von ca. $640 \mu \mathrm{mol} / \mathrm{l}$ (Dawson et al., 2003). Bei Ratten wurden im Blutplasma Sulfatkonzentration von 840-900 $\mu \mathrm{mol} / \mathrm{l}$ gemessen (Fernandes et al., 2001) (oder 700-1000 $\mu \mathrm{mol} / \mathrm{l}$ im Serum; Markovich und Aronson, 2007 zitiert nach Krijgsheld, 1980).

In menschlichem Blutplasma sind in unterschiedlichen Lebensphasen höhere und niedrige Konzentrationen an Sulfat zu finden (Beck und Silve, 2001). Bei der Frau sind eine zyklusabhängige Veränderung der Plasmasulfatkonzentration, ein Abfall der Konzentration während der Menopause und ein Anstieg im dritten Schwangerschaftstrimester zu beobachten (Benincosa et al., 1995). 


\subsubsection{Transporter für Sulfat in den Nieren}

$\mathrm{Da}$ das hydrophile Anion $\mathrm{SO}_{4}{ }^{2-}$ nicht passiv über die Lipiddoppelschicht von Zellmembranen der proximalen Tubuluszellen diffundieren kann, benötigen die Nieren das kombinierte Sulfattransportsystem aus luminalem NaS1 und basolateralem sat1. Nach freier Filtration wird ein Großteil des Sulfats über dieses System rückresorbiert, sodass die fraktionelle Sulfatexkretion bei ca. $10 \%$ liegt. Die Kapazität der Sulfattransporter ist limitiert und sättigbar. Unter physiologischen Bedingungen arbeitet das Transportsystem bereits nahe seiner maximalen Transportrate. Steigt die Sulfatkonzentration im Blut über physiologische Werte ist das Maximum der Transportfähigkeit schnell erreicht und es wird vermehrt Sulfat über den Urin ausgeschieden (Markovich und Aronson, 2007). Im Falle des chronischen Nierenversagens kommt es demnach auf Grund der mangelnden Filtrationsrate zu einer Hypersulfatämie und nachfolgend auf Grund der limitierten Sulfatrückresrptionsrate zu einer Hypersulfaturie.

\subsubsection{Sulfattransporter-Expression bei NMRI- und SvJ/129-Maus}

Die Untersuchung der NMRI-Mäuse diente unterschiedlichen Zwecken. Das Hauptinteresse lag darin, herauszufinden, ob - ähnlich wie bei Ratten - auch bei Mäusen geschlechtsabhängige Unterschiede der Transporterexpression von NaS1 und sat1 und ihrer RNS vorliegen. Des Weiteren wurde untersucht, ob verschiedene Mäusestämme unterschiedliche Expressionsmuster im Hinblick auf die Sulfattransporter aufweisen.

Diese Arbeit zeigte einen geschlechtsspezifischen Unterschied der Expression der Sulfattransporter. Für NaS1 fand sich in den Nieren bei weiblichen NMRI-Mäusen signifikant mehr RNS. Die Untersuchung von sat1 in Nieren und Leber zeigte sowohl auf RNS- als auch auf Proteinebene signifikant höhere Werte für Weibchen als für Männchen. Es besteht also eine feminine Dominanz in der sat1-Proteinexpression, sowohl in den Nieren als auch in der Leber der NMRI-Mäuse. Auch bei COL4A3 ${ }^{+/+}$Mäusen zeigten sich geschlechstspezifische Unterschiede in der NaS1-Expression. So exprimieren männliche gesunde SvJ/129-Mäuse mehr NaS1-RNS als weibliche. Für sat1 ließ sich kein signifikanter Unterschied feststellen.

Auffällig ist, dass die geschlechtsspezifische Verteilung von NaS1-RNS bei NMRIund SvJ-Mäusen eine genau entgegengesetzte Geschlechtsspezifität aufweist. Beim NMRI-Stamm expremieren weibliche Tiere den NaS1 stärker, bei SvJ/129-Mäusen 
männliche Tiere. Die stärkere NaS1-RNS-Expression bei männlichen SvJ-Mäusen ist jedoch eventuell mit Ergebnissen von Donahue (http://phenome.jax.org/db/qp?rtn=views/measplot\&brieflook=11531) in Einklang zu bringen, nach denen männliche Tiere des SvJ/129-Stammes eine 49\% höhere Konzentration von Schilddrüsenhormonen im Blut aufwiesen als ihre weiblichen Pendants. Bei 29 untersuchten Mäusestämmen liegt die Hormonkonzentration der SvJ/129-Weibchen deutlich über dem Mittelwert der Weibchen aller Mäusestämme, der Wert für Thyroxin bei männlichen SvJ/129-Tieren liegt unter dem Mittelwert der männlichen Mäuse. Dawson und Markovich zeigten 2002, dass erhöhte Schilddrüsenwerte mit einer erhöhten NaS1-Expression einhergehen. Für Mäuse des NMRI-Stammes sind keine Daten bezüglich Thyroxinkonzentrationen im Blut in Abhängigkeit vom Geschlecht bekannt. Schlußfolgernd kann vermutet werden, dass sich die hohen Konzentrationen von Thyroxin im Blut von männlichen SvJ/129Mäusen inhibierend auf die Expression des NaS1 auswirken.

In Nieren und Leber von Ratten fanden Brzica et al. (2009a) keine Geschlechtsunterschiede auf RNS-Ebene, jedoch eine stärkere Expression des sat1Proteins bei männlichen Tieren. Die Versuche lassen vermuten, dass bei Ratten Estradiol und Progesteron die Proteinexpression unterdrücken.

Zusammenfassend ist zu sagen, dass geschlechtsspezifische Unterschiede im Metabolismus und Transport von Sulfat vorliegen, die jedoch keine einheitliche Dominanz eines Geschlechts zeigen. Sowohl zwischen verschiedenen Nagerarten (Maus und Ratte), als auch zwischen verschiedenen Stämmen von Mäusen findet sich kein einheitliches Bild der geschlechtsspezifischen Expression von NaS1 und sat1. Diese Unterschiede sind besonders beim Einsatz dieser Tiere in der pharmakologischen Forschung zu beachten. Auf Grund des unterschiedlichen Sulfatmetabolimus kann nicht davon ausgegangen werden, dass Erkenntnisse, die an einem dieser Mäusestämme erlangt wurden, für einen anderen Stamm ebenfalls gelten.

\subsubsection{Pathophysiologie des Transports von Sulfat}

Der Sulfathaushalt des Körpers kann durch verschiedene Pathologien gestört werden. So steigt die Sulfatkonzentration im Blut im Falle von Nierenversagen stark an (Fernandes et al., 2001), da vermutlich auf Grund der erniedrigten GFR zu wenig Sulfat über die Nieren ausgeschieden wird und die Sulfatresorption möglicherweise 
zusätzlich erhöht ist. Ebenso wird eine verminderte GFR durch toxische Wirkung des im Falle von angeborenen Vitamin D-Metabolismusstörungen therapeutisch eingenommenen Calcitriols, für ein erhöhtes Sulfat verantwortlich gemacht. Bei Schilddrüsenüberfunktion soll ein erhöhter Proteinumsatz den Anstieg von Sulfat verursachen. Außerdem führt die Aufnahme von sulfat- oder sulfithaltigen Nahrungsmitteln und Medikamenten zu einer Hypersulfatämie. Im Falle von niedrigen Sulfatkonzentrationen im Plasma können beispielsweise Sulfit-Oxidase-Störungen, Hypothyreodismus und Medikamente, die eine erhöhte Sulfatkonjugation bewirken, für eine Hyposulfatämie verantwortlich gemacht werden (Cole und Evrovski, 2000).

Demnach sind verminderte Sulfatkonzentrationen meist auf einen gestörten oder verlangsamten Abbau von sulfathaltigen Stoffen oder auf den erhöhten Verbrauch von Sulfat durch gesteigerte Sulfatkonjugation zurückzuführen. Erhöhte Sulfatspiegel werden hauptsächlich durch vermehrte Aufnahme, Abbau von sulfathaltigen Nährtoffen oder mangelnde Nierenfunktion verursacht.

\subsubsection{Nierenversagen bei der Alport-Maus}

\subsubsection{Expression der Sulfattransporter bei $\mathrm{COL}_{4 \mathrm{~A}} 3^{+/+}$- und $\mathrm{COL4A3} 3^{-/-}$-Mäusen}

Um mehr von den oben beschriebenen Zusammenhängen und Vorgängen zu verstehen, wurde in dieser Arbeit die Expression der Sulfattransporter bei Mäusen mit und ohne durch das Alport-Syndrom induzierte Nierenfibrose in Abhängigkeit von Alter und Geschlecht untersucht.

Bei am Alport-Syndrom erkrankten Tieren liegt ein Kollagen-Typ-IV-Defekt vor. Durch Mutationen am Kollagen Typ IV entstehen strukturelle Veränderungen der glomerulären und tubulären Basalmembranen der Niere. Die daraus resultierende mangelnde Filterfunktion der Niere führt zur chronisch progredienten Schädigung des Nierengewebes. Die geschädigten Nierenareale werden durch Bindegewebe ersetzt, so dass eine chronisch progrediente Nierenfibrose entsteht. Die Sulfattransporter NaS1, an der apikalen Membran der Tubuluszelle und sat1, an der basolateralen Membran, dienen (wie in 1.5 beschrieben) der kombinierten Rückresorption von Sulfat aus dem Urin. Aus der verminderten glomerulären Filtration bei Nierenfibrose resultiert ein erhöhter Serumsulfatspiegel. Dieser Serumsulfatspiegel im Blut steht in direktem Zusammenhang mit der Rate an Sulfatierungsreaktionen. Ein Anstieg der Sulfatkonzentration im Blut führt demnach zu einem Anstieg der intrazellulären Synthese von PAPS und dessen Verfügbarkeit (Lee, A. et al., 2000). Ein 
Hauptbestandteil von Bindegewebe sind Proteoglykane mit sulfatieren Glykosaminen, zu deren Synthese PAPS benötigt wird. Die Änderung des Expressionsverhaltens der Sulfattransporter ist demnach aus verschiedenen Gründen von Interesse: (1) Steht die Expression der Transporter im Zusammenhang mit der erhöhten Plasmasulfatkonzentration bei Nierenfibrosen, oder ist dafür allein die verminderte GFR verantwortlich? (2) Steht die Expression der Sulfattransporter, die Sulfat ins Interstitium, dem Ort der Nierenfibrose, transportieren, im Zusammenhang mit dem Fortschreiten der Fibrose? (3) Verstärkt das veränderte Expressionsmuster der Transporter bei Nierenfibrose die intrazelluläre Sulfatkonzentration und damit die Synthese von extrazellulärer Matrix? (4) Lässt sich erkennen, ob die Sulfattransporter NaS1 und sat1 physiologisch gekoppelt sind?

Fernandes et al. (2001) untersuchten neben der Sulfatkonzentration im Blut die Expression der Sulfattransporter NaS1 und sat1 an einem Rattenmodell des chronischen Nierenversagens. Teilnephrektomierte Tiere entwickelten eine Nierenfibrose und eine deutliche Hypersulfatämie drei Wochen nach Behandlung. Bei Messung nach sechs Wochen war die Sulfatkonzentration im Blut weiter angestiegen. Im Vergleich zu den scheinoperierten Tieren blieb bei Tieren mit Nierenfibrose zwar die NaS1-RNS der Nieren in ihrer Gesamtzahl gleich, die Dichte der NaS1-RNS pro $\mu \mathrm{g}$ RNS war nach sechs Wochen jedoch erhöht. Für sat1-RNS fand man bereits nach drei Wochen einen Abfall der Gesamtzahl um $50 \%$ bei fibrotischen Nieren. Die Dichte der Transporter-RNS hatte sich nach drei Wochen noch nicht verändert, war nach sechs Wochen aber deutlich niedriger als bei den Kontroll-Ratten. Die Anzahl der Transporterproteine war für beide Transporter reduziert. Die Dichte von NaS1-Protein pro $\mu g$ Protein aus Bürstensaummembranen war nach sechs Wochen erhöht, wohingegen die Dichte von sat1-Protein pro $\mu \mathrm{g}$ Protein aus basolateralen Nierenmembranen erniedrigt war.

Die Untersuchung der NaS1-RNS bei COL4A3 ${ }^{+/+}$- im Vergleich zu COL4A3 ${ }^{-/}$-Tieren ergab eine geringere Expression bei erkrankten Männchen im Vergleich zu gesunden Männchen, signifikant im Alter von 4,5-7,5 Wochen. Für sat1-RNS zeigte sich bei männlichen Mäusen keine Veränderung der Expression im Alter von 4,5-9 Wochen. Auch die immunhistochemischen Färbungen ließen keine unterschiedlich starken Expressionsmuster des sat1-Proteins bei gesunden und kranken Tieren erkennen. 
Bei weiblichen Tieren war für NaS1 ebenfalls tendenziell ein Abfall zu beobachten. Die Anzahl der weiblichen Tiere ist zu gering um valide Ergebnisse zu erzeugen. Auffällig ist aber die große Varianz der relativen Expression von sat1 bei erkrankten Tieren im Alter von 7,5 und 9 Wochen.

Diese Ergebnisse könnten die verminderte Rückresorption und die damit verbundene hohe Ausscheidungsrate von Sulfat im Urin erklären. Wenn Sulfat nach der freien Filtration auf Grund einer niedrigeren Expression des $\mathrm{NaS} 1$ in der Bürstensaummembran der proximalen Tubulszellen weniger rückresorbiert wird, wird es vermehrt ausgeschieden, da bis jetzt keine weiteren Transportsysteme für Sulfat entlang des Nephrons bekannt sind.

\subsubsection{Zeitlicher Verlauf der Expression von NaS1 und sat1 bei COL4A3 ${ }^{+/+}$- und $\mathrm{COL}_{4 A 3}{ }^{-/-}$-Tieren}

Es ist bekannt, dass sich die Rolle von Sulfat im Körper des Menschen mit dem Wachstum und Alter des Menschen verändert (Cole und Scriver, 1980). So fällt die Sulfatkonzentration im Blut von der Geburt zum erwachsenen Alter hin insgesamt ab. Ein besonderer Abfall ist während der Pubertät zu beobachten und ein Anstieg bei Männern und Frauen über 45 und 75 Jahren (Benincosa et al., 1995).

Bei weiblichen Mäusen finden sich weder bei gesunden noch kranken Tieren signifikante Unterschiede der Transporter-Expression in Abhängigkeit vom Alter der Tiere. Bei männlichen $\mathrm{COL} 4 \mathrm{~A}^{+/+}$- und $\mathrm{COL} 4 \mathrm{~A}^{-/-}$-Mäusen hingegen trägt die altersbhängige Expression der Transporter NaS1 und sat1 ein ähnliches Muster (siehe Abbildung 20 bis Abbildung 23). Für beide Transporter ist für 4,5 und 7,5 Wochen alte Tiere ein höherer Wert zu finden als für 6 Wochen alte Tiere. Dies entspricht auf den Menschen übertragen dem Alter von 10-12 Jahren (4,5 Wochen), 16-18 Jahren (6 Wochen) und knapp 20 Jahren (7,5 Wochen) (Grounds et al., 2008). Da bei Grounds et al. der Vergleich des Alters von Menschen und Mäusen nur bis zu 25 menschlichen Lebensjahren aufgezeigt ist und da am Alport-Syndrom erkrankte Tiere nur ein Lebensalter von circa 10 Wochen erreichen, konnte in dieser Arbeit das Verhalten des Sulfatmetabolimus in älteren Lebensjahren nicht beleuchtet werden. 
Tabelle 26: Mögliche Parallelen des Alters von Mäusen und Menschen nach Grounds et al. (2008)

\begin{tabular}{|l|c|c|c|c|c|c|c|c|}
\hline $\begin{array}{l}\text { Maus } \\
\text { (Wochen) }\end{array}$ & 1 & 2 & 3 & 4 & 6 & 8 & 12 & 26 \\
\hline $\begin{array}{l}\text { Mensch } \\
\text { (Jahre) }\end{array}$ & $\begin{array}{c}\text { Neu- } \\
\text { geborenes }\end{array}$ & 0,25 & 0,5 & 10 & $16-18$ & 20 & 25 & $>25$ \\
\hline
\end{tabular}

Mit circa 4-4,5 Wochen erreichen die Konzentrationen an Wachstumshormonen bei Mäusen die höchsten Werte (Alba und Salvatori, 2004) und die ersten geschlechtsabhängigen Unterschiede entwickeln sich. Mit 5-7 Wochen neigt sich die Pubertät der Mäuse dem Ende zu, die Tiere sind geschlechtsreif und das Wachstum nimmt ab (Rodriguez et al., 2007). Die Abnahme der NaS1-Expression steht im Gegensatz zu den Ergebnissen von Markovich und Aronson (2007) nach denen sich die Expression des Transporters unter Wachstumshormoneinfluss vermehrt.

In der Abnahme der Sulfattransporterexpression in den Nieren bei pubertierenden männlichen Mäusen, kann man eine Parallele zur Abnahme der Plasmasulfatkonzentration bei menschlichen Jugendlichen erkennen. Es wäre nun interessant zu wissen, ob es sich mit der Sulfattransporterexpression bei Menschen und mit der Plasmasulfatkonzentration bei Mäusen ähnlich verhält. Außerdem stellt sich die Frage, warum dieses Phänomen bei männlichen Mäusen deutlich ausgeprägt ist, nicht aber bei weiblichen. Die geringe Anzahl der weiblichen Tiere lässt zu diesem Punkt keine eindeutigen Schlüsse zu.

Die COL4A3 ${ }^{-/}$-Tiere haben eine durchschnittliche Lebenszeit von $71 \pm 6 \mathrm{~d}$ (Gross et al., 2004). Im Alter von 9,5 Wochen ist die Erkrankung so weit fortgeschritten, dass die Tiere versterben. Die unterschiedlich ausfallende Expression der Transporter im fortgeschrittenen Krankheitsverlauf ist eventuell dadurch zu erklären, dass das Regenerationspotential einzelner Tiere sehr unterschiedlich sein kann. Epigenetische und genetische Faktoren formen die individuelle Reaktion auf die Krankheit. So reagiert das Immunsystem postpubertär je nach Geschlecht unterschiedlich (Lamason et al., 2006). 


\section{Zusammenfassung und Ausblick}

Das System des Sulfatmetabolismus und die Expression von Sulfattransportern unterliegen vielen verschiedenen Einflüssen. In dieser Arbeit haben wir einen Teil dieses Systems, die Sulfattransporter NaS1 und sat1, im besonderen Hinblick auf ihre Expressiom in Abhängigkeit von Alter, Geschlecht und bei Nierenfibrose beleuchtet. Auf Grund der vielfältigen Einflüsse, wahrschienlich hauptsächlich durch Hormone, ist es schwierig, eindeutige Schlüsse aus den erhaltenen Daten zu ziehen. Es ist festzuhalten, dass bei verschiedenen Stämmen von Mäusen die geschlechtsspezifische Expression der Transporter unterschiedlich ist. Dabei könnten beispielsweise Sexual- oder Schilddrüsenhormone einen Einfluss haben. Die Untersuchungen zur Altersabhängigkeit lassen vermuten, dass die Pubertät der Tiere Veränderungen bewirkt, die sich auch auf die Expression der Sulfattransporter auswirken. Eine Rolle könnten Wachstumshormone oder Sexualhormone spielen. Auch im Mausmodell zur Nierenfibrose, der COL4A3 ${ }^{-1}$ „Alport-Maus“, sind Veränderungen im Vergleich zu gesunden Tieren festzuhalten. Es ist jedoch nicht auszumachen, ob diese Veränderungen als unregulierte Reaktion auf die Fibrose auftreten, ob sie die Entstehung dieser Fibrose unterstützen, oder ob sie vielleicht als regulatorische Reaktion des Körpers die Nephrodegeneration verlangsamen. Um die Rolle der Sulfattransporter NaS1 und sat1 besser zu verstehen und damit einen tieferen Einblick in das System des Sulfatmetabolimus zu erhalten, sind weitere Studien zu diesen Themengebieten zu erheben. So wäre es zum Beispiel von Interesse, wie sich die Expression der Transporter NaS1 und sat1 verhält, wenn vom Alport-Syndrom betroffene und damit an der Nierenfibrose erkrankende Tiere medikamentös behandelt würden. Studien von Gross et al. (2004) haben gezeigt, dass sich Medikamente wie ACE-Hemmer und Angiotensin1-Blocker nephroprotektiv auswirken. So war vor allem bei COL4A3 ${ }^{-1-}$-Mäusen, die therapeutische Dosen von ACE-Hemmer erhielten, die Nierenfibrose weniger stark ausgeprägt als bei den Mäusen, die ein Placebo-Präparat erhielten. Es wäre von Interesse, wie sich die Expression der Sulfattransporter bei dieser medikamentösen Behandlung verhalten würde. 


\section{Abkürzungsverzeichnis}

ABC ATP-binding cassette

Ak Antikörper

AP-1 Aktivator-Protein-1

ATP Adenosintriphosphat

BCIP 5-bromo-4-chloro-3-indolyl-Phosphat

BME $\quad \beta$-Mercaptoethanol

BSA bovines Serumalbumin

cDNS komplementäre Desoxyribonukleinsäure

$\mathrm{COL} \quad$ Kollagen

cRNS Ribonukleinsäure mit Capstruktur

$\triangle \mathrm{Ct} \quad$ Schwellenwert-Zyklus (Cycle Treshold)

DEPC Diethylpyrocarbonat

DIDS 4,4'-Diisothiocyanatostilben 2,2'-Disulfonat

DNS Desoxyribonucleinsäure

dNTP Desoxyribonukleosidtriphosphat

EDTA Ethylendiamintetraacetat

GAM-AP goat anti-mouse / Ziege-anti-Maus-alkalische Phosphatase

GAPDH Glycerinaldehyd-3-phosphat-Dehydrogenase

GFR Glomeruläre Filtrationsrate

GTC Guanidiniumthiocyanat

Ig Immunglobulin

KG Körpergewicht

$\mathrm{Km} \quad$ Michaelis-Menten-Konstante

M-MLV Moloney-Maus-Leukämievirus

NaS1 natriumabhängiger Sulfattransporter-1

NBT nitro-blue-tetrazolium

NMRI Naval Medical Research Institute

OCT optimal cutting temperature

OP Optische Dichte

PAPS Phosphoadenosin-Phosphosulfat

PAGE Polyacrylamid-Gelelektrophorese

PBS Phosphat-gepufferte Salzlösung (Phosphate buffered Saline)

PCR Polymerase-Kettenreaktion (Polymerase Chain Reaction)

PVDF Polyvinylidenfluorid 


$\begin{array}{ll}\text { RNA } & \text { Ribonucleinsäure } \\ \text { RT } & \text { reverse Transkription } \\ \text { sat1 } & \text { Sulfat-Anionen-Transporter1 } \\ \text { SDS } & \text { Natrium-Laurylsulfat (Sodium Dodecyl Sulfate) } \\ \text { SLC } & \text { solute carrier } \\ \text { TBE } & \text { Tris-Borat-EDTA-Puffer } \\ \text { T}_{3} \text { RE } & \text { T }_{3} \text {-responsives Element } \\ \text { TRIS } & \text { Trishydroxymethylaminomethan } \\ \text { UMG } & \text { Universitätsmedizin Göttingen } \\ \text { UV } & \text { Ultraviolett } \\ \text { VDRE } & \text { Vitamin-D-responsives Element } \\ V_{\max } & \text { maximale Transportgeschwindigkeit }\end{array}$




\section{Literaturverzeichnis}

Alba, M. \& Salvatori, R. (2004): A mouse with targeted ablation of the growth hormone-releasing hormone gene: a new model of isolated growth hormone deficiency. Endocrinology, 145, 4134-43.

Alnouti, Y. \& Klaassen, C. D. (2006): Tissue distribution and ontogeny of sulfotransferase enzymes in mice. Toxicol Sci, 93, 242-55.

Andrews, K. L., Mudd, J. L., Li, C. \& Miner, J. H. (2002): Quantitative trait loci influence renal disease progression in a mouse model of Alport syndrome. Am $J$ Pathol, 160, 721-30.

Aravind, L. \& Koonin, E. V. (2000): The STAS domain - a link between anion transporters and antisigma-factor antagonists. Curr Biol, 10, R53-5.

Beck, L. \& Markovich, D. (2000): The mouse $\mathrm{Na}(+)$-sulfate cotransporter gene Nas1. Cloning, tissue distribution, gene structure, chromosomal assignment, and transcriptional regulation by vitamin D. J Biol Chem, 275, 11880-90.

Beck, L. \& Silve, C. (2001): Molecular aspects of renal tubular handling and regulation of inorganic sulfate. Kidney Int, 59, 835-45.

Beirowski, B., Weber, M. \& Gross, O. (2006): Chronic renal failure and shortened lifespan in COL4A3+/- mice: an animal model for thin basement membrane nephropathy. J Am Soc Nephrol, 17, 1986-94.

Benincosa, L. J., Sagawa, K., Massey, L. K. \& Morris, M. E. (1995): Effects of acute caffeine ingestion and menopause on sulfate homeostasis in women. Life Sci, 57, 1497-505.

Besseghir, K. \& Roch-Ramel, F. (1987): Renal excretion of drugs and other xenobiotics. Ren Physiol, 10, 221-41.

Bissig, M., Hagenbuch, B., Stieger, B., Koller, T. \& Meier, P. J. (1994): Functional expression cloning of the canalicular sulfate transport system of rat hepatocytes. J Biol Chem, 269, 3017-21.

Bohle, A., Mackensen-Haen, S. \& von Gise, H. (1987): Significance of tubulointerstitial changes in the renal cortex for the excretory function and concentration ability of the kidney: a morphometric contribution. Am J Nephrol, 7, 421-33.

Borza, D. B., Bondar, O., Ninomiya, Y., Sado, Y., Naito, I., Todd, P. \& Hudson, B. G. (2001): The NC1 domain of collagen IV encodes a novel network composed of the alpha 1, alpha 2, alpha 5, and alpha 6 chains in smooth muscle basement membranes. J Biol Chem, 276, 28532-40.

Brzica, H., Breljak, D., Krick, W., Lovric, M., Burckhardt, G., Burckhardt, B. C. \& Sabolic, I. (2009a): The liver and kidney expression of sulfate anion transporter sat- 1 in rats exhibits male-dominant gender differences. Pflugers Arch, 457, 1381-92.

Brzica, H., Breljak, D., Ljubojevic, M., Balen, D., Micek, V., Anzai, N. \& Sabolic, I. (2009b): Optimal methods of antigen retrieval for organic anion transporters in cryosections of the rat kidney. Arh Hig Rada Toksikol, 60, 7-17. 
Bustin, S. A. \& Nolan, T. (2004): Pitfalls of quantitative real-time reverse-transcription polymerase chain reaction. $J$ Biomol Tech, 15, 155-66.

Cheong, H. I., Kashtan, C. E., Kim, Y., Kleppel, M. M. \& Michael, A. F. (1994): Immunohistologic studies of type IV collagen in anterior lens capsules of patients with Alport syndrome. Lab Invest, 70, 553-7.

Cikos, S., Bukovska, A. \& Koppel, J. (2007): Relative quantification of mRNA: comparison of methods currently used for real-time PCR data analysis. BMC Mol Biol, 8, 113.

Cole, D. E. \& Scriver, C. R. (1980): Age-dependent serum sulfate levels in children and adolescents. Clin Chim Acta, 107, 135-9.

Cole, D. E. \& Evrovski, J. (2000): The clinical chemistry of inorganic sulfate. Crit Rev Clin Lab Sci, 37, 299-344.

Cosgrove, D., Samuelson, G. \& Pinnt, J. (1996): Immunohistochemical localization of basement membrane collagens and associated proteins in the murine cochlea. Hear Res, 97, 54-65.

Dawson, P. A. \& Markovich, D. (2002): Regulation of the mouse Nas1 promoter by vitamin D and thyroid hormone. Pflugers Arch, 444, 353-9.

Dawson, P. A., Beck, L. \& Markovich, D. (2003): Hyposulfatemia, growth retardation, reduced fertility, and seizures in mice lacking a functional NaSi-1 gene. Proc Natl Acad Sci U S A, 100, 13704-9.

Dawson, P. A., Steane, S. E. \& Markovich, D. (2004): Behavioural abnormalities of the hyposulphataemic Nas1 knock-out mouse. Behav Brain Res, 154, 457-63.

Dawson, P. A., Steane, S. E. \& Markovich, D. (2005): Impaired memory and olfactory performance in NaSi-1 sulphate transporter deficient mice. Behav Brain Res, $159,15-20$.

Dawson, P. A., Russell, C. S., Lee, S., McLeay, S. C., van Dongen, J. M., Cowley, D. M., Clarke, L. A. \& Marcovich, D. (2010): Urolithiasis and hepatotoxicity are linked to the anion transporter Sat1 in mice. J Clin Invest, 120, 706-12.

Deetjen, Speckmann, Heschler. Physiologie. 4. Auflage, Kap.10, S. 526, 2005

Detro-Dassen, S., Schanzler, M., Lauks, H., Martin, I., zu Berstenhorst, S. M., Nothmann, D., Torres-Salazar, D. Hidalgo, P., Schmalzing, G. \& Fahlke, C. (2008): Conserved dimeric subunit stoichiometry of SLC26 multifunctional anion exchangers. J Biol Chem, 283, 4177-88.

Donahue, L.R., et al. 2002. Phenotyp project data set: Donahue 1.

URL: http://phenome.jax.org/db/qp?rtn=views/measplot\&brieflook=11531 (abgerufen am 9. Februar 2011)

Dorwart, M. R., Shcheynikov, N., Yang, D. \& Muallem, S. (2008): The solute carrier 26 family of proteins in epithelial ion transport. Physiology (Bethesda), 23, 104-14.

Dubey, R. K., Jackson, E. K., Rupprecht, H. D. \& Sterzel, R. B. (1997): Factors controlling growth and matrix production in vascular smooth muscle and glomerular mesangial cells. Curr Opin Nephrol Hypertens, 6, 88-105. 
Eddy, A. A. (1996): Molecular insights into renal interstitial fibrosis. J Am Soc Nephrol, 7, 2495-508.

Eikmans, M., Baelde, H. J., de Heer, E. \& Bruijn, J. A. (2001): Effect of age and biopsy site on extracellular matrix mRNA and protein levels in human kidney biopsies. Kidney Int, 60, 974-81.

Fernandes, I., Hampson, G., Cahours, X., Morin, P., Coureau, C., Couette, S., Prie, D., Biber, J., Murer, H., Friedlander, G. \& Silve, C. (1997): Abnormal sulfate metabolism in vitamin D-deficient rats. J Clin Invest, 100, 2196-203.

Fernandes, I., Laouari, D., Tutt, P., Hampson, G., Friedlander, G. \& Silve, C. (2001): Sulfate homeostasis, NaSi-1 cotransporter, and SAT-1 exchanger expression in chronic renal failure in rats. Kidney Int, 59, 210-21.

Frick, A. \& Durasin, I. (1986): Regulation of the renal transport of inorganic sulfate: effects of metabolic changes in arterial blood pH. Pflugers Arch, 407, 541-6.

Go, A. S., Chertow, G. M., Fan, D., McCulloch, C. E. \& Hsu, C. Y. (2004): Chronic kidney disease and the risks of death, cardiovascular events, and hospitalization. N Engl J Med, 351, 1296-305.

Gross, O. (2008): Understanding renal disorders as systemic diseases: the fascinating world of basement membranes beyond the glomerulus. Nephrol Dial Transplant, 23, 1823-5.

Gross, O., Netzer, K. O., Lambrecht, R., Seibold, S. \& Weber, M. (2002): Metaanalysis of genotype-phenotype correlation in X-linked Alport syndrome: impact on clinical counselling. Nephrol Dial Transplant, 17, 1218-27.

Gross, O., Beirowski, B., Koepke, M. L., Kuck, J., Reiner, M., Addicks, K., Smyth, N., Schulze-Lohoff, E \& Weber, M. (2003): Preemptive ramipril therapy delays renal failure and reduces renal fibrosis in COL4A3-knockout mice with Alport syndrome. Kidney Int, 63, 438-46.

Gross, O., Schulze-Lohoff, E., Koepke, M. L., Beirowski, B., Addicks, K., Bloch, W., Smyth, N. \& Weber, M. (2004): Antifibrotic, nephroprotective potential of ACE inhibitor vs AT1 antagonist in a murine model of renal fibrosis. Nephrol Dial Transplant, 19, 1716-23.

Grounds, M. D., Radley, H. G., Lynch, G. S., Nagaraju, K. \& De Luca, A. (2008): Towards developing standard operating procedures for pre-clinical testing in the mdx mouse model of Duchenne muscular dystrophy. Neurobiol Dis, 31, 119.

Gubler, M. C. (2008): Inherited diseases of the glomerular basement membrane. Nat Clin Pract Nephrol, 4, 24-37.

Haas, M. (2009): Alport syndrome and thin glomerular basement membrane nephropathy: a practical approach to diagnosis. Arch Pathol Lab Med, 133, 224-32.

Hallan, S. I., Coresh, J., Astor, B. C., Asberg, A., Powe, N. R., Romundstad, S., Hallan, H. A., Lydersen, S. \& Holmen, J. (2006): International comparison of the relationship of chronic kidney disease prevalence and ESRD risk. J Am Soc Nephrol, 17, 2275-84. 
He, L., Vasiliou, K. \& Nebert, D. W. (2009): Analysis and update of the human solute carrier (SLC) gene superfamily. Hum Genomics, 3, 195-206.

Hediger, M. A., Romero, M. F., Peng, J. B., Rolfs, A., Takanaga, H. \& Bruford, E. A. (2004): The ABCs of solute carriers: physiological, pathological and therapeutic implications of human membrane transport proteinsIntroduction. Pflugers Arch, 447, 465-8.

Hewitson, T. D. (2009): Renal tubulointerstitial fibrosis: common but never simple. Am J Physiol Renal Physiol, 296, F1239-44.

Hewitson, T. D., Wu, H. L. \& Becker, G. J. (1995): Interstitial myofibroblasts in experimental renal infection and scarring. Am J Nephrol, 15, 411-7.

Hudson, B. G., Tryggvason, K., Sundaramoorthy, M. \& Neilson, E. G. (2003): Alport's syndrome, Goodpasture's syndrome, and type IV collagen. N Engl J Med, 348, 2543-56.

Jais, J. P., Knebelmann, B., Giatras, I., De Marchi, M., Rizzoni, G., Renieri, A., Weber, M., Gross, O., Netzer, K. O., Flinter, F., Pirson, Y., et al. (2003): Xlinked Alport syndrome: natural history and genotype-phenotype correlations in girls and women belonging to 195 families: a "European Community Alport Syndrome Concerted Action" study. J Am Soc Nephrol, 14, 2603-10.

Johnson, E. S., Thorp, M. L., Yang, X., Charansonney, O. L. \& Smith, D. H. (2007): Predicting renal replacement therapy and mortality in CKD. Am J Kidney Dis, 50, 559-65.

Jorgensen, P. L., Hakansson, K. O. \& Karlish, S. J. (2003): Structure and mechanism of Na,K-ATPase: functional sites and their interactions. Annu Rev Physiol, 65, 817-49.

Kalluri, R., Shield, C. F., Todd, P., Hudson, B. G. \& Neilson, E. G. (1997): Isoform switching of type IV collagen is developmentally arrested in X-linked Alport syndrome leading to increased susceptibility of renal basement membranes to endoproteolysis. J Clin Invest, 99, 2470-8.

Karniski, L. P. (1998): Effects of sulfate and chloride on three separate oxalate transporters reconstituted from rabbit renal cortex. Am J Physiol, 274, F18996.

Karniski, L. P., Lotscher, M., Fucentese, M., Hilfiker, H., Biber, J. \& Murer, H. (1998): Immunolocalization of sat-1 sulfate/oxalate/bicarbonate anion exchanger in the rat kidney. Am J Physiol, 275, F79-87.

Khoshnoodi, J., Pedchenko, V. \& Hudson, B. G. (2008): Mammalian collagen IV. Microsc Res Tech, 71, 357-70.

Knebelmann, B., Breillat, C., Forestier, L., Arrondel, C., Jacassier, D., Giatras, I., Drouot, L., Deschênes, A., Jacassier, D., Giatras, I., et al. (1996): Spectrum of mutations in the COL4A5 collagen gene in X-linked Alport syndrome. Am J Hum Genet, 59, 1221-32.

Krijgsheld, K.R., Scholtens, E. and Murer, G.J. (1980): Serum concentration of inorganic sulfate in mammals: Species differences and circadium rhythm. Comp. Biochem. Physiol., 67A, 683-686 
Lamason, R., Zhao, P., Rawat, R., Davis, A., Hall, J. C., Chae, J. J., Agarwal, R., Cohen, P., Rosen, A., Hoffmann, E. P. \& Nagarju, K. (2006): Sexual dimorphism in immune response genes as a function of puberty. BMC Immunol, 7, 2.

Lee, A. \& Markovich, D. (2004): Characterization of the human renal $\mathrm{Na}(+)$-sulphate cotransporter gene ( NAS1) promoter. Pflugers Arch, 448, 490-9.

Lee, A., Beck, L. \& Markovich, D. (2000): The human renal sodium sulfate cotransporter (SLC13A1; hNaSi-1) CDNA and gene: organization, chromosomal localization, and functional characterization. Genomics, 70, 35463.

Lee, A., Beck, L. \& Markovich, D. (2003): The mouse sulfate anion transporter gene Sat1 (Slc26a1): cloning, tissue distribution, gene structure, functional characterization, and transcriptional regulation thyroid hormone. DNA Cell Biol, 22, 19-31.

Lee, H. J., Sagawa, K., Shi, W., Murer, H. \& Morris, M. E. (2000): Hormonal regulation of sodium/sulfate co-transport in renal epithelial cells. Proc Soc Exp Biol Med, 225, 49-57.

Markovich, D. \& Murer, H. (2004): The SLC13 gene family of sodium sulphate/carboxylate cotransporters. Pflugers Arch, 447, 594-602.

Markovich, D. \& Aronson, P. S. (2007): Specificity and regulation of renal sulfate transporters. Annu Rev Physiol, 69, 361-75.

Markovich, D., Forgo, J., Stange, G., Biber, J. \& Murer, H. (1993): Expression cloning of rat renal Na+/SO4(2-) cotransport. Proc Natl Acad Sci U S A, 90, 8073-7.

Markovich, D., Murer, H., Biber, J., Sakhaee, K., Pak, C. \& Levi, M. (1998): Dietary sulfate regulates the expression of the renal brush border $\mathrm{Na} / \mathrm{Si}$ cotransporter NaSi-1. J Am Soc Nephrol, 9, 1568-73.

Markovich, D., Wang, H., Puttaparthi, K., Zajicek, H., Rogers, T., Murer, H., Biber, J., \& Levi, M. (1999): Chronic K depletion inhibits renal brush border membrane $\mathrm{Na} /$ sulfate cotransport. Kidney Int, 55, 244-51.

Markovich, D., Romano, A., Storelli, C. \& Verri, T. (2008): Functional and structural characterization of the zebrafish Na+-sulfate cotransporter 1 (NaS1) cDNA and gene (slc13a1). Physiol Genomics, 34, 256-64.

Miner, J. H. (1999): Renal basement membrane components. Kidney Int, 56, 201624.

Nakanishi, K., Yoshikawa, N., lijima, K., Kitagawa, K., Nakamura, H., Ito, H., Yoshioka, K., Kagawa, M. \& Sado, Y. (1994): Immunohistochemical study of alpha 1-5 chains of type IV collagen in hereditary nephritis. Kidney Int, 46, 1413-21.

Ohana, E., Yang, D., Shcheynikov, N. \& Muallem, S. (2009): Diverse transport modes by the solute carrier 26 family of anion transporters. J Physiol, 587, 2179-85. 
Peissel, B., Geng, L., Kalluri, R., Kashtan, C., Rennke, H. G., Gallo, G. R., Yoshioka, K., Sun, M. J., Hudson, B. G., Neilson, E.G. \& Zhon, J. (1995): Comparative distribution of the alpha 1 (IV), alpha 5(IV), and alpha 6(IV) collagen chains in normal human adult and fetal tissues and in kidneys from X-linked Alport syndrome patients. J Clin Invest, 96, 1948-57.

Pescucci, C., Mari, F., Longo, I., Vogiatzi, P., Caselli, R., Scala, E., Abatersusso, C., Gusmano, R., Seri, M., Migletti, N., et al. (2004): Autosomal-dominant Alport syndrome: natural history of a disease due to COL4A3 or COL4A4 gene. Kidney Int, 65, 1598-603.

Pfaffl, M.W.: Quantification strategies in real-time PCR. - In: The real-time PCR Encyclopaedia A-Z of quantitative PCR (Bustin S.A. Hrsg.), International University Line (IUL), La Jolla, CA., USA 2004, 87-120

Puttaparthi, K., Markovich, D., Halaihel, N., Wilson, P., Zajicek, H. K., Wang, H., Biber, J., Murer, H., Rogers, T. \& Levi, M. (1999): Metabolic acidosis regulates rat renal Na-Si cotransport activity. Am J Physiol, 276, C1398-404.

Quondamatteo, F., Krick, W., Hagos, Y., Kruger, M. H., Neubauer-Saile, K., Herken, R., Ramadori, G., Burckhardt, G. \& Burckhardt, B. C. (2006): Localization of the sulfate/anion exchanger in the rat liver. Am J Physiol Gastrointest Liver Physiol, 290, G1075-81.

Regeer, R. R., Lee, A. \& Markovich, D. (2003): Characterization of the human sulfate anion transporter (hsat-1) protein and gene (SAT1; SLC26A1). DNA Cell Biol, 22, 107-17.

Rodriguez, A., Muller, D. C., Metter, E. J., Maggio, M., Harman, S. M., Blackman, M. R. \& Andres, R. (2007): Aging, androgens, and the metabolic syndrome in a longitudinal study of aging. J Clin Endocrinol Metab, 92, 3568-72.

Roos-van Groningen, M. C., Eikmans, M., Baelde, H. J., de Heer, E. \& Bruijn, J. A. (2004): Improvement of extraction and processing of RNA from renal biopsies. Kidney Int, 65, 97-105.

Sagawa, K., Benincosa, L. J., Murer, H. \& Morris, M. E. (1998a): Ibuprofen-induced changes in sulfate renal transport. J Pharmacol Exp Ther, 287, 1092-7.

Sagawa, K., DuBois, D. C., Almon, R. R., Murer, H. \& Morris, M. E. (1998b): Cellular mechanisms of renal adaptation of sodium dependent sulfate cotransport to altered dietary sulfate in rats. J Pharmacol Exp Ther, 287, 1056-62.

Sagawa, K., Murer, H. \& Morris, M. E. (1999): Effect of experimentally induced hypothyroidism on sulfate renal transport in rats. Am J Physiol, 276, F164-71.

Schnedler, N.: Transportcharakteristika des Sulfat-Anionen-Transporter 1, sat-1, und seine Regulation durch Vorstufen des Oxalats. Oec. troph. Diss. Göttingen 2010.

Strutz, F. \& Zeisberg, M. (2006): Renal fibroblasts and myofibroblasts in chronic kidney disease. J Am Soc Nephrol, 17, 2992-8.

Suslov, O. \& Steindler, D. A. (2005): PCR inhibition by reverse transcriptase leads to an overestimation of amplification efficiency. Nucleic Acids Res, 33, e181.

Timpl, R. (1989): Structure and biological activity of basement membrane proteins. Eur J Biochem, 180, 487-502. 
van der Loop, F. T., Heidet, L., Timmer, E. D., van den Bosch, B. J., Leinonen, A., Antignac, C., Jefferson, J. A., Maxwell, A. P., Monnens, L. A. H., Schröder, C. H. \& Smeets, H. J. M. (2000): Autosomal dominant Alport syndrome caused by a COL4A3 splice site mutation. Kidney Int, 58, 1870-5.

Wynn, T. A. (2007): Common and unique mechanisms regulate fibrosis in various fibroproliferative diseases. J Clin Invest, 117, 524-9.

Yurchenco, P. D. \& O'Rear, J. J. (1994): Basal lamina assembly. Curr Opin Cell Biol, 6, 674-81.

Zeisberg, M., Strutz, F. \& Muller, G. A. (2001): Renal fibrosis: an update. Curr Opin Nephrol Hypertens, 10, 315-20.

Zhang, K. W., Colville, D., Tan, R., Jones, C., Alexander, S. I., Fletcher, J. \& Savige, J. (2008): The use of ocular abnormalities to diagnose X-linked Alport syndrome in children. Pediatr Nephrol, 23, 1245-50. 


\section{Danksagung}

Mein besonderer Dank gebührt Frau Prof. Dr. Brigitta C. Burckhardt für die beispielhafte Betreuung und die engagierte Förderung meiner Arbeit. Besonders hervorzuheben ist, dass sie bei Fragen stets Zeit für Besprechungen und Hilfestellungen fand.

Herrn Prof. Dr. Gerhard Burckhardt danke ich dafür, mir die Durchführung der Promotion in der Abteilung Vegetative Physiologie und Pathophysiologie der Universität Göttingen zu ermöglichen.

Mein herzlichster Dank gilt Frau Dr. Nina Schnedler, die mich bei meiner Arbeit mit viel Geduld, Mühe und guten Ratschlägen unterstützt hat.

Herrn Prof. Dr. Oliver Groß danke ich für die Bereitstellung der „Alport-Mäuse“.

Besonders danke ich auch Herrn Dr. Ivan Sabolic dafür, mir die Mitarbeit in seiner Abteilung in Zagreb ermöglicht zu haben, sowie vor allem den Mitarbeitern Hrovje Brzica und Davorka Breljak, von denen ich sehr viel über immunhistochemische Labormethodik und über statistische Auswertung von Daten lernte.

Weiterhin danke ich Sören Petzke, Gesche Dallmeyer, Anette Hillemann und allen anderen Mitarbeitern und Kollegen des Instituts, die zum Gelingen meiner Arbeit beigetragen haben. Frau Prof. Dr. Katschinski und ihrer Arbeitsgruppe danke ich für die Bereitstellung zahlreicher Arbeitsmaterialien.

Besonders danke ich auch meiner Mutter und meinem Vater für das Korrekturlesen und die Hilfe bei der Formatierung der Arbeit. 


\section{Lebenslauf}

Ich, Grit Marcia Mirgel, wurde am 01.02.1986 als erstes Kind der Ärztin Karin Mirgel und des Ingenieurs Holger Zeltwanger in Nürnberg geboren. Von 1992 bis 1996 besuchte ich die Adam-Kraft-Grundschule in Nürnberg, von 1996 bis 2002 das Gymnasium der Peter-Vischer Schule in Nürnberg und von 2002 bis 2005 das Labenwolf-Gymnasium, an dem ich 2005 mein Abitur in den Fächern Mathematik, Geschichte, Physik und Deutsch ablegte. Seit dem Sommersemester 2006 studiere ich Humanmedizin an der Georg-August-Universität in Göttingen. Den ersten Abschnitt der ärztlichen Prüfung absolvierte ich im Frühjahr 2008. Derzeit durchlaufe ich das praktische Jahr im Rahmen des Medizinstudiums. Die vorliegende Arbeit fertigte ich zwischen 2008 und 2011 in der Abteilung der Vegetativen Physiologie der Universität Göttingen unter Leitung von Prof. Dr. phil. nat. B. C. Burckhardt an. In diese Arbeit fließen außerdem Erkenntnisse ein, die ich während meines Forschungsaufenthaltes im Institute for Medical Research and Occupational Health in Zagreb unter der Leitung von Dr. med. I. Sabolic gewinnen konnte. Der Forschungsaufenthalt in Zagreb wurde von der deutschen Forschungsgemeinschaft (DFG) unter dem Antrag BU 998/4-2 gefördert. 